\title{
Coordination and Lock-In: Competition with Switching Costs and Network Effects
}

\author{
May 2006 \\ the latest version of this paper, and related material, will be at \\ www.paulklemperer.org \\ Joseph Farrell \\ University of California, Berkeley, 549 Evans Hall \# 3880 \\ Berkeley, CA 94720-3880, USA \\ email: farrell@econ.berkeley.edu \\ and \\ Paul Klemperer \\ Nuffield College, Oxford University, Oxford OX1 1NF, England \\ Int Tel: +44 1865278588 Int Fax: +44 1865278557 \\ email: paul.klemperer@economics.ox.ac.uk \\ First draft: $1997 \quad$ This draft: 2006

\section{PRELIMINARY DRAFT: PLEASE SEND COMMENTS}

KEYWORDS: switching costs, network effects, lock-in, network externalities, co-ordination, indirect network effects

JEL CLASSIFICATIONS:

L130 market structure, firm strategy and market performance: oligopoly and other imperfect markets; monopolistic competition; contestable markets

L150 information and product quality; standardization and compatibility

L120 market structure, firm strategy and market performance: monopoly

L140 transactional relationships: contracts and reputation: networks

D430 market structure and pricing: oligopoly and other forms of market imperfection

D420 market structure and pricing: monopoly.

ACKNOWLEDGMENTS: We're grateful to many friends and colleagues for numerous helpful suggestions and comments over several substantial rewrites of this paper since our first 1997 draft. Special thanks are due to Alan Beggs, Simon Board, Tim Bresnahan, Yongmin Chen, Matthew Clements, David Gill, Jonathan Good, Moshe Kim, Catherine McNeill, Markus Mobius, Meg Meyer, Tore Nilssen, Hiroshi Ohashi, Pierre Regibeau, Garth Saloner, Marius Schwartz, Oz Shy, Rebecca Stone, John Vickers, Matthew White, Miguel Villas-Boas, and the Editors of this Volume. Joe Farrell was chief economist at the Federal Communications Commission 1996-7 and at the Antitrust Division of the Department of Justice 2000-1, and Paul Klemperer served as a Member of the UK Competition Commission 2001-5, but all the views expressed are personal ones.

(C) Joseph Farrell and Paul Klemperer, 2006 


\begin{abstract}
Switching costs and network effects bind customers to vendors if products are incompatible, locking customers or even markets in to early choices. Lock-in hinders customers from changing suppliers in response to (predictable or unpredictable) changes in efficiency, and gives vendors lucrative ex post market power - over the same buyer in the case of switching costs (or brand loyalty), or over others with network effects.

Firms compete ex ante for this ex post power, using penetration pricing, introductory offers, and price wars. Such "competition for the market" or "life-cycle competition" can adequately replace ordinary compatible competition, and can even be fiercer than compatible competition by weakening differentiation. More often, however, incompatible competition not only involves direct efficiency losses but also softens competition and magnifies incumbency advantages. With network effects, established firms have little incentive to offer better deals when buyers' and complementors' expectations hinge on non-efficiency factors (especially history such as past market shares), and although competition between incompatible networks is initially unstable and sensitive to competitive offers and random events, it later "tips" to monopoly, after which entry is hard, often even too hard given incompatibility. And while switching costs can encourage small-scale entry, they discourage sellers from raiding one another's existing customers, and so also discourage more aggressive entry.

Because of these competitive effects, even inefficient incompatible competition is often more profitable than compatible competition, especially for dominant firms with installed-base or expectational advantages. Thus firms probably seek incompatibility too often. We therefore favor thoughtfully pro-compatibility public policy.
\end{abstract}

(C) Joseph Farrell and Paul Klemperer 


\section{Coordination and Lock-In: Competition with Switching Costs and Network Effects CONTENTS}

\section{INTRODUCTION}

2. SWITCHING COSTS AND COMPETITION

2.1 Introduction

2.2 Empirical Evidence

2.3 Firms who Cannot Commit to Future Prices

2.3.1 Bargains Followed by Ripoffs

2.3.2 Inefficiency of the Price-Path

2.4 Firms who Cannot Discriminate Between Cohorts of Consumers

2.4.1 Free-Entry Model

2.4.2 Do Oligopolists Hold Simultaneous Sales?, or Staggered Sales?, or No Sales?

2.4.3 Oligopoly Dynamics

2.4.4 The Level of Profits

2.4.5 The Effect of Consumers' Expectations on Prices

(i) Consumers who Assume any Price Cut below their Expected Price will be Maintained in the Future

(ii) Consumers whose Expectations about Future Prices are Unaffected by Current Prices

(iii) Consumers with Rational Expectations

2.4.6 Collusive Behavior

2.5 Consumers Who Use Multiple Suppliers

2.5.1 Paying Consumers to Switch

2.5.2 Is There Too Much Switching?

(i) Price Differences Don't Reflect Cost Differences

(ii) Consumers Switch In Order To Affect Prices

(iii) Switching Costs Are Not Real Social Costs

2.5.3 Multiproduct Firms

2.6 Battles for Market Share

2.6.1 The Value of Market Share

2.6.2 Penetration Pricing

2.6.3 Harvesting vs Investing: Macroeconomic and International Trade Applications 
2.7 Entry

2.7.1 Small Scale Entry is (Too) Easy

2.7.2 Large Scale Entry is (Too) Hard

2.7.3 Single-Product Entry May Be (Too) Hard

2.7.4 Artificial Switching Costs Make Entry (Too) Hard

2.8 Endogenous Switching Costs: Choosing How to Compete

2.8.1 Reducing Switching Costs to Enhance Efficiency

2.8.2 Increasing Switching Costs to Enhance Efficiency

2.8.3 Increasing Switching Costs to Enhance Oligopoly Power

2.8.4 Reducing Switching Costs to Enhance Oligopoly Power

2.8.5 Increasing Switching Costs to Prevent or Exploit Entry

2.9 Switching Costs and Policy

\section{NETWORK EFFECTS AND COMPETITION}

3.1 Introduction

3.2 Empirical Evidence

3.2.1 Case Studies

(i) Ex ante: did QWERTY pass a good market test when the market tipped to it?

(ii) Ex post: As of now, would a switch be socially efficient?

3.2.2 Econometric Approaches

3.3 Under-Adoption and Network Externalities

3.3.1 Formalities

3.3.2 What are the Groups?

3.3.3 Total and Marginal Effects

3.3.4 Under-Adoption of Single Network

3.3.5 Are Network Effects Externalities?

3.4 The Coordination Problem

3.4.1 Coordination Breakdowns: Mistakes, Splintering, Wait-and-See

3.4.2 Coordinating on the Wrong Equilibrium

(i) Single network

(ii) Competing networks

3.4.3 Cheap Talk and Consensus Standards

3.4.4 Coordination through Sequential Choice

3.5 Inertia in Adoption

3.5.1 Ex Post Inertia

3.5.2 Early Power

3.5.3 Positive Feedback and Tipping

3.5.4 Option Value of Waiting

3.6 Sponsored Price and Strategy for a Single Network

3.6.1 Pricing to Different Groups: Penetration Pricing

3.6.2 Single Monopoly Price

3.6.3 Commitment Strategies

3.6.4 Contingent Contracts 
3.7 Sponsored Pricing of Competing Networks

3.7.1 Competition With Cost/Quality Differences

3.7.2 Competition With Cost/Quality Differences that Vary Over Time

3.7.3 Static Competition When Consumers' Preferences Differ

3.7.4 Dynamic Competition When Consumers' Preferences Differ

3.8 Endogenous Network Effects: Choosing How to Compete

3.8.1 Efficiency Effects

3.8.2 Competitive Effects

3.8.3 Institutions and Rules: Who chooses?

(i) Horizontal competitors

(ii) Vertical locus of compatibility choice

(iii) Means to network benefits

(iv) International trade

3.9 Network Effects and Policy

\section{CONCLUSION}

\section{References}




\section{Introduction}

The economics of switching costs and network effects have received a great deal of popular, as well as professional, attention in the last two decades. They are central to the "new economy" information technology industries. But these new topics are closely linked to traditional concepts of contract incompleteness, complementarity, and economies of scale and scope.

Both switching costs and proprietary network effects arise when consumers value forms of compatibility that require otherwise separate purchases to be made from the same firm. Switching costs arise if a consumer wants a group, or especially a series, of his own purchases to be compatible with one another: this creates economies of scope among his purchases from a single firm. Network effects arise when a user wants compatibility with other users so that he can interact or trade with them, or use the same complements; this creates economies of scope between different users' purchases.

These economies of scope make a buyer's best action depend on other, complementary transactions. When those transactions are in the future, or made simultaneously by others, his expectations about them are crucial. When they are in the past, they are history that matters to him. History also matters to a firm because established market share is a valuable asset: in the case of switching costs, it represents a stock of individually locked-in buyers, while in the case of network effects an installed base directly lets the firm offer more network benefits and may also boost expectations about future sales.

Vying for valuable share, firms may compete hard for early adoptions, notably with penetration pricing but perhaps also in less efficient ways. Early sales induce lucrative follow-on sales, which we often call locked-in, although lock-in is seldom absolute. Both switching costs and proprietary network effects thus shift the locus of competition from smaller to larger units of sales, as economies of scope, tying, and bundling do.

When switching costs are high, buyers and sellers actually trade streams of products or services, but their contracts often cover only the present. Similarly, network effects push large groups of users toward doing the same thing as one another, but contracts usually cover only a bilateral transaction between a seller and one user. If users choose sequentially, early choices constrain later buyers and create "collective switching costs"; if users choose simultaneously, they face a coordination problem. Clever contracts can solve these problems, but ordinary contracts generally do not.

Because firms compete to capture buyers, those problems are more subtle than the mere fact that buyers are locked in ex post. For example, in the simplest switching-cost models, initial sales contracts do not specify future prices, yet competition for the stream of purchases is efficient. Similarly, in some simple network models, users efficiently coordinate and network effects

cause no trouble. As such models illustrate, conventional competition "in the market" can be replaced by well-functioning competition "for the market" - 
for a buyer's lifecycle requirements in the case of switching costs, or for the business of many buyers when there are network effects. Early adoptions are often pivotal and competition focuses on them; later, locked-in buyers pay more and create ex post rents; but ex ante competition passes those rents through to the pivotal buyers. This can be efficient, though it raises distributional issues unless (as in simple switching cost markets) locked-in buyers were themselves previously pivotal.

But these simplest models are misleading: things do not usually work so well. Despite ex ante competition for the market, incompatibilities often reduce efficiency and harm consumers in a number of ways:

Direct costs are incurred if consumers actually switch or actually adopt incompatible products. ${ }^{1}$ Consumers may avoid those costs by not switching, or by buying from the same firm, but that ties together transactions and thus often obstructs efficient buyer-seller matching. Variety may be more sustainable if niche products don't force users to sacrifice network effects or incur switching costs by being incompatible with mainstream products. Entrants lack installed bases and consumers' expectations may naturally focus on established firms, so entry with network effects, and large-scale entry with switching costs, are hard. These entry hurdles may be broadly efficient given incompatibility, but they nevertheless represent a social cost of incompatibility.

Ex ante competition often fails to compete away ex post rents: switching costs typically raise oligopoly profits and proprietary network effects often do, especially if expectations fail to track relative surplus. And even when ex ante competition dissipates ex post rents, it may do so in unproductive ways such as through socially inefficient marketing; at best it induces "bargain-then-ripoff" pricing (low to attract business, high to extract surplus) that normally distorts buyers' quantity choices, gives consumers wrong signals about whether to switch, and (in the case of network effects) provides artificial incentives to be or appear pivotal.

Thus while incompatibility does not necessarily damage competition, it often does.

\subsection{Switching Costs}

A product has classic switching costs if a buyer will purchase it repeatedly and will find it costly to switch from one seller to another. Switching costs also arise if a buyer will purchase follow-on products such as service and repair, and will find it costly to switch from the supplier of the original product.

Large switching costs lock in a buyer once he makes an initial purchase, so he is effectively buying a series of goods, just as (more generally) with strong enough relationship-specific economies of scope, sellers compete on

\footnotetext{
${ }^{1}$ Firms may also dissipate resources creating and defending incompatibility.
} 
bundles of goods rather than single goods. Sometimes sellers offer complete ("life-cycle") contracts that specify all prices. But often contracts do not specify all the future prices, so that a long-term relationship is governed by short-term contracts. This pattern creates ex post monopoly, for which firms compete ex ante. ${ }^{2}$

Some of the same issues arise if contracts are incomplete for other reasons. For instance, shops often advertise some, but not all, of their prices: the consumer learns others only once he is in the shop and will find it costly to go elsewhere. Just as with dynamic switching costs, this tends to produce ripoffs on un-advertised (small print) prices and corresponding bargains on advertised (loss leader) prices.

The same consumer-specific economies of scope are present in "shoppingcost" markets where consumers face costs of using different suppliers for different goods in a single period and with all prices advertised, but neither time nor commitment problems arise. Such shopping costs encourage firms to offer a full (perhaps too broad) product line - and so help explain multiproduct firms - but can lead firms to offer similar products to each other so that there may be too little variety in the market as a whole. We argue below that the shopping-cost framework is the best way to understand the "mix and match" literature.

Switching costs shift competition away from what we normally think of as the default (a single consumer's needs in a single period) to something broader - a single consumer's needs over time. Even when that long-term relationship is governed by short-term contracts, this shift need not cause competitive problems: competing on first-period terms can be an adequate proxy for competition with complete contracts. Likewise, the theory of bilateral contracts with hold-up shows that when parties cannot readily contract on future variables and there are switching costs, it can be efficient to accept that hold-up will occur and to compensate the prospective victim up front. But this only works if the parties can efficiently transfer rents across periods; often, instead, "hold up" or "bargain-then-ripoff" pricing distorts quantity choices, incentives to switch suppliers, and entry incentives.

The bargain-then-ripoff structure is clearest when new and locked-in customers are clearly distinguished and can be charged separate bargain and ripoff prices respectively. This will be the case when prices are individually negotiated (and existing customers are known); it will also be the case when locked-in buyers buy separate "follow-on" products such as parts and service, rather than repeatedly buying the same good.

If, however, each firm has to set a single price to old (locked-in) and new customers, then its trade with a locked-in customer affects its trade with a new customer and the problem is no longer bilateral. A form of bargain-thenripoff pricing sometimes survives, with firms engaging in repeated "sales",

\footnotetext{
${ }^{2}$ Williamson (1985) stressed the "fundamental transformation, in which the initial winner of a bidding competition thereafter enjoys an advantage over rival suppliers because of its ownership of or control over transaction specific assets."
} 
but prices will often instead be a compromise between high prices to exploit locked-in buyers and lower prices to build a locked-in customer base

Whether with bargain-then-ripoff dynamics or with a single compromise price, switching costs may either raise or lower average oligopoly prices. The outcome depends heavily on how consumers form expectations about future prices, but on balance switching costs seem more likely to increase prices. Furthermore, switching costs can segment an otherwise undifferentiated market as firms focus on their established customers and do not compete aggressively for their rivals' buyers, letting oligopolists extract positive profits.

Switching costs also affect entry conditions, in two opposing ways. They hamper forms of entry that must persuade customers to pay those costs. So in a classic switching-cost market they hamper large-scale entry that seeks to attract existing customers (for instance to achieve minimum viable scale, if the market is not growing quickly). Likewise, shopping costs make singleproduct entry hard.

On the other hand, if incumbents must set a single price to old and new buyers, a firm with a larger customer base puts relatively more weight on harvesting this base than on winning new customers. Thus switching costs create a fat-cat effect that actually encourages entry that focuses purely on new customers, and makes competition stable: large shares tend to shrink and small shares to grow. More generally, the tradeoff between harvesting and investing depends on interest rates, the state of the business cycle, expectations about exchange-rates, etc, with implications for macroeconomics and international trade.

\section{$1.2 \quad$ Network Effects}

A good exhibits direct network effects if adoption by different users is complementary, so that each user's adoption payoff, and his incentive to adopt, increases as more others adopt. Thus users of a communications network or speakers of a language gain directly when others adopt it, because they have more opportunities for (beneficial) interactions with peers.

Indirect network effects arise through improved opportunities to trade with the other side of a market. Although buyers typically dislike being joined by other buyers because it raises price given the number of sellers, they also like it because it attracts more sellers. If thicker markets are more efficient, then buyers' indirect gain from the re-equilibrating entry by sellers can outweigh the terms-of-trade loss for buyers, and vice versa; if so, there is an indirect network effect.

From a cooperative game theory perspective, network effects are just economies of scale: the per-buyer surplus available to a coalition of buyers and a seller increases with the size of the coalition. ${ }^{3}$ But the contracting

\footnotetext{
${ }^{3}$ The analogy becomes weaker if network effects are less anonymous. Likewise, switching costs correspond to economies of scope on the production side in a single-consumer context, but the analogy is imperfect with many consumers because individual customer-supplier
} 
and coordination issues seem much harder.

Unless adoption prices fully internalize the network effect (which is difficult), there is a positive externality from adoption, and a single network product tends to be under-adopted at the margin. But when one network competes with another, adopting one network means not adopting another; this dilutes or overturns that externality.

More interestingly, network effects create incentives to "herd" with others. Self-fulfilling expectations create multiple equilibria and cause chicken-andegg or critical-mass behavior with positive feedback or "tipping": a network that looks like succeeding will as a result do so.

How adopters form expectations and coordinate their choices dramatically affects the performance of competition among networks. If adopters smoothly coordinate on the best deal, vendors face strong pressure to offer such deals. Indeed, competition may be unusually fierce because all-or-nothing competition neutralizes horizontal differentiation - since adopters focus not on matching a product to their own tastes but on joining the expected winner.

Smooth coordination is hard, especially when different adopters would prefer different coordinated outcomes, as in the Battle of the Sexes, perhaps because each has a history with a different network and faces individual switching costs. However, some institutions can help. Consensus standard setting (informally or through standards organizations) can help avert "splintering"; contingent contracts seem theoretically promising but little used; and - most important - adoption is very often sequential. If one trusts long chains of backward induction, fully sequential adoption eliminates the starkest coordination traps, in which an alternative equilibrium would be strictly better for all.

However, sequential adoption may not help overall efficiency in the Battleof-the-Sexes case. Sequential adoption translates multiple static (simultaneousadoption) equilibria into the adoption dynamics characteristic of network markets: early instability and later lock-in. In particular, sequential adoption implements tradeoffs between early and late efficiencies that are not generally efficient. Because early adoptions affect later ones, long-term behavior is driven by early events, whether accidental or strategic. Thus early adopters' preferences count for more than later adopters': "excess early power."

These adoption dynamics are the essence of competition if each network is competitively supplied, and the playing field for competition if each network is proprietary to one "sponsor". Sponsors compete ex ante, in particular with penetration pricing, and perhaps also using other tactics such as preannouncements, to appeal to the pivotal early adopters, since the ex post lock-in creates ex post dominance and profits. This competition for the market can neutralize or overturn excess early power if sponsors' anticipated later relative efficiency feeds through into their early willingness to set low penetration prices. But where that feed-through is obstructed or asymmetric, networks

matches matter in switching-cost markets. 
that appeal to early pivotal customers thrive, while late developers have a hard time. Much has been written on whether incompatible transitions are even harder than they should be, given ex-post incompatibility, but whether there is such "excess inertia" or its opposite, "excess momentum," long-term choices still hinge mainly on early preferences and early information. In section 3.2 below, we illustrate these themes in the famous case of the QWERTY keyboard.

If such incompatible competition does not tip all the way to one network, it sacrifices network benefits and may segment the market; if it does tip, it sacrifices matching of products to customers or to time periods and loses the option value from the possibility that a currently inferior technology might become superior. Moreover, if adopters don't coordinate well, or coordinate using cues - such as history - other than the surpluses firms offer, the direct loss in performance is exacerbated by vendors' weaker incentive to offer good deals. For example, if one firm clearly has the ability to offer the highest quality, so buyers know it could profitably recapture the market even after losing any one cohort's business, they may quite rationally all buy from it even if it never actually produces high quality or offers a low price. Finally, the excess power of early adopters biases outcomes towards networks that are more efficient early on, when unsponsored networks compete; biases outcomes in favor of sponsored over unsponsored alternatives; and often biases the outcome even when both alternatives are sponsored.

If firms choose to compete with compatible products, then consumers obtain full network benefits even when they don't all buy from the same firm. This raises consumers' willingness to pay, which can persuade firms to make their products compatible. But, as with switching costs, compatibility often sharpens competition and neutralizes the competitive advantage of a large installed base; furthermore, while switching costs tend to soften competition, hindering attempts to lure customers from rivals (though they may facilitate small-scale entry, they also encourage entry to stay small), proprietary network effects tend to make competition all-or-nothing, with risks of exclusion. Thus large firms and those who are good at steering adopters' expectations may prefer their products to be incompatible with rivals'. If others favor compatibility, this can lead to complex maneuvering, but intellectual property can help firms insist on incompatibility.

\subsection{Strategy and Policy}

Switching costs and proprietary network effects imply complementarities that in turn make success selling in one period or to one customer an advantage in another. This central fact has important implications for competitive strategy and for public policy.

For a firm, it makes market share a valuable asset, and encourages a competitive focus on affecting expectations and on signing up pivotal (notably early) customers, which is reflected in strategies such as penetration 
pricing; competition is shifted from textbook competition in the market to a form of Schumpeterian competition for the market in which firms struggle for dominance.

For a consumer, it may make early choices tantamount to long-term commitments - necessitating great care and raising the value of accurate information at that stage; it may make those choices a coordination problem with other adopters, or it may mean that there is no real choice because of what others have done or are expected to do.

And for policy, these facts collectively have broad repercussions. Because early choices are crucial, consumer protection (against deception, etc.) and information can be key; because coordination is often important and difficult, institutions such as standards organizations matter. Finally, because competition for the market differs greatly from competition in the market, competition policy gets involved in issues of compatibility, as well as in the analysis of mergers, monopolization, intellectual property, and predation, all of which behave differently in the presence of switching costs and network effects.

\section{Switching Costs and Competition}

\section{$2.1 \quad$ Introduction}

A consumer faces a switching cost between sellers when an investment specific to his current seller must be duplicated for a new seller. ${ }^{4}$ That investment might be in equipment, in setting up a relationship, in learning how to use a product, or in buying a high-priced first unit that then allows one to buy subsequent units more cheaply (when firms' prices are non-linear). Switching costs may be psychological. ${ }^{5}$ Klemperer (1995) gives many examples of each of these kinds of switching costs, and Section 2.2 discusses empirical evidence for switching costs.

Switching costs may be learning costs, in which case a consumer who switches from firm A to firm B has no switching cost of later buying from either firm. Alternatively, switching costs may be transactional, in which case a consumer who switches from A to B would incur an additional switching cost if he reswitched back to A (an example is the cost of returning rented equipment and renting from a new supplier). Of course, many switching costs have both learning and transactional aspects.

We will generally assume that switching costs are real social costs, but there can also be contractual or pecuniary switching costs (that are not social

\footnotetext{
${ }^{4}$ There can also be switching costs among different products of a single firm, as there were among IBM computers until the internally compatible System/360 family. But we (following the economics literature) focus on switching costs between firms.

${ }^{5}$ Social psychologists have shown that consumers change their own preferences in favour of products that they have previously chosen or been given, in order to reduce "cognitive dissonance" (Brehm, 1956).
} 
costs). Examples include airlines' "frequent-flyer" programs, and "loyalty contracts" that rebate a fraction of past payments to consumers who continue to patronise the firm. These pecuniary switching costs are a form of quantity discount or bundling. Lars Stole (forthcoming) discusses such price discrimination strategies elsewhere in this Volume, so we will focus mainly on "real" switching costs. ${ }^{6},{ }^{7}$

We assume consumers have perfect information about the existence and qualities of all firms' products, even before purchasing any. So "new" consumers who have not yet developed an attachment to any particular product are especially important in markets with switching costs. In contrast, "search costs" directly affect even consumers' initial purchases. But search costs and switching costs have much in common, and models of the effects of switching costs can also apply to search costs. For example, either kind of friction makes a firm's market share important for its future profitability (see Section 2.6) and much empirical work does not distinguish between search and switching costs. ${ }^{8}$ For a survey of search costs, see, for example, Stiglitz (1989) in Volume 1 of this Series.

"Experience-good" markets in which each consumer needs to purchase a product to determine its quality (see Nelson, 1970) and so prefers to repurchase a brand he tried and liked rather than try a new brand of unknown quality, also have much in common with switching-cost markets. But with experience goods, unlike with switching costs, complications can arise from the possibility of prices signaling qualities, and from the existence of con-

\footnotetext{
${ }^{6}$ Typically, a consumer who has not previously bought from any firm incurs a start-up cost similar to (or greater than) the new investment (switching cost) that a brand switcher must make. We will use the term "switching cost" to include these start-up costs. So a consumer may have a "switching cost" of making a first purchase. In many models consumers have high enough willingnesses to pay that this cost has little consequence since it does not affect consumers' preferences between firms.

${ }^{7}$ Sometimes costs of forming a new relationship fall upon the supplier, not (or as well as) on the customer, and firms' costs of serving new customers have parallels to consumers' switching costs (see Klemperer (1995)). Firms' switching costs have been less studied, but in some contexts, such as the simple model of the next subsection, the total prices (including any switching costs) paid by consumers are unaffected by whether firms or consumers actually pay the switching costs. Thus the equilibrium incidence need not coincide with the apparent incidence of switching costs.

${ }^{8}$ For example, empirical findings about the credit card (Ausubel (1991) etc. - see footnote 66) and telecommunications (see, e.g., Knittel (1997)) markets, and about the effects of firms' discount rates on prices (Froot and Klemperer (1989), Chevalier and Sharfstein (1996), Fitoussi and Phelps (1988) etc.) could be the result of either switching or search costs. On the other hand, Moshkin and Shachar (2000) develop a discrete-choice empirical model to estimate how many consumers behave as if they have switching costs and search costs respectively. Their test is based on the fact that whereas the switching probability of a consumer facing search costs depends on the match between his tastes and the attributes of the alternative he last chose, the switching probability of a consumer facing switching costs depends on the match between his tastes and the attributes of all available alternatives. Using panel data on television viewing choices, they suggest $72 \%$ of viewers act as if they have switching costs between TV channels, while $28 \%$ act as if they have search costs.
} 
sumers who disliked the product they last purchased. $^{9},{ }^{10}$

Switching costs not only apply to repeat-purchases of identical goods. An important class of examples involves "follow on" goods, such as spare parts and repair services, bought in "aftermarkets": buyers face additional "switching" costs if the follow-on goods are not compatible with the original purchase, as may be the case if they are not bought from the same firm. ${ }^{11}$

Similar issues arise when retailers each advertise the prices of only some of their products (often the "loss leaders"), but expect consumers who enter their stores to buy other products also. ${ }^{12}$ See, for example, Lal and Matutes (1994) and Lee and Png (2004). In these models, consumers decide whether or not to buy the advertised goods before entering a store, that is, consumers are making purchase decisions about the advertised goods and the unadvertised ("follow-on") products in different "periods". ${ }^{13}$

If all prices are advertised, consumers may incur switching costs, or "shopping costs", at a single date by choosing to buy related products from multiple suppliers rather than from a single supplier. In this case a static (singleperiod) model is appropriate. (These "shopping costs" can be real social costs or contractual costs created by quantity discounts and bundling.)

Either in a static context, or in a dynamic context when firms can commit to future prices and qualities, a market with switching costs is closely analogous to a market with economies of scope in production; with switching costs each individual consumer can be viewed as a market with economies of scope between "purchases now" and "purchases later". Just as a market with large production economies of scope is entirely captured by the firm with the lowest total costs in the simplest price-competition model, so in a simple model with complete contracts each individual buyer's lifetime requirements in a market with large switching costs are filled by the lowest-cost supplier of those requirements. That is, firms compete on "lifecycle" prices and the market lifecycle price is determined by lifecycle costs, with any subdivision of the lifecycle price being arbitrary and meaningless. In this case, the outcome

\footnotetext{
${ }^{9}$ Schmalensee (1982) and Villas Boas (2006) analyse models of experience goods that show similarities to switching costs models. Hakanes and Peitz (2003) and Doganoglu (2004) model experience goods when there are also learning or transactional switching costs; Doganoglu shows that adding small switching costs to Villas Boas' (2006) model can sometimes reduce price levels.

${ }^{10}$ For related models in which consumers differ in their "quality" from firms' point of view, and firms are uncertain about consumers they have not supplied and can exploit those they know to be of "high quality", see, for example, Nilssen (2000) and Cohen (2005) on insurance markets and Sharpe (1990) and Zephirin (1994) on bank loan markets.

${ }^{11}$ Aftermarkets have been much studied since a US Supreme Court decision (ITS v. Kodak) held that it was conceptually possible for ITS, an independent repair firm, to prove that Kodak had illegally monopolized the aftermarket for servicing Kodak photocopiers: see e.g. Shapiro (1995), Shapiro and Teece (1994), MacKie-Mason and Metzler (1999), and Borenstein, MacKie-Mason, and Netz (1995, 2000).

${ }^{12}$ If the unadvertised follow-on product is always purchased, it can be interpreted as the "quality" of the advertised product - see Ellison (2005) and Vickers (2003).

${ }^{13}$ Gabaix and Laibson (2006) analyse this case when only some consumers are rational.
} 
is efficient and switching costs confer no market power on firms.

However, most of the literature focuses on dynamic problems and emphasises the resulting commitment problems. The simple analogy in the paragraph above - including the efficiency of the outcome - can survive even if firms cannot credibly commit to future prices or qualities. But even small steps outside the simplest story suggest ways in which the analogy and the efficiency break down (Section 2.3). The analogy is still weaker if firms cannot discriminate between different customers (Section 2.4), or consumers use multiple suppliers (Section 2.5). After treating these cases (and having discussed empirical evidence in Section 2.2), we analyze the "market share" competition that switching costs generate (Section 2.6). All this discussion takes both the switching costs and the number of firms as exogenous, so we then consider entry (Section 2.7) and endogenous switching costs (Section 2.8), before addressing implications for competition policy (Section 2.9).

\section{$2.2 \quad$ Empirical Evidence}

The empirical literature on switching costs is much smaller and more recent than the theoretical literature. ${ }^{14},{ }^{15}$ Some studies test specific aspects of the theory (see later sections), but only a few studies directly attempt to measure switching costs.

Where micro data on individual consumers' purchases are available, a discrete choice approach can be used to explore the determinants of a consumer's probability of purchasing from a particular firm. Greenstein (1993) analyses federal procurement of commercial mainframe computer systems during the 1970s, and finds that an agency is likely to acquire a system from an incumbent vendor, even when controlling for factors other than the buyer's purchase history that may have influenced the vendor-buyer match; he suggests switching costs were an important source of incumbent advantage in this market. ${ }^{16}$ Shum (1999) analyzes panel data on breakfast cereal purchases, and finds that households switching brands incur average implicit switching costs of $\$ 3.43$ - which exceeds every brand's price! (However he also finds advertising can be effective in attracting customers currently loyal to rival brands).

Because switching costs are usually both consumer-specific and not directly observable, and micro data on individual consumers' purchase histories are seldom available, less direct methods of assessing the level of switching

\footnotetext{
${ }^{14}$ Experimental studies are even fewer and more recent, but include Cason and Friedman (2002), and Cason, Friedman, and Milam (2003). See footnote 36.

${ }^{15}$ The theoretical literature arguably began with Selten's (1965) model of "demand inertia" (which assumed a firm's current sales depended in part on history, even though it did not explicitly model consumers' behavior in the presence of switching costs), and then took off in the 1980s.

${ }^{16}$ Breuhan (1997) studies the switching costs associated with the Windows and DOS operating systems for personal computers. See Chen and Hitt (2002) for a general survey of the literature on switching costs in information technology.
} 
costs are often needed. Kim et al. (2003) estimate a first-order condition and demand and supply equations in a Bertrand oligopoly to extract information on the magnitude and significance of switching costs from highly aggregated panel data which do not contain customer-specific information. Their point estimate of switching costs in the market for Norwegian bank loans is $4.12 \%$ of the customer's loan, which seems substantial in this market, and their results also suggest that switching costs are even larger for smaller, retail customers. ${ }^{17}$ Shy (2002) argues that data on prices and market shares reveal that the cost of switching between banks varies from 0 to $11 \%$ of the average balance in the Finnish market for bank accounts. He also uses similar kinds of evidence to argue that switching costs in the Israeli cellular phone market approximately equal the price of an average phone.

One defect of all these studies is that none of them models the dynamic effects of switching costs that (as we discuss below) are the main focus of the theoretical literature; in effect, these empirical studies assume consumers myopically maximise current utility without considering the future effects of their choices. ${ }^{18}$

Other empirical studies, many of which we will discuss below in the context of specific theories, provide evidence for the importance of switching costs for credit cards (Ausubel (1991), Calem and Mester (1995), Stango (2002)); cigarettes (Elzinga and Mills $(1998,1999)$ ); computer software (Larkin (2004)); supermarkets (Chevalier and Scharfstein (1996)); air travel, and alliances of airlines in different frequent-flyer programmes (Fernandes (2001), Carlsson and Löfgren (2004)); individual airlines for different flight-segments of a single trip (Carlton, Landes, and Posner (1980)); phone services (Knittel (1997), Gruber and Verboven (2001), Viard (forthcoming)); television viewing choices (Moshkin and Shachar (2000)); online brokerage services (Chen and Hitt (2002)); electricity suppliers (Waterson (2003)); bookstores (Lee and Png (2004)); and automobile insurance (Schlesinger and von der Schulenberg (1993), Israel (2005), Waterson (2003)).

There is also an extensive empirical marketing literature on brand loyalty (or "state dependence") which often reflects, or has equivalent effects to, switching costs. Seetharaman et al (1999) summarise this literature; a widely cited paper is Guadagni and Little's (1983) analysis of the coffee market. ${ }^{19}$ Finally, Klemperer (1995) gives many other examples of markets

\footnotetext{
${ }^{17}$ Sharpe (1997) studies the bank retail deposit market and argues that the data support the model of Klemperer (1987b). See also Waterson (2003).

${ }^{18}$ But Viard (forthcoming) studies the impact of number portability on prices in the US market for toll-free numbers using a dynamic model in which consumers consider the future effects of their choices.

${ }^{19}$ Jacoby and Chestnut (1978) survey earlier attempts in the marketing literature to measure brand loyalty. Theoretical marketing papers include Wernerfelt (1991) (see footnote 34), Villas Boas (2006) (see footnote 9), and Kim et al (2001) who study incentives to offer reward programs that create pecuniary switching costs. Seetharaman and Che (forthcoming) discusses adopting switching costs models to model "variety seeking" consumers with negative switching costs.
} 
with switching costs, and U.K. Office of Fair Trading (2003) presents useful case studies.

\subsection{Firms who Cannot Commit to Future Prices}

\subsubsection{Bargains Followed by Ripoffs}

The core model of the switching costs literature posits that firms cannot commit to future prices.

The simplest model has two periods and two symmetric firms, with costs $c_{t}$ in periods $t=1,2 .{ }^{20} \quad$ A single consumer has a switching cost $s$ and reservation price $r_{t}>c_{t}+s$ for one unit of the period $-t$ good, firms set prices, and there is no discounting. Then in period 2 the firm that sold in period 1 will exercise its ex post market power by pricing (just below) $c_{2}+s$ (the rival firm will offer price $c_{2}$ but make no sale). Foreseeing this, firms are willing to price below cost in period 1 to acquire the customer who will become a valuable follow-on purchaser in period 2 ; undifferentiated competition to win the customer drives period-1 prices down to $c_{1}-s$.

Note that in this simple model the consumer's expectations do not matter. Competition among non-myopic firms makes buyer myopia irrelevant. ${ }^{21}$

Although first-period prices are below cost, there is nothing predatory about them, and this pattern of low "introductory offers", or "penetration pricing" (see section 2.6), followed by higher prices to exploit lockedin customers is familiar in many markets. For example, banks offer gifts to induce customers to open new accounts, and Klemperer (1995) gives more examples. ${ }^{22}$ This "bargains-then-ripoffs" pattern is a main theme of many two-period models in the switching-costs literature, including Klem-

\footnotetext{
${ }^{20} c_{2} \neq c_{1}$ is especially natural if the second-period good is spare parts/repair services/consumables for a first-period capital good.

It makes no difference if there are $n>2$ firms.

${ }^{21}$ Because firms are symmetric and so charge the same price in period 2 , the consumer is indifferent in period 1. If firms $\mathrm{A}, \mathrm{B}$ had different costs $\mathrm{c}_{A 2}$ and $\mathrm{c}_{B 2}$ in period 2, then if A made the period-1 sale, its period-2 price would be $\mathrm{p}_{A 2}=\mathrm{c}_{B 2}+s$ (that is, constrained by $\mathrm{B}$ ), while if $\mathrm{B}$ made the period- 2 sale, its period- 2 price would be $\mathrm{p}_{B 2}=\mathrm{c}_{A 2}+s$. In this case, the prices that firms charge in period 1 (and hence also firms' incentives to invest in cost reduction, etc.) depend on whether the consumer has rational expectations about the period-2 prices it will face or whether the consumer acts myopically. We discuss the role of expectations in Section 2.4.5. Other simple models such as that in Klemperer (1995, Section 3.2) sidestep the issue of consumers' expectations by assuming period-2 prices are constrained by consumers' reservation price $r_{2}$, hence independent of consumers' period-1 choice. The distinction between these modelling approaches is crucial in some analyses of network effects (see Section 3.7.3).

It is important for the modelling that the customer buys from just one firm in period 1. If a unit mass of consumers splits evenly betwen the firms in period 1, there may be no pure-strategy equilibrium in period 2. See footnote 31 .

${ }^{22}$ Skott and Jepsen (2000) argue that a tough drug policy may encourage the aggressive marketing of illegal drugs to new users, by increasing the costs of switching between dealers.
} 
perer (1987a, b, 1995 [Sec 3.2]), Basu and Bell (1991), Padilla (1992), Basu (1993), Ahtiala (1998), Lal and Matutes (1994), Pereira (2000), Gehrig and Stenbacka (2002), Ellison (2005), and Lee and Png (2004). Of these models, Klemperer (1995; Section 3.2) is particularly easy to work with and to extend for other purposes. ${ }^{23}$

Although the switching cost strikingly affects price in each period, it does not affect the life-cycle price $c_{1}+c_{2}$ that the consumer pays in the simple model of this subsection. As in the case of full commitment noted in section 2.1 , we can here view the life-cycle (the bundle consisting of the period-1 good and the period-2 good) as the real locus of competition, and competition in that product has worked exactly as one would hope. In particular, the absence of price commitment did not lead to any inefficiency in this very simple model.

\subsubsection{Inefficiency of the Price-Path}

Although the outcome above is socially efficient, the inability to contract in period 1 on period-2 prices in general leads to inefficiencies, even if firms still earn zero profits over the two periods. Even slight generalizations of the simple model above show this.

In particular, if the consumer has downward-sloping demand in each period and firms are restricted to linear pricing (i.e. no two-part pricing), or if firms face downward-sloping demands because there are many heterogeneous consumers with different reservation prices among whom they cannot distinguish, then there will be excessive sales in period 1 and too few sales in period 2 (Klemperer (1987a)). ${ }^{24}$

Our simple model also assumed that ex-post profits can feed through into better early deals for the consumers. In practice this may not be possible. For example, setting very low introductory prices may attract worthless customers who will not buy after the introductory period. ${ }^{25}$ If for this or other reasons firms dissipate their future profits in unproductive activities (e.g., excessive advertising and marketing) rather than by offering first-period customers truly better deals, or if, for example, risk-aversion and liquidity concerns limit the extent to which firms charge low introductoryperiod prices to the consumers whom they will exploit later, then consumers are made worse off by switching costs, even if competition ensures that firms are no better off.

In our simple model firms make zero profits with or without switching

\footnotetext{
${ }^{23}$ For example, the many-period extension of this model is Beggs and Klemperer (1992).

${ }^{24}$ Thus discussions of aftermarket power point out the possibility of sub-optimal tradeoffs between aftermarket maintenance services, self-supplied repair, and replacement of machines. See Borenstein, MacKie-Mason, and Netz (2000), for instance.

${ }^{25}$ This is a particular problem if the introductory price would have to be negative to fully dissipate the ex-post rents. There may also be limits on firms' ability to price discriminate in favour of new customers without, for example, antagonizing their "regular" customers. See Section 2.4 for the case in which price-discrimination is infeasible.
} 
costs. But switching costs and the higher ex-post prices and lower ex-ante prices that they create can either raise or lower oligopolists' profits. The reason is that, in cutting its first-period price, each firm sets its marginal first-period profit sacrifice equal to its marginal second-period gain, so the total first-period profit given up can be greater or less than the total secondperiod gain (see, especially, Klemperer (1987a,b)). However, the arguments we will review in Section 2.4 (which also apply to two-period models) suggest firms typically gain from switching costs. ${ }^{26}$

Finally note that while we (and the literature) primarily discuss firms exploiting locked-in consumers with high prices, consumers can equally be exploited with low qualities. And if it is hard to contract on future quality, contracting on price does not easily resolve the inefficiencies discussed above. $^{27}$

\subsection{Firms who Cannot Discriminate Between Cohorts of Consumers}

In our first bargains-then-ripoffs model, we assumed that there was just one customer. It is easy to see that the basic lessons extend to the case where there are many customers but firms can charge different prices to "old" and "new" consumers, perhaps because "old" consumers are buying "follow on" goods such as spare parts. But when old consumers buy the same good as new consumers, it can be difficult for firms to distinguish between them. We now consider this case when a new generation of consumers arrives in the market in each of many periods.

\subsubsection{Free-Entry Model}

Even if firms cannot distinguish between cohorts of consumers, we may get the same pricing pattern if firms specialize sufficiently. In particular, in a simple model with free entry of identical firms and constant returns to scale, in each period some firm(s) will specialise in selling to new consumers while any firm with any old locked-in customers will sell only to those old customers.

If consumers have constant probability $\phi$ of surviving into each subsequent period, new-entrant firms with constant marginal costs $c$ and discount factor $\delta$ offer price $c-\phi \delta s$ and sell to any new consumers, while established firms charge $s$ more, i.e., charge $c+(1-\phi \delta) s$ in every period. ${ }^{28}$ That is,

\footnotetext{
${ }^{26}$ See, especially, Klemperer (1987b). Ellison (2005) argues that firms gain from switching costs for a natural type of demand structure.

${ }^{27}$ Farrell and Shapiro (1989) show that price commitments may actually be worse than pointless. See footnote 78 .

${ }^{28}$ See Klemperer (1983). This assumes all consumers have reservation prices exceeding $c+(1-\phi \delta) s$ for a single unit in each period, and that all consumers survive into the next period with the same probability, $\phi$, so a consumer's value is independent of his age. If consumers live for exactly two periods the price paths in general depend on whether firms
} 
established firms charge the highest price such that no "old" consumers want to switch, and new entrants' expected discounted profits are zero. Thus the price paths consumers face are exactly as if firms could perfectly discriminate between them. In either case one can think of every (new and old) consumer as getting a "discount" of $\phi \delta s$ in each period reflecting the present value of the extent to which he can be exploited in the future, given his option of paying $s$ to switch to an entrant; simultaneously, every "old" consumer is indeed exploited by $s$ in every period. The outcome is socially efficient.

\subsubsection{Do Oligopolists Hold Simultaneous Sales?, or Staggered Sales?, or No Sales?}

Just as in the free-entry model, if there is a small number of firms who face no threat of entry and who cannot distinguish between cohorts of consumers, it is possible that in every period one firm might hold a "sale", setting a low price to attract new consumers, while the other(s) set a higher price to exploit their old consumers. Farrell and Shapiro (1988) explore such an equilibrium in a model that has just one new and one old consumer in each period. Since this assumption implies that in any period one firm has no customer base while the other already has half the market "locked-in", it is not surprising that this model predicts asynchronous sales. However, Padilla's (1995) many-customer model yields somewhat similar results: firms mix across prices but a firm with more locked-in customers has more incentive to charge a high price to exploit them, and so sets high prices with greater probabilities than its rival. ${ }^{29}$ These papers illustrate how switching costs can segment an otherwise undifferentiated products market as firms focus on their established customers and do not compete aggressively for their rivals' buyers, letting oligopolists extract positive profits.

More generally it is unclear whether oligopolists will hold sales simultaneously or will stagger them. On the one hand, it might make most sense to forgo short run profits to go after new customers when your rivals are not doing so. On the other hand, if switching costs are learning costs, then staggered sales cause switching and create a pool of highly mobile consumers who have no further switching costs, intensifying future competition (see Section 2.5). Klemperer $(1983,1989)$ and the extension of the latter model in Elzinga and Mills (1999) all have simultaneous sales. ${ }^{30}, 31$

can directly distinguish between old and new consumers (as in the previous subsection) or cannot do this (as in this section).

${ }^{29}$ Farrell and Shapiro assume firms set price sequentially in each period, but Padilla assumes firms set prices simultaneously. See also Anderson, Kumar and Rajiv (2004).

${ }^{30}$ Elzinga and Mills' model fits with observed behaviour in the cigarette market. See also Elzinga and Mills (1998).

${ }^{31}$ In a single-period model in which all consumers have the same switching cost, $s$, and many customers are already attached to firms before competition starts, the incentive to either undercut a rival's price by $s$ or to overcut the rival's price by just less than $s$ generally 
Another possibility is that rather than holding occasional sales, each oligopolist in every period sets a single intermediate price that trades off its incentive to attract new consumers and its incentive to exploit its old customers. In a steady state, each firm's price will be the same in every period. Such an equilibrium could break down in several ways: if the flow of new consumers is too large, a firm would deviate by cutting price significantly to specialise in new consumers. If some consumers' switching costs and reservation prices are too large, a firm would deviate by raising price significantly to exploit old customers while giving up on new ones. And if firms' products are undifferentiated except by switching costs, a firm might deviate to undercut the other slightly and win all the new consumers. ${ }^{32}$ But when none of these breakdowns occurs, there may be a stationary "no-sales" equilibrium: much of the literature examines such equilibria. ${ }^{33}$

Beggs and Klemperer (1992) explore a no-sales equilibrium in which in period $t$, firm $i$ sets price

$$
p_{t}^{i}=c^{i}+\alpha+\beta \sigma_{t-1}^{i}+\gamma\left(c^{j}-c^{i}\right)
$$

where $c^{i}$ is $i$ 's cost, $\sigma_{t-1}^{i}$ is $i$ 's previous-period market share (i.e., the fraction of consumers $i$ sold to in the previous period) and $\alpha, \beta$, and $\gamma$ are positive constants. These constants depend on four parameters: the discount factor, the market growth rate, the rate at which individual consumers leave the market, and the extent to which the firms' products are functionally

eliminates the possibility of pure-strategy equilibria if $s$ is not too large: numerous papers (Baye et al (1992), Padilla (1992), Deneckere et al (1992), Fisher and Wilson (1995), Green and Scotchmer (1986), Rosenthal (1980), Shilony (1977), Varian (1980)), analyse single-period models of switching costs (or models that can be interpreted in this way) that yield mixed strategy equilibria, and Padilla (1995) finds mixed-strategy equilibria in a multi-period model. However, adding more real-world features to some of these models yields either asymmetric pure-strategy equilibria or symmetric pure-strategy BayesianNash equilibria (if information is incomplete) rather than mixed-strategy equilibria.

Asymmetric pure-strategy equilibrium can be interpreted as asynchronous sales. Like Farrell and Shapiro (1988), Deneckere et al find that if firms can choose when to set their prices, the firm with fewer locked-in customers sets price second and holds a "sale".

Symmetric Bayesian equilibria correspond to "tradeoff pricing" of the kind discussed in the next paragraph of the text. Bulow and Klemperer (1998, Appendix B) give an example of this by incorporating incomplete information about firms' costs into a one-period model with switching costs that would otherwise yield mixed-strategy equilibria.

Gabrielson and Vagstad (2003, 2004) analyse when a pure-strategy equilibrium that looks like monopoly pricing exists in a single-period duopoly with heterogeneous switching costs.

${ }^{32}$ However, if consumers have rational expectations about future prices, a small price cut may win only a fraction of new consumers: see section 2.4 .5 below.

${ }^{33}$ Even if there are occasional "sales", firms will balance exploiting the old with attracting the new in "ordinary" periods, and this literature is relevant to these ordinary periods.

In the case of monopoly, both stationary "no-sales" models (see Holmes, 1990) and models in which periodic sales arise in equilibrium (see Gallini and Karp, 1989) can be constructed. 
differentiated; when firms are symmetric, the steady-state equilibrium price increases in the last of these four variables and decreases in the other three. ${ }^{34}$

\subsubsection{Oligopoly Dynamics}

We have seen that sometimes a lean and hungry firm with few locked-in customers holds a sale while its rivals with larger customer bases do not. Similarly, in no-sale models in which all firms sell to both old and new consumers, a firm with more old locked-in customers has a greater incentive to exploit them, so will usually price higher and win fewer new unattached consumers. In both cases, the result is stable industry dynamics as more aggressive smaller firms catch up with larger ones.

In the equilibrium of Beggs' and Klemperer's (1992) no-sale duopoly model, described in (1) above, for example, $\beta>0$, so larger firms charge higher prices, yielding stable dynamics. Indeed, it can be shown that $\sigma_{t}^{i}=\sigma^{i}+(\mu)^{t}\left(\sigma_{0}^{i}-\sigma^{i}\right)$ in which $\sigma^{i}$ is firm $i$ 's steady-state market share and $0<\mu<<\frac{1}{2}$, so the duopoly converges rapidly and monotonically back to a stable steady state after any shock. Chen and Rosenthal (1996) likewise demonstrate a tendency for market shares to return to a given value, while in Taylor (2003) any initial asymmetries in market shares between otherwise symmetric firms may persist to some extent but are dampened over time.

However, the opposite is possible. If larger firms have lower marginal costs, and especially if economies of scale make it possible to drive smaller firms completely out of the market, then a larger firm may charge a lower price than its smaller rivals. In this case, any small advantage one firm obtains can be magnified and the positive-feedback dynamics can result in complete dominance by that firm. This is just as is typical with network effects (see Section 3.5.3) —indeed, switching costs create positive network effects in this case, because it is more attractive to buy from a firm that other consumers buy from (Beggs, 1989).

So switching-costs markets can "tip" like network-effects markets. But the simple models suggest a presumption that markets with switching costs are stable, with larger firms acting as less-aggressive "fat cats". ${ }^{35}$

\subsubsection{The Level of Profits}

A central question in policy and in the literature is whether switching costs raise or lower oligopoly profits. The simple two-period model of Section

\footnotetext{
${ }^{34}$ Klemperer (1995) discusses this model further: variants are in Chow (1995), and To (1995). Other important "no-sales" models are von Weizsäcker (1984) and Wernerfelt (1991); Phelps and Winter's (1970) and Sutton's (1980) models of search costs, and Radner's (2003) model of "viscous demand", are related.

${ }^{35}$ In the terminology introduced by Fudenberg and Tirole (1984). In the terminology introduced by Bulow, Geanakoplos, and Klemperer (1985a,b), there is strategic complementarity between a firm's current price and its competitors' future prices. See also Farrell (1986a).
} 
2.3.1 suggests they do neither, but many non-theorist commentators, notably Porter (1980, 1985), believe switching costs raise profits. ${ }^{36}$ As we discuss next, most models that are richer than the simple model tend to confirm the popular idea that switching costs raise profits.

If duopolists who cannot discriminate between old and new buyers hold asynchronous sales, they can earn positive profits in price competition even if their products are undifferentiated except by switching costs. The switching costs segment the market, and when one firm (generally the firm with the larger customer base) charges a high price to exploit its locked-in customers, the other firm then has market power even over new consumers because it can operate under the price umbrella of its fat-cat rival (see Farrell and Shapiro (1988) and Padilla (1995)). So in these models, a duopolist earns positive profits even in a period in which it starts with no locked-in customers. (However, if there were two identical new firms entering in every period, they would not generally earn any profits.)

Furthermore, if switching costs are heterogenous, a similar effect means even duopolists who can (and do) discriminate between old and new customers can earn positive profits in price competition with products that are undifferentiated except by switching costs - see our discussion of Chen (1997) and Taylor (2003) in Section 2.5.1, below.

In addition, the symmetric stationary price of a "no-sales" equilibrium of the kind described in Section 2.4.3 is also usually higher than if there were no switching costs. There are two reasons:

First, the "fat cat" effect applies here too, though in the indirect way discussed in Section 2.4.3; firms price less aggressively because they recognise that if they win fewer customers today, their rivals will be bigger and (in simple models with switching costs) less aggressive tomorrow.

Second, when consumers face switching costs, they care about expected future prices as well as current prices. Depending on how expectations of future prices react to current prices, this may make new customers (not yet locked into any firm), react either more or less elastically to price differences. However, as we now discuss, the presumption is that it makes their response less elastic than absent switching costs, thus raising firms' prices and profits.

\subsubsection{The Effect of Consumers' Expectations on Prices}

How consumers' expectations about future prices depend on current prices critically affects competition and the price level - just as in other parts of the lock-in literature. ${ }^{37}$ Consumers' expectations about their own future

\footnotetext{
${ }^{36}$ We know of no convincing empirical evidence, but Cason and Friedman (2002) provide supportive laboratory evidence.

${ }^{37}$ Consumers' expectations about how future prices depend on costs are, of course, also important in determining whether firms have the correct incentives to invest in future cost reduction. This issue does not seem to have been directly addressed by the switching-costs literature, but we discuss in Section 3.7 how a network-effects model can be reinterpreted to address it. See also footnote 21.
} 
tastes also matter in a market with real (functional) product differentation; we assume consumers expect some positive correlation between their current and future tastes.

In a market without switching costs, a consumer compares differences between products' prices with differences between how well they match his current tastes. But with switching costs, he recognises that whichever product he buys today he will, very likely buy again tomorrow. So switching costs make him more willing to change brands in response to a price cut if, roughly speaking, he expects that price cut to be more permanent than his tastes; they will lower his willingness to change in reponse to a price cut if he expects the price cut to be less permanent than his tastes.

(i) Consumers who Assume any Price Cut below their Expected Price will be Maintained in the Future

If consumers expect a firm that cuts price today to maintain that price cut forever then, relative to the case of no switching costs, they are more influenced by such a price cut than by their current (impermanent) product preferences. ${ }^{38}$ (In the limit with infinite switching costs, a consumer's product choice is forever, so unless his preferences are also permanent, products are in effect less differentiated.) So switching costs then lower equilibrium prices; see von Weizsäcker's (1984) model in which each firm chooses a single once-and-for-all price (and quality) to which it is (by assumption) committed forever, but in which consumers are uncertain about their future tastes. ${ }^{39}$

We will see below (see Section 3.7) that a similar effect arises when there are strong proprietary network effects and differentiated products. Then, consumers' desire to be compatible with others overwhelms their differences in tastes and drives firms whose networks are incompatible towards undifferentiated Bertrand competition. Here, with switching costs, each consumer's desire to be compatible with his future self (who in expectation has tastes closer to the average) likewise reduces effective differentiation and drives the firms towards undifferentiated Bertrand competition.

(ii) Consumers whose Expectations about Future Prices are Unaffected by Current Prices

If consumers expect that a firm that unexpectedly cuts price this period

\footnotetext{
${ }^{38} \mathrm{~A}$ related model with these expectations is Borenstein, Mackie-Mason and Netz (2000). In their model, consumers buy a differentiated durable good ("equipment") from one of two firms and must then buy an aftermarket product ("service") in the next period from the same firm. High service prices generate profits from locked-in customers, but deter new customers from buying equipment because they expect high service prices in the following period. So the stationary equilibrium service price lies between marginal cost and the monopoly price, even if firms' products are undifferentiated except by switching costs.

${ }^{39}$ The effect we discussed in the previous subsection, 2.4.4- that firms moderate price competition in order to fatten and so soften their opponents - is also eliminated by von Weizsäcker's commitment assumption.
} 
will return to setting the expected price next period, then price changes are less permanent than, and so influence consumers less than, taste differences. So switching costs raise price levels. Each consumer is making a product choice that his future selves must live with, and his future selves' preferences (while possibly different from his own) are likely to be closer to his currently-preferred product than to other products. Consumers are therefore less attracted by a current price cut than absent switching costs.

\section{(iii) Consumers with Rational Expectations}

If consumers have fully rational expectations they will recognise that a lower price today generally presages a higher price tomorrow. As we discussed above, a firm that wins more new consumers today will be a "fatter cat" with relatively greater incentive to price high tomorrow; and we expect that this will typically be the main effect, although other effects are possible. $^{40}$ So consumers with rational expectations will be even less sensitive than in (ii) to price cutting, and switching costs thus raise prices. ${ }^{41}$

In summary, while there is no unambiguous conclusion, under either economists' standard rational-expectations assumption ((iii)), or a more myopic assumption ((ii)), switching costs raise prices overall. Only if consumers believe unanticipated price changes are more permanent than their product preferences do switching costs lower prices. For these reasons, Beggs and Klemperer (1992) argue that switching costs tend to raise prices when new and old customers are charged a common price. There is therefore also a more general presumption that switching costs usually raise oligopolists' total profits.

\footnotetext{
${ }^{40}$ See e.g., Beggs and Klemperer (1992), Klemperer (1987a,b,c), Padilla (1992, 1995). As discussed above, the fat cat effect can be reversed if e.g. economics of scale or network effects are strong enough. (Doganoglu and Grzybowski (2004) show how appending network benefits to Klemperer's (1987b) model lowers prices.) Another caveat is that with incomplete information about firms' costs a lower price might signal lower costs, so consumers might rationally expect a lower price today to presage a lower price tomorrow. But if there is incomplete information about costs, firms might price high in order to signal high costs and thus soften future competition. (A search-costs model that is suggestive about how firm-specific cost shocks might affect pricing in a switching-costs model is Fishman and Rob (1995).) Furthermore, if firms differ in the extent that they can or wish to exploit locked-in customers, consumers will expect that a lower price today means a higher price tomorrow, which will also be a force for higher prices.

${ }^{41}$ Holmes (1990) analyses price-setting by a monopolist facing overlapping generations of consumers who must sink set-up costs before using the monopolist's good. He finds that if consumers have rational expectations, then prices are higher than those that would prevail if the firm could commit to future prices. The reason is similar: rational consumers are insensitive to price cuts because they understand that a low price today will encourage other consumers to sink more costs which in turn results in higher future prices.
} 


\subsubsection{Collusive Behavior}

Like most of the literature, the discussion above assumes noncooperative behavior by firms, without strategic threats of punishment if others compete too hard. ${ }^{42}$

One should also ask whether switching costs hinder or facilitate collusion, in which high prices are supported by firms punishing any other firm thought to have deviated. While many people's intuition is that switching costs support collusion, this remains unclear as a theoretical matter:

Switching costs make deviating from a collusive agreement less profitable in the short run, because it is harder to quickly "steal" another firm's customers. But, for the same reason, switching costs make it more costly to punish a deviating firm. So it is not obvious whether collusion is easier or harder on balance, and in Padilla's (1995) model, which incorporates both these effects, switching costs actually make collusion more difficult.

Switching costs may also make it easier for firms to monitor collusion, because the large price changes necessary to win away a rival's locked-in customers may be easy to observe. And switching costs may additionally facilitate tacit collusion by providing "focal points" for market division, breaking a market into well-defined submarkets of customers who have bought from different firms. However, while these arguments are discussed in Stigler (1964) and Klemperer (1987a), they have not yet been well explored in the literature, and do not seem easy to formalise satisfactorily. Furthermore, if collusion is only easier after most customers are already locked-in, this is likely to induce fiercer competition prior to lock-in, as in the simple bargainthen-ripoff model.

\subsection{Consumers Who Use Multiple Suppliers}

In the models above, as in most leading models of switching costs, switching costs affect prices but there is no switching in equilibrium. In reality a consumer may actually switch, and use different suppliers in different periods, either because firms' products are differentiated and his tastes change, or because firms' relative prices to him change over time, as they will, in particular, when each firm charges new customers less than existing customers.

Furthermore, although we assumed above that each consumer buys one unit from one firm in each period, a consumer who values variety may buy multiple products even in a single period. Consumers may therefore use multiple suppliers in a period or, as we will discuss, each firm may produce a range of products.

\footnotetext{
${ }^{42}$ For example, Beggs and Klemperer assume each firm's price depends only on its current market share and not otherwise on history, and rule out the kind of strategies described by, for example, Abreu (1988) or Green and Porter (1984) that support collusive outcomes in contexts without switching costs.
} 


\subsubsection{Paying Consumers to Switch}

Most of the switching costs literature assumes a firm offers the same price to all consumers in any given period. However, as the bargains-then-rip-offs theme stresses, firms would often like to price discriminate between their old locked-in customers, unattached (new) customers, and customers lockedin to a rival. And firms often do pay consumers to switch to them from rivals. For example, long-distance phone carriers make one-time payments to customers switching from a rival; credit card issuers offer lower interest rates for balance transfers from another provider; and economics departments pay higher salaries to faculty members moving from other departments. How does the possibility of such discrimination affect pricing?

Chen (1997) analyses a two-period, two-firm, model in which each firm can charge one price to its old customers and another to other consumers in the same period. In effect, second-priced consumers are in two separate markets according to which firm they bought from in the first period. Each of these "markets" is like the second period of our core (Section 2.3.1) twoperiod model. In that model all consumers had the same switching costs, $s$, so the period-2 incumbent charged a price just low enough to forestall actual switching. ${ }^{43}$ But in Chen's model, old consumers have heterogenous switching costs (and firms cannot discriminate between them, perhaps because they cannot observe individual consumers' switching costs), so firms charge higher prices than their rivals to their old consumers but consumers with low switching costs switch firms.

In Chen's model both firms' second-period profits and their total discounted profits are lower than if they could not discriminate between old and new customers. However, consumers might also be worse off overall, because of the costs of actually switching.

Firms' total discounted profits are nevertheless higher than absent switching costs because (as in Section 2.4.4) the switching costs segment the market, so firms have some market power even over customers who are new to them

\footnotetext{
${ }^{43}$ Likewise, the simple model of section 2.4.1 shows that if firms can price discriminate, the price will be $c+(1-\phi \delta) s$ to all old consumers, and will be $s$ lower to new consumers, but no consumers will ever actually switch. Similarly, Nilssen (1992) observes that if each firm can charge a different price to each consumer, there will be no actual switching. Nilssen showed that transactional switching costs give consumers less incentives to switch than do learning switching costs. Thus transactional costs lead to lower prices for new consumers, higher prices for loyal consumers, and so also a bigger within-period quantity distortion if there is downward-sloping demand in each period. (Gabrielsen and Vagstad (2002) note that two-part tariffs can in theory avoid this distortion.)
} 
in the second period. ${ }^{44},{ }^{45}$

In Chen's two-firm model, consumers who leave their current supplier have only one firm to switch to, so this other firm can make positive profits even on new customers, and the duopolists earn positive profits in equilibrium. But with three or more firms, there are always at least two firms vying for any consumer willing to leave his current supplier and, if products are undifferentiated, these firms will bid away their expected lifetime profits from serving those consumers in their competition to attract them. So, as Taylor (2003) shows, with three or more firms, firms earn positive rents only on their current customers, and these rents are competed away ex ante, as in our core model.

These models of "paying customers to switch" suggest repeat buyers pay higher rather than lower prices. While this is often observed, we also often observe the opposite pattern in which customers are rewarded for loyalty. Taylor's model provides one possible explanation. He shows that if switching costs are transactional, consumers may move between suppliers to signal that they have low switching costs and so improve their terms of trade. Because this switching is socially costly, equilibrium contracts may discourage it through "loyal customer" pricing policies that give better terms to loyal customers than to those who patronised other firms in the past. But Taylor nevertheless finds that firms charge the lowest prices to new customers.

Shaffer and Zhang (2000) study a single-period model that is similar to the second period of Chen's model but in which the distributions of switching costs from the two firms are different. If firm A's customers have lower and more uniform switching costs than firm B's, then A's loyal-customer demand is more elastic than its new-customer demand, so it may charge a lower price to its loyal customers than to customers switching from B. But this rationale is asymmetric, and this model never results in both firms charging lower prices to loyal customers than to switching customers. ${ }^{46}$

\footnotetext{
${ }^{44}$ Because in this model a firm's old and new customers are effectively in unconnected markets, both of the firm's prices are independent of its previous-period market share, by contrast with the no-price-discrimination models discussed above. This feature allows Taylor (2003) to extend Chen's model to many periods and many firms, but Arbatskaya (2000) shows that the "independence" result does not persist if there is functional product differentiation as well as switching costs.

${ }^{45}$ Gehrig and Stenbacka (2004a) develop a model in which the last two periods are similar to Chen's model, and in which profits are increasing in the size of switching costs; in Gehrig and Stenbacka's three-period model firms therefore (non-cooperatively) make product choices that maximize the switching costs between them. See also Gehrig and Stenbacka (2004b). In another related model, Gehrig and Stenbacka (2005) find that when goods are vertically differentiated and consumers have switching costs, two firms choose to produce the highest quality, by contrast with most models of vertical product differentiation in which just one firm produces the top quality.

${ }^{46}$ Lee (1997) also studies a one-period switching-cost model similar to the second period of Chen's model. Fudenberg and Tirole (2000) explore a two-period model with some similar features to Chen's, in which firms price discriminate between consumers based on their past demands, but with real functional product differentiation between firms and
} 
There are also models of contractual switching costs that result in lower effective prices to repeat customers than to new customers, and contracts that favour repeat customers arise endogeously in some of these models (see Section 2.8.3). But the literature has found it hard to explain how real switching costs might generate discrimination in favor of old customers.

\subsubsection{Is There Too Much Switching?}

Consumers decide whether or when to switch, and pay the switching costs. So there will generally be the wrong amount of switching if (i) firms' relative prices to a consumer fail to reflect their relative marginal $\operatorname{costs}^{47}$, or (ii) consumers switch (or not) in order to affect firms' future prices, or (iii) consumers' switching costs are not real social costs. Most simple models recognize no efficiency role for switching, so any switching in such models is inefficient.

\section{(i) price differences don't reflect cost differences}

The bargains-then-ripoffs theme predicts that, when they can do so, firms charge lower prices to their new consumers. As a result, a given consumer will face different prices from different firms that do not reflect any cost differences between firms. This is true even when all firms symmetrically charge high prices to old customers and lower prices to new customers. Although some simple models such as our core (Section 2.3.1) model predict no switching, in general inefficient switching results. ${ }^{48}$

When firms do not price discriminate between new and old consumers, the same result applies for a slightly different reason. As we saw in section 2.4, a firm with a larger customer base will then charge a larger markup over its marginal cost. So if consumers have differing switching costs, such a firm's price exploits its old high switching-cost customers and induces its low switching-cost consumers to switch to a smaller firm or entrant. Thus Gabszewicz, Pepall and Thisse (1992), Farrell and Shapiro (1988), and Wang

without real (socially costly) switching costs; they too find that loyal customers are charged higher prices than switchers. However, they also show that firms may wish to offer longterm contracts that offer consumers a high period-one price in return for a guaranteed low period-two price (see Section 2.8.3). (Villas-Boas (1999) analyses a many-period model similar to Fudenberg and Tirole's but does not consider long-term contracts.) Acquisti and Varian (2005) present a related two-period monopoly model which can be interpreted as being of consumers with switching costs.

${ }^{47}$ Consumers must also have rational expectations about future price differences, etc.

${ }^{48}$ Even if all consumers have the same switching cost, if an entrant's production cost plus that switching cost exceeds the incumbent's production cost, then in a quantitycompetition model the entrant will sell to some of them, thus inducing inefficient switching (Klemperer (1988)). This result is just the standard oligopoly result that a higher-cost firm wins a socially excessive market share (though at a smaller markup).

A caveat is that these excessive-switching results take the number of firms as given. If the switching costs mean there is too little entry from the social viewpoint (see Section 2.7.2) then there may for this reason be too little switching. 
and Wen (1998) also predict excessive switching to smaller firms and entrants.

(ii) consumers switch in order to affect prices

If a consumer is a large fraction of the market, or if firms can discriminate between consumers (so each consumer is, in effect, a separate market), a consumer may switch to affect future prices.

If switching costs are learning costs, switching strengthens a consumer's outside option, so he may switch in order to strengthen his bargaining positionby switching he effectively creates a second source of supply and thereby increases the competition to supply him in the future (Lewis and Yildirim, forthcoming). And even if switching costs are transactional (and firms are imperfectly informed about their magnitude), we saw in section 2.5.1 that consumers may switch to signal that their switching costs are low and so improve their terms of trade.

Strategic consumers may also commit to ignore switching costs (or acting as if their switching costs were lower than they truly are) in their future purchase decisions, in order to force the incumbent supplier to price more competitively (Cabral and Greenstein (1990)); ${ }^{49}$ this strategy will generally increase the amount of switching.

In all these cases, socially costly switching in order to affect prices is inefficient to the extent that it merely shifts rents from firms to the customer who switches. On the other hand, if firms cannot discriminate between consumers, such switching usually lowers prices and so improves the efficiency of other consumers' trades with sellers, so there may then be less switching than is socially desirable.

(iii) switching costs are not real social costs

If switching costs are contractual, and not social costs, consumers will ceteris paribus switch less than is efficient. But if real (social) switching costs exist, then contractual switching costs may prevent socially inefficient switches of the types discussed above. ${ }^{50}$

\subsubsection{Multiproduct Firms}

A consumer who buys several products in a single period may incur additional "shopping costs" for each additional supplier used. These shopping costs may be the same as the switching costs incurred by consumers who change suppliers between periods. However, the dynamic and commitment issues that switching-cost models usually emphasise no longer arise. In particular, firms and consumers can contract on all prices, so the analogy with economies

\footnotetext{
${ }^{49}$ The literature has largely assumed that consumers have no commitment power (see Section 2.8 for exceptions).

${ }^{50}$ In Fudenberg and Tirole (2000) firms endogenously offer long term contracts that create contractual switching costs that reduce inefficient switching to less preferred products and increase social welfare, conditional on firms being permitted to price discriminate between old and new customers.
} 
of scope in production is particularly strong. ${ }^{51}$ Thus shopping costs provide an efficiency reason for multiproduct firms just as economies of scope in production do. ${ }^{52}$

The analogy is not perfect, because switching costs and shopping costs are based on specific consumer-firm matches, whereas the production-side economies of scope emphasised by Panzar and Willig (1981) and others depend only on a firm's total sales of each product and not on whether the same consumers buy the firm's different products or whether some consumers use multiple suppliers. ${ }^{53}$

However, the analogy is particularly good if firms' product lines are sufficiently broad that most consumers use just one supplier. For example, Klemperer and Padilla (1997) demonstrate that selling an additional product can provide strategic benefits for a firm in the markets for its current products if consumers have shopping costs of using additional suppliers (because selling an extra variety can attract demand away from rival suppliers for this firm's existing varieties). This parallels Bulow et al (1985)'s demonstration of the same result if consumers' shopping costs are replaced by production-side economies of scope (because selling an additional variety lowers the firm's marginal costs of its existing products). In both cases each firm, and therefore the market, may therefore provide too many different products. More obviously, mergers can be explained either by consumer switching costs (Klemperer and Padilla (1997)) or by production economies of scope.

Some results about single-product competition over many periods with switching costs carry over to multi-product competition in a single period with shopping costs. For example, we suggested in Section 2.4.2 that when switching costs are learning costs, oligopolists might benefit by synchronizing their sales to minimize switching and so reduce the pool of highly pricesensitive (no-switching cost) customers. Likewise multiproduct firms competing in a single period may have a joint incentive to minimize the number of consumers who buy from more than one firm. Indeed Klemperer (1992, 1995 ex.4) shows that firms may inefficiently offer similar products to each other, or similar product lines to each other, for this reason. Taken together with the previous paragraph's result, this suggests that each firm may pro-

\footnotetext{
${ }^{51}$ But some superficially single-period contexts are better understood as dynamic. For instance, supermarkets advertise just a few "loss leaders"; unadvertised prices are chosen to be attractive once the consumer is in the shop ("locked in") but might not have drawn him in. (See Section 2.1.)

${ }^{52}$ Examples include supermarkets, shopping malls, hospitals and airlines: Dranove and White (1996) models hospitals as multi-product providers with switching costs between providers. Several studies document that travelers stongly prefer to use a single airline for a multi-segment trip, and the importance of these demand-side complementarities in air travel (e.g. Carlton, Landes, and Posner (1980)).

${ }^{53}$ As we noted in Section 2.1, if firms can discriminate between consumers, then each consumer becomes an independent market which, in the presence of switching costs, is closely analogous to a market with production economies of scope.
} 
duce too many products, but that there may nevertheless be too little variety produced by the industry as a whole.

An important set of shopping-cost models are the "mix-and-match" models pioneered by Matutes and Regibeau (1988), Economides (1989) and Einhorn (1992). Most of this literature takes each firm's product-line as given, and asks whether firms prefer to be compatible (no shopping costs) or incompatible (effectively infinite shopping costs); see Sections 2.7.3 and 2.8.

Similarly, when firms "bundle" products (see, e.g., Whinston (1990), Matutes and Regibeau (1992), Nalebuff (2000, forthcoming)) they are creating contractual shopping costs between their products; we discuss bundling briefly in Sections 2.7 .3 and 2.8. ${ }^{54}$

"Shopping costs" models are distinguished from other "switching costs" models in that consumers can observe and contract on all prices at the same time in the "shopping costs" models. We will henceforth use the term switching costs to cover all these costs, but continue to focus mainly on dynamic switching costs.

\subsection{Battles for Market Share}

\subsubsection{The Value of Market Share}

We have seen that with switching costs (or indeed proprietary network effectssee Section 3.7), a firm's current customer base is an important determinant of its future profits.

We can therefore write a firm's current-period value function, (i.e., total discounted future profits), $V_{t}$, as the sum of its current profits, $\pi_{t}$, and its discounted next-period value function $\delta V_{t+1}\left(\sigma_{t}\right)$, in which $\delta$ is the discount factor and the next-period value function, $V_{t+1}(\cdot)$, is a function of the size of its current-period customer base, $\sigma_{t}$.

$$
V_{t}=\pi_{t}+\delta V_{t+1}\left(\sigma_{t}\right)
$$

For example, in our core model with free entry, $V_{t+1}=s \sigma_{t}$, and Biglaiser, Crémer and Dobos (2003) have explored various cases in which this simple formula holds. More generally, however, (2) is a simplification. In general, the firm's future profits depend on its customers' types and their full histories, how market share is distributed among competing firms, how many consumers in the market make no purchase, etc. However, $V_{t+1}$ depends only on current-period market share in models such as Klemperer (1987b, 1995), Farrell and Shapiro (1988), Beggs and Klemperer (1992), Padilla (1992, 1995), and Chen and Rosenthal (1996), which all model just two firms and a fixed set of consumers whose reservation prices are high enough that they always purchase. (For example, equation (1) shows for Beggs and Klemperer's model how prices, and therefore also quantities, and hence value functions,

\footnotetext{
${ }^{54}$ Varian's (1989) and Stole's (forthcoming) surveys describe models of quantity discounts and bundling in Volume 1 and the current volume of this Series, respectively.
} 
in a period depend on the firm's previous-period market share.) So $\sigma_{t}$ is often interpreted as "market share", and this explains firms' very strong concern with market shares in markets with switching costs and/or (we shall see) network effects. ${ }^{55}$

\subsubsection{Penetration Pricing}

From (2), the firm's first-order condition for the optimal choice of a period- $t$ price is

$$
0=\frac{\partial V_{t}}{\partial p_{t}}=\frac{\partial \pi_{t}}{\partial p_{t}}+\delta \frac{\partial V_{t+1}}{\partial \sigma_{t}} \frac{\partial \sigma_{t}}{\partial p_{t}}
$$

Provided that the firm's value function is increasing in its market share, ${ }^{56}$ therefore, the firm charges a lower price or sets a higher quantity ${ }^{57}$ than would maximize short-run profits, in order to raise its customer base and hence its future profits. That is, $\partial \pi_{t} / \partial p_{t}>0$ (since we assume $\partial \sigma_{t} / \partial p_{t}<0$ ).

In the early stages of a market, therefore, when few consumers are locked in, so even short-run profit-maximising prices are not high relative to costs, equation (3) implies low penetration pricing, just as in the core two-period model. ${ }^{58} 59$ Equation (3) also suggests that the larger the value of the future market, $V_{t+1}$, the deeper the penetration pricing will be. For example, a more rapidly growing market will have lower prices. ${ }^{60}$

\footnotetext{
${ }^{55}$ Because switching costs make current market share such an important determinant of a manufacturer's future profits, Valletti (2000) suggests they may provide a motive for vertical integration with retailers to ensure sufficient investment in a base of repeat subscribers.

${ }^{56}$ This case, $\partial V_{t+1} / \partial \sigma_{t}>0$, seems the usual one, although in principle, stealing customers from rival(s) may make the rival(s) so much more aggressive that the firm is worse off. See Banerjee and Summers (1987), Klemperer (1987c).

In Beggs and Klemperer (1992), $V_{t+1}$ is quadratic in $\sigma_{t}$. (The fact that the sum of the duopolists' value functions is therefore maximised at the boundaries is consistent with stable dynamics because lowering current price is less costly in current profits for the firm with the smaller market share. See Budd et al (1993).)

${ }^{57}$ We can perform a similar analysis with similar results for a quantity-setting firm. The analysis is also unaffected by whether each firm sets a single price to all consumers or whether, as in section 2.5, each firm sets different prices to different groups of consumers in any period.

${ }^{58}$ It is unclear whether we should expect "penetration pricing" patterns from a monopolist, since $\partial V_{t+1} / \partial \sigma_{t}$ may be smaller in monopoly - where consumers have nowhere else to go - than in oligopoly, and (if goods are durable) durable-goods effects imply falling prices in monopoly absent switching-cost effects (equation (3) only implies that early period prices are lower than in the absence of switching-costs, not that prices necessarily rise). Cabral et al (1999) show it is hard to obtain penetration pricing in a network-effects monopoly model (see Section 3.6).

${ }^{59}$ Of course, as noted in Section 2.3.2, in a more general model the "penetration" might be through advertising or other marketing activities rather than just low prices.

${ }^{60}$ Strictly, (3) tells us prices are lower if $\partial V_{t+1} / \partial \sigma_{t}$ is larger, but this is often true for a more rapidly growing market. See, for example, Beggs and Klemperer (1992), Borenstein, Mackie-Mason and Netz (2000) and also Holmes' (1990) steady-state model of a monopolist
} 


\subsubsection{Harvesting vs Investing: Macroeconomic and International Trade Applications}

As equations (2) and (3) illustrate, the firm must balance the incentive to charge high prices to "harvest" greater current profits $\left((3)\right.$ showed $\pi_{t}$ is increasing in $p_{t}$ ) against the incentive for low prices that "invest" in market share and hence increase future profits $\left(V_{t+1}\right.$ is increasing in $\sigma_{t}$, which is decreasing in $p_{t}$ ).

Anything that increases the marginal value of market share will make the firm lower price further to invest more in market share. Thus, for example, a lower $\delta$, that is, a higher real interest rate, reduces the present value of future market share (see (2)) so leads to higher current prices (see (3): lower $\delta$ implies lower $\partial \pi_{t} / \partial p_{t}$ implies higher $\left.p_{t}{ }^{61}\right)$.

Chevalier and Scharfstein (1996) develop this logic in a switching-cost model based on Klemperer (1995). They argue that liquidity-constrained firms perceive very high real interest rates and therefore set high prices, sacrificing future profits in order to raise cash in the short term. They provide evidence that during recessions (when financial constraints are most likely to matter) the most financially-constrained supermarket chains indeed raise their prices relative to other chains, and Campello and Fluck (2004)'s subsequent empirical work shows that these effects are larger in industries where consumers face higher switching costs. ${ }^{62}$

Fitoussi and Phelps (1988) use a similar logic (emphasising search costs rather than switching costs) to argue that high interest rates contributed to the high rates of inflation in Europe in the early 1980s.

Froot and Klemperer (1989) also apply the same logic to international trade in a model of competition for market share motivated by switching costs and network effects. A current appreciation of the domestic currency lowers a foreign firm's costs (expressed in domestic currency) and so tends to lower prices. However, if the appreciation is expected to be only temporary then the fact that the domestic currency will be worth less tomorrow is equivalent to an increase in the real interest rates which raises prices. So exchange-rate changes that are expected to be temporary may have very little impact on import prices. But if the currency is anticipated to appreciate in the future, both the "cost effect" and "interest-rate effect" are in the same directionmarket share tomorrow is probably worth more if future costs are lower, and tomorrow's profits are worth more than today's profits, so for both reasons today is a good time to invest in market share rather than harvest current profits. So import prices may be very sensitive to anticipated exchange-rate

selling a single product to overlapping generations of consumers who incur set-up costs before buying the product.

${ }^{61}$ See Klemperer (1995). We assume stable, symmetric, oligopoly and that the dominant effect of lowering $\delta$ is the direct effect.

${ }^{62}$ See also Campello (2003). Beggs and Klemperer (1989, Section 5.3) and Klemperer (1995) provide further discussion of how "booms" and "busts" affect the trade-offs embodied in equation (3) and hence affect price-cost margins. 
changes. Froot and Klemperer (1989) and Sapir and Sekkat (1995) provide empirical support for these theories. ${ }^{63}$

\section{$2.7 \quad$ Entry}

Switching costs may have important effects on entry: with real, exogenous switching costs, small-scale entry to win new, unattached, consumers is often easy and indeed often too easy, but attracting even some of the old "lockedin" customers may not just be hard, but also be too hard from the social standpoint.

Furthermore, firms may also create unnecessary switching costs in order to discourage entry.

\subsubsection{Small-Scale Entry is (Too) Easy}

We saw in Section 2.4 that if firms cannot discriminate between old and new consumers, then the "fat cat" effect may make small scale entry very easy: incumbent firms' desire to extract profits from their old customers creates a price umbrella under which entrants can profitably win new unattached (or low switching cost) customers. And even after entry has occurred, the erstwhile incumbent(s) will continue to charge higher prices than the entrant, and lose market share to the entrant, so long as they remain "fatter" firms with more old consumers to exploit.

So if there are no economies of scale, even an entrant that is somewhat less efficient than the incumbent(s) can enter successfully at a small scale that attracts only unattached buyers. ${ }^{64} \quad$ (See Klemperer (1987c), Farrell and Shapiro (1988), Gabszewicz, Pepall and Thisse (1992), Wang and Wen (1998), etc.)

Of course, the flip-side of this is that the same switching costs that encourage new entry also encourage the new entrants to remain at a relatively small scale unless there are many unattached buyers. ${ }^{65}$

\footnotetext{
${ }^{63}$ For other applications of switching-costs theory to international trade, see Tivig (1996) who develops "J-curves" (since sales quantities respond only slowly to price changes if there are switching costs), Gottfries (2002), To (1994), and Hartigan (1995).

${ }^{64}$ This result depends on there being (sufficient) new customers in each period (which is a natural assumption). For an analogous result that entry was easy into just one product in a shopping-cost market, there would have to be sufficient buyers without shopping costs, or who wished to purchase just that product (this may be a less natural assumption). Failing that, "small scale" entry in a shopping cost market is not easy.

Our assumption of no discrimination between old and new consumers means the easyentry result also does not apply to aftermarkets. Entry may be hard in this case if first-period prices cannot fall too low, and the incumbent has a reputational or similar advantage. For example, the UK Office of Fair Trading found in 2001 that new entry was very hard into the hospital segment of the market served by NAPP Pharmaceutical Holdings Ltd where prices were less than one-tenth of those in the "follow-on" community market.

${ }^{65}$ Good (2006) shows that, for this reason, switching costs may lead an incumbent firm
} 


\subsubsection{Large Scale Entry is (Too) Hard}

While the fat-cat effect gives new entrants an advantage in competing for new customers, it is very hard for them to compete for customers who are already attached to an incumbent. There is also adverse selection: consumers who switch are likely to be less loyal, hence less valuable, ones. ${ }^{66}$ So entry may be hard if small-scale entry is impractical, due perhaps to economies of scale, or to network effects. Furthermore, even new consumers may be wary of buying from a new supplier if they know that it can only survive at a large scale, since with switching costs consumers care about the future prospects of the firms they deal with.

Of course, this does not imply that there is too little large-scale entry. If switching costs are social costs, then large-scale entry may not be efficient even if the entrant's production costs are modestly lower than an incumbent's. That is, to some extent these obstacles to profitable large-scale entry reflect social costs of such entry.

However, this reflection is imperfect. If the entrant cannot discriminate between consumers, then large-scale entry requires charging all consumers a price equal to the incumbent's price less the marginal old buyer's switching cost. But socially the switching cost applies only to the old switching buyers, not to the new consumers, and only applies to switching buyers at the average level of their switching cost, not at the marginal switching cost. So efficient large-scale entry may be blocked.

Furthermore, entry can sometimes be strategically blockaded. In particular, an incumbent may "limit price", that is, cut price to lock in more customers and make entry unprofitable at the necessary scale, when entry at the same scale would have been profitable, and perhaps efficient, if the additional customers had not been "locked-up" prior to entry (see Klemperer $(1987 \mathrm{c})){ }^{67}$

Of course, entry can be too easy or too hard for more standard reasons. Entry can be too hard if it expands market output, and consumers rather

to prefer to delay innovation and instead rely on new entrants to introduce new products which the incumbent can then imitate.

${ }^{66}$ Some work on the credit card market emphasises this adverse-selection problem: creditworthy borrowers may have been granted high credit limits by their current card issuers so have higher switching costs. Furthermore, low-default risk customers may be less willing to switch (or even search) because they do not intend to borrow-but they often do borrow nevertheless (Ausubel, 1991). Calem and Mester (1995) provide empirical evidence that this adverse selection is important, Ausubel provides evidence that the US bank credit card issuing market earns positive economic profit and attributes this, at least in part, to switching costs or search costs, and Stango (2002) also argues that switching costs are an important influence on pricing.

${ }^{67}$ The incumbent's advantage is reduced if it does not know the entrant's costs, or quality, or even the probability or timing of entry, in advance of the entry. Gerlach (2004) explores the entrant's choice between pre-announcing its product (so that more consumers wait to buy its product) and maintaining secrecy so that the incumbent cannot limit price in response to the information. 
than the entrant capture the surplus generated. And entry is too easy if its main effect is to shift profits from the incumbent to the entrant. ${ }^{68}$ But these caveats apply whether or not there are switching costs; the arguments specific to switching costs suggest that entry that depends for its success on consumers switching is not just hard, but too hard.

\subsubsection{Single-Product Entry May Be (Too) Hard}

If switching costs (or shopping costs) "tie" sales together so consumers prefer not to patronise more than one firm, and consumers wish to buy several products (see Section 2.5.3), then an entrant may be forced to offer a full range of products to attract new customers (let alone any old consumers). If offering a full range is impractical, entry can effectively be foreclosed. Thus in Whinston (1990), Nalebuff (forthcoming), and Klemperer and Padilla (1997), tying can foreclose firms that can only sell single products. In Whinston and Nalebuff the "switching costs" are contractual, while in Klemperer and Padilla the products are "tied" by real shopping costs. ${ }^{69}$ If the switching/shopping costs are real, entry need not be too hard given the switching costs, but the arguments of the previous subsection suggest it often may be.

\subsubsection{Artificial Switching Costs Make Entry (Too) Hard}

The previous discussion addressed whether entry is too easy or too hard, taking the switching costs as given: we observed that switching costs make certain kinds of entry hard, but that this is at least in part because they also make entry socially costly, so entry may not be very much too hard given the switching costs. A larger issue is whether the switching costs are inevitable real social costs. They may instead be contractual, ${ }^{70}$ or may be real but caused by an unnecessary technological choice that an entrant cannot copy. In these cases, it is the incumbent's ability to choose incompatibility that is the crucial entry barrier.

\footnotetext{
${ }^{68}$ Klemperer (1988) illustrates the latter case, showing that new entry into a mature market with switching costs can sometimes be socially undesirable. The point is that just as entry of a firm whose costs exceed the incumbent's is often inefficient in a standard Cournot model without switching costs (Bulow et al, 1985, section VI E, Mankiw and Whinston, 1986) so entry of a firm whose production cost plus consumers' switching cost exceeds the incumbent's production cost is often inefficient in a quantity-setting model with switching costs (see footnote 48).

${ }^{69}$ Choi (1996a) shows that tying in markets where R\&D is critical can allow a firm with an R\&D lead in just one market to pre-empt both. The welfare effects are ambiguous.

${ }^{70}$ This includes those created by "loyalty contracts", "exclusive contracts" and "bundling" or "tying" etc.
} 


\subsection{Endogenous Switching Costs: Choosing How to Compete}

Market participants may seek to either raise or to lower switching costs in order to reduce inefficiencies (including the switching cost itself), to enhance market power, to deter new entry, or to extract returns from a new entrant:

\subsubsection{Reducing Switching Costs to Enhance Efficiency}

As we have seen, a firm that cannot commit not to exploit its ex-post monopoly power must charge a lower introductory price. If the price-path (or quality-path) is very inefficient for the firm and consumers jointly, the firm's surplus as well as joint surplus may be increased by nullifying the switching costs. Thus, for example, a company may license a second source to create a future competitor to which consumers can costlessly switch (Farrell and Gallini (1988)) ${ }^{71}$

Likewise, firms producing differentiated products (or product lines) may deliberately make them compatible (i.e., choose zero switching costs). This increases the variety of options available to consumers who can then "mixand-match" products from more than one firm without paying a switching cost. So eliminating switching costs can raise all firms' demands, and hence all firms' profits. $^{72}$

Where suppliers are unwilling to reduce switching costs (see below), third parties may supply converters, ${ }^{73}$ or regulators may intervene.

We have also already noted that customers may incur the switching (or start-up) cost of using more than one supplier, or may pre-commit to ignoring the switching costs in deciding whether to switch, ${ }^{74}$ in order to force suppliers to behave more competitively. ${ }^{75}$

Finally, firms may be able to mitigate the inefficiencies of distorted prices and/or qualities by developing reputations for behaving as if there were no switching costs. ${ }^{76}$

\footnotetext{
${ }^{71}$ In Gilbert and Klemperer (2000) a firm commits to low prices that will result in rationing but will not fully exploit the consumers ex-post, to induce them to pay the start-up costs of switching to the firm.

${ }^{72}$ See Matutes and Regibeau (1988), Economides (1989), Garcia Mariñoso (2001), Stahl (1982), etc. But the mix-and-match models reveal other effects too; see Section 2.8.4. Note that many models ignore the demand-reducing effect of switching costs by considering a fixed number of consumers all of whom have reservation prices that are sufficiently high that total demand is fixed.

${ }^{73}$ See Section 3.8.3 for more on converters.

${ }^{74}$ See Cabral and Greenstein (1990).

${ }^{75}$ Greenstein (1993) discusses the procurement strategies used by U.S. federal agencies in the late 1970 s to force suppliers of mainframe computers to make their systems compatible with those of their rivals.

${ }^{76}$ See Eber (1999). Perhaps more plausibly firms may develop reputations for, or otherwise commit to, treating old and new customers alike (since this behaviour is easy for consumers to understand and monitor); this behavior may also mitigate the inefficiencies due to the distorted prices (though see footnote 78) - it is most likely to be profitable if
} 


\subsubsection{Increasing Switching Costs to Enhance Efficiency}

Firms may also mitigate the inefficiencies of distorted prices and qualities by contracting, or even vertically integrating, with their customers. ${ }^{77} \quad 78$ Likewise Taylor (2003) finds firms might set lower prices to loyal consumers to reduce inefficient switching. Of course, a downside of these strategies of increasing switching costs is that they also limit the variety available to consumers unless they pay the switching costs.

\subsubsection{Increasing Switching Costs to Enhance Oligopoly Power}

Although switching costs typically reduce social surplus, we saw in Sections 2.3-2.5 that they nevertheless often increase firms' profits. If so, firms jointly prefer to commit (before they compete) to real social switching costs than to no switching costs. Thus, firms may artificially create or increase switching costs.

Of course, a firm may prefer switching costs from but not to its product if it can achieve this, especially where the switching costs are real social costs. Adams (1978) describes how Gillette and its rivals tried to make their razor blades (the profitable follow-on product) fit one another's razors but their razors accept only their own blades. However, Koh (1993) analyses a model in which each duopolist chooses a real social cost of switching to it, and shows the possibility that each chooses a positive switching cost in order to relax competition. $^{79}$

In Banerjee and Summers (1987) and Caminal and Matutes (1990) firms have the option to generate contractual switching costs by committing in period zero to offering repeat-purchase coupons in a two-period duopoly, and both firms (independently) take this option. ${ }^{80}$ Similarly Fudenberg and Tirole (2000) explore a two-period model in which firms can price discriminate between consumers based on their past demands; if firms can also offer long term contracts - that is, generate contractual switching costs - then firms do offer such contracts in equilibrium, in addition to spot contracts. ${ }^{81}$

\footnotetext{
bargain-then-ripoff pricing is particularly inefficient.

${ }^{77}$ See Williamson (1975) and Klein, Crawford, and Alchian (1978).

${ }^{78}$ However incomplete contracts to protect against suppliers' opportunism may be less desirable than none at all. Farrell and Shapiro (1989) call this the Principle of Negative Protection. The point is that it is better (ex ante) for customers to be exploited efficiently than inefficiently ex-post. So if contracts cannot set all future variables (e.g. can set prices but not qualities), so customers anyway expect to be exploited ex-post, it may be better that there are no contracts.

${ }^{79}$ Similarly Bouckaert and Degryse (2004) show in a two-period credit market model that each bank may reduce switching costs from itself, in order to relax competition.

${ }^{80}$ However, Kim and Koh (2002) find that a firm with a small market share may reduce contractual switching costs by choosing to honour repeat-purchase coupons that its rivals have offered to their old customers.

${ }^{81}$ These papers are discussed in more detail elsewhere in this Volume, in Stole (forthcoming).
} 


\subsubsection{Reducing Switching Costs to Enhance Oligopoly Power}

An important class of models which suggests that firms may often be biased towards too much compatibility from the social viewpoint is the "mixand-match" models (see Section 2.5) in which different firms have different abilities in producing the different components of a "system". Consumers' ability to mix-and-match the best product(s) offered by each firm is an efficiency gain from compatibility (that is, from zero rather than infinite shopping costs), but firms' private gains from compatibility may be even greater because - perhaps surprisingly - compatibility can increase prices.

In the simplest such model, Einhorn (1992) assumed that a single consumer wants one each of a list of components produced by firms A, B, with production costs $a_{i}$ and $b_{i}$ respectively for component $i$. In compatible competition the price for each component is $\max \left\{a_{i}, b_{i}\right\}$, so the consumer pays a total price $\sum_{i} \max \left\{a_{i}, b_{i}\right\}$ for the system. But if the firms are incompatible, the Bertrand price for a system is $\max \left\{\sum_{i} a_{i}, \sum_{i} b_{i}\right\}$ which is lower unless the same firm is best at everything: if different firms are best at providing different components, then the winning seller on each component appropriates its full efficiency margin in compatible competition, but in incompatible competition the winner's margin is its efficiency advantage where it is best, minus its rival's advantage where its rival is best. Firms thus (jointly) more than appropriate the efficiency gain from compatibility, and consumers actually prefer incompatibility.

This result depends on (among other assumptions) duopoly at each level. If more than two firms produce each component, the sum of the second-lowest cost of each component (which the consumer pays under compatibility) may easily be lower than the second-lowest system cost when firms are incompatible, so consumers often prefer compatibility and firms' incentives may be biased either way (see Farrell, Monroe and Saloner (1998))..$^{82}$

The "order-statistic" effect emphasised in these models is not the only force, however. Matutes and Regibeau (1988) stressed that under compatibility a price cut by one firm in one component increases demand for the other firms' complements, whereas under incompatibility all of this boost in complementary demand accrues to the firm, so compatibility reduces incentives to cut prices. ${ }^{83}$ Economides (1989) argued that, unlike the Einhorn

\footnotetext{
${ }^{82}$ Einhorn's results, but not those of Farrell, Monroe and Saloner, are qualitatively unaffected by whether or not firms know their own efficiencies in each component. The analysis of these two papers is related to Palfrey (1983).

${ }^{83}$ Matutes and Regibeau (1992) allowed firms to set separate prices for bundles (not necessarily the sum of the component prices) and found that the force toward compatibility weakens. Furthermore, compatibility also changes the structure of demand, so even Matutes and Regibeau (1988) found that firms are sometimes biased towards incompatibility. And Klemperer (1992) also shows that firms may prefer incompatibility to compatibility when the latter is socially preferred, and that the firms may even distort their product choices to sustain incompatibility. Garcia Mariñoso (2001) examines a mixand-match model in which purchase takes place over two periods, and finds that firms are biased towards compatibility because it reduces the intensity of competition in the first
} 
result, this logic does not depend on duopoly, so provides a clear argument why firms may try too hard to reduce switching costs and shopping costs. ${ }^{84}$

\subsubsection{Increasing Switching Costs to Prevent or Exploit Entry}

The mix-and-match literature of the previous subsection ignores the fact that entry provides a much greater discipline on prices when compatability means a new firm can enter offering just one component of a system than when any entrant needs to offer a whole system.

More generally, we have seen (Section 2.7) that an incumbent firm may protect a monopoly position against entry by writing exclusionary contracts, or by artificially creating real switching costs through technological incompatibility with potential entrants. ${ }^{85}$ Imposing contractual switching costs (but not real social switching costs) can also enable an incumbent to extract rents from an entrant without preventing its entry - the entrant is forced to pay a fee (the "liquidated damages") to break the contracts. ${ }^{86}$

\subsection{Switching Costs and Policy}

As we have seen, with (large) switching costs firms compete over streams of goods and services rather than over single transactions. So one must not jump from the fact that buyers become locked in to the conclusion that there is an overall competitive problem. Nor should one draw naive inferences from individual transaction prices, as if each transaction were the locus of ordinary competition. Some individual transactions may be priced well above cost even when no firm has (ex-ante) market power; others may be priced below cost without being in the least predatory. ${ }^{87} 88$ Thus switching-cost

period - see also Haucap (2003) and Garcia Mariñoso (2003). (All these models, unlike Einhorn and Farrell, Monroe, and Saloner, assume some product differentiation between firms' components even under compatibility). See also Anderson and Leruth (1993).

${ }^{84}$ Most of the "mix-and-match" literature assumes that each firm offers a full line of products, but DeNicolo (2000) analyzes competition with one full-line and a pair of specialist firms. In our terminology, there are then no additional shopping costs of buying from an additional specialist firm after having bought from one of the specialist firms, but the specialist firms do not internalize the complementarities between them.

${ }^{85}$ Imposing switching costs would not be worthwhile for the incumbent if they reduced consumers' willingnesses to pay by more than the gains from excluding entry. In models such as Rasmusen, Ramseyer, and Wiley (1989), and Segal and Whinston (2000), it is unprofitable to enter and serve only one customer, so no customer loses by signing an exclusive contract if other customers have already done so; in equilibrium this can mean that no customer needs to be compensated for signing an exclusive contract.

Deterring entry is also profitable if it can transfer rents from an entrant to the incumbent.

${ }^{86}$ See Aghion and Bolton (1987) and Diamond and Maskin (1979).

${ }^{87}$ For instance, in an aftermarket context such as the Kodak case, the fact that repair services are priced well above cost does not by itself prove that there is a serious competitive problem.

${ }^{88}$ Another naïve argument is that if one observes little or no switching, then firms do not constrain one another's prices: firms that compete on a life-cycle basis (rather than 
markets can be more competitive than they look, and switching costs need not generate supernormal profits, even in a closed oligopoly. These points emerge clearly from the core two-period model with which we began.

But, as our further discussion shows, while switching costs need not cause competitive problems, they probably do make competition more fragile, especially when they coexist with ordinary scale economies (or, as we will see in section 3, with network effects). Because large-scale entry into switching-cost markets is hard (whether or not inefficiently so), there may be much more incentive for monopolizing strategies such as predation or merger than there is in markets in which easy entry limits any market power. Thus switching costs, in combination with other factors, could justify heightened antitrust scrutiny. ${ }^{89}$

Furthermore, while sometimes (as in our core model) firms must give all their ex post rents to consumers in ex ante competition, that is not always true. The ex post rents may be less than fully competed away, as in most of the oligopoly models we discussed. Or, if the ex post rents are dissipated in unproductive activities such as excessive marketing or advertising, then consumers are harmed by switching costs even if firms are no better off. So switching costs often do raise average prices. Moreover, as in our core model, switching costs often cause a bargain-then-ripoff pattern of prices, and (going beyond the core model) this can be inefficient even when the average level of prices remains competitive; they make matching less efficient by discouraging re-matching or the use of multiple suppliers; and, of course, they result in direct costs when consumers do switch.

For these reasons, despite the warnings in the first paragraph of this subsection, markets may indeed perform less well with switching costs than without, so policy intervention to reduce switching costs may be appropriate. ${ }^{90}$

on an individual transaction basis) constrain one another's life-cycle prices and, of course, firms may be constrained even ex post by the threat of customer switching even when that threat is not carried out in equilibrium.

${ }^{89}$ For example, the UK Competition Commission in July 2001 blocked the proposed merger of two banks, Lloyds TSB and Abbey National, even though Abbey National accounted for only 5 per cent of the market for personal banking. An important part of the Commission's reasoning was that consumer switching costs, combined with some scale economies, make new entry very hard, and that existing firms with low market shares tend to compete more aggressively than larger firms in markets with switching costs, so smaller firms are particularly valuable competitors to retain. (Klemperer is a UK Competition Commissioner, but was not involved in this decision.) See also Lofaro and Ridyard (2003).

Footnote 64 gives another example where policy makers were concerned that entry was very hard in a market with switching costs. In this case the UK regulator (the Director of the Office of Fair Trading) limited NAPP's aftermarket price to no more than five times the foremarket price in order to ameliorate the bargains-then-ripoffs price pattern. (He also limited the absolute level of the aftermarket price.)

${ }^{90} \mathrm{Gans}$ and King (2001) examine the regulatory trade-offs in intervening to reduce switching costs and show that who is required to bear the costs of ameliorating switching costs can importantly affect the efficiency of the outcome. See also Galbi (2001).

Viard (forthcoming) found that the introduction of number portability for U.S. tollfree telephone services substantially reduced switching costs and led to the largest firm 
For example, policy might cautiously override intellectual property rights, especially of copyright-like intellectual property that may have little inherent novelty, if those rights are used only as a tool to enforce incompatibility and so create private rewards that bear no relationship to the innovation's incremental value. ${ }^{91}$

In general firms may be biased either towards or against compatibility relative to the social standpoint. But switching costs seem more likely to lower than to raise efficiency, so when firms favor switching costs the reason is often because they enhance monopoly or oligopoly power by directly raising prices or by inhibiting new entry. ${ }^{92}$ This suggests that policy-makers should take a close look when firms with market power choose to have switching costs (through contract form or product design) when choosing compatibility would be no more costly. ${ }^{93} 94$

\section{Network Effects and Competition}

\subsection{Introduction}

It can pay to coordinate and follow the crowd. For instance, it is useful to speak English because many others do. A telephone or a fax machine or an

substantially reducing prices; the U.S. wireless industry strongly resisted the introduction of number portability in the wireless market. Aoki and Small (2000) and Gans, King, and Woodbridge (2001) also analyse number portability in the telecoms market.

The UK government is currently considering recommendations to reduce switching costs in the mortgage market, see Miles (2004).

${ }^{91}$ Thus, for example, the European Commission in 2004 ruled that Microsoft had abused its market power by, inter alia, refusing to supply interface infrastructure to competitors, thus making entry hard by products that could form part of a "mix-and-match" system with Microsoft's dominant Windows PC operating system. Microsoft was ordered to provide this information even if it was protected by intellectual property.

${ }^{92} \mathrm{~A}$ caveat is that firms often do not make a coordinated joint choice of whether to compete with switching costs or without, and different firms may be able to control the costs of different switches. See Section 2.8.

${ }^{93}$ For example, the Swedish competition authority argued that Scandinavian Airlines' "frequent-flyer" program blocked new entry on just one or a few routes in the Swedish domestic air-travel market in which entry on the whole range of routes was impractical (see Section 2.7.3), and the airline was ordered to alter the program from October 2001. A similar decision was made by the Norwegian competition authority with effect from April 2002. Fernandes (2001) provides some support for these decisions by studying alliances formed by U.S. airlines, and showing that "frequent-flyer" programs that cover more routes are more attractive to consumers and confer greater market power on the airlines operating the programs. See also Klemperer and Png (1986).

${ }^{94} \mathrm{~A}$ caveat is that the policy debate is often held ex-post of some lock-in. At this point incumbents' preference to maintain high switching costs is unsurprising and does not prove that switching costs raise prices overall (nor do the switching costs necessarily cause inefficiencies). Reducing switching costs ex-post also expropriates the incumbents' ex-ante investments, which may be thought objectionable, though the fear of expropriation of this kind of ex-ante investment seems unlikely to harm dynamic efficiency (and may in fact improve efficiency). 
email account is more valuable if many others have them. Driving is easier if everyone keeps right — or if everyone keeps left. While following the crowd may involve a variety of choices, we follow the literature in using the metaphor of "adoption of a good," construed broadly. We say that there are network effects if one agent's adoption of a good (a) benefits other adopters of the good (a "total effect") and (b) increases others' incentives to adopt it (a "marginal effect").

Classic (or peer-to-peer) network effects arise when every adoption thus complements every other, although the effects may be "localized:" for instance, an instant-messaging user gains more when her friends adopt than when strangers do. Indeed, adoption by spammers or telemarketers harms other adopters and makes them less keen to adopt, yet a few such nuisance adopters will not overturn the overall network effect: "generally" increased adoption makes the good more appealing.

An important kind of network effect arises when following the crowd enhances opportunities to trade. If thicker markets work better, then all traders want to join (adopt) a big market, and gain when the market grows. This fits the definition if each trader expects both to buy and to sell; but when traders can be divided into buyers and sellers, it is not true that each trader's arrival makes all others better off or encourages them to adopt. Each buyer gains when more sellers join, but typically loses when more other buyers join: he doesn't want to trade with them and may suffer an adverse terms-of-trade effect. Thus the effect of a buyer's adoption on sellers fits the definition above, as does the effect of a seller's adoption on buyers, but the buyer-buyer spillovers and the seller-seller spillovers often go the other way. Indirect network effects describe market-thickness effects from one side of the market, typically buyers, as the other side re-equilibrates. That is, when an additional buyer arrives, the "marginal effect" on sellers attracts additional sellers, and the total and marginal effects of additional sellers on buyers can then be attributed (indirectly, hence the name) to the additional buyer. If those effects outweigh any adverse terms-of-trade effect of the new buyer on other buyers, they induce network effects among buyers, treating sellers not as adopters subject to the definition but as a mere background mechanism.

This can all take place in terms of just one good. For instance, a firm's price policies create a network effect among buyers if price falls when demand rises. This can reflect production-side economies of scale if those are passed through to consumers. For example, if public transport is always priced at average cost, it gets cheaper the more it is used. Similarly, Bagwell and Ramey (1994) and Bagwell's chapter in this Handbook show how economies of scale in retailing can encourage consumers to coordinate (perhaps by responding to advertising) on large retailers. With or without scale economies, a firm's price policy can create an artificial network effect among buyers, as when a mobile-phone provider offers subscribers free calls to other subscribers. If a product will be abandoned without sufficient demand, one 
can view that as a price increase; thus buyers who will face switching costs want to buy a product that enough others will buy (Beggs 1989). At the industry rather than firm level, there may be price-mediated network effects in decreasing-cost competitive industries; or a larger market may support more sellers and thus be more competitive (Ramseyer, Rasmusen and Wiley 1991; Segal and Whinston 2000) or more productively efficient (Stigler 1951).

But, usually, the concept gets an additional layer: the background mechanism is re-equilibration of sellers of varied complements to a "platform" that buyers adopt. For instance, when more buyers adopt a computer hardware platform, more vendors supply software that will run on it, making the computer (with the option to buy software for it) more valuable to users: the hardware-software paradigm. ${ }^{95}$ Similarly, buyers may want to buy a popular car because a wider (geographic and other) variety of mechanics will be trained to repair it, or may hesitate to buy one that uses a less widely available fuel. We give more examples in 3.2 and discuss indirect network effects further in 3.3.2. ${ }^{96}$

While such indirect network effects are common-indeed, Rochet and Tirole (2003) argue that network effects predominantly arise in this way-it is worth warning against a tempting short-cut in the logic. Even in classic competitive markets, "sellers like there to be more buyers, and buyers like there to be more sellers," and this does not imply network effects if these effects are pecuniary and cancel one another. Indirect network effects driven by smooth free entry of sellers in response to additional buyers can only work when larger markets are more efficient, as we discuss further in 3.3.5

Section 3.2 describes some case studies and empirical work. Section 3.3, like the early literature, explores whether network effects are externalities and cause network goods to be under-adopted at the margin, a question that draws primarily on the total effect. But the modern literature focuses on how the marginal effect can create multiple equilibria among adopters, making coordination challenging and giving expectations a key role in competition and efficiency. As a result, network markets often display unstable dynamics such as critical mass, tipping, and path dependence, including collective switching costs. Section 3.4 argues that coordination is central and can be hard even despite helpful institutions. Section 3.5 discusses how adoption in network

\footnotetext{
${ }^{95}$ Somewhat confusingly, a leading example puts Microsoft's Windows in the role of "hardware" and applications software in the role of "software."

${ }^{96}$ For theories of indirect network effects through improved supply in a complement see Katz and Shapiro (1985), Church and Gandal (1992, 1993), Chou and Shy (1990), and Economides and Salop (1992); Gandal (1995) and Katz and Shapiro (1994) review this literature. Liebowitz and Margolis (1994) argue that indirect network effects lack the welfare properties of direct effects; see also Clements (2004); but Church, Gandal and Krause (2003) argue otherwise.

Presumably we could have network effects with several classes of adopter, each class benefiting only from adoption by one other class, but in practice models tend to assume either classic (single-class) or indirect (two-class) cases, although multi-component systems are sometimes studied.
} 
markets favors the status quo; such "inertia" has important implications for competition. Sections 3.3 to 3.5 thus study adopters' collective behavior, given their payoff functions including prices. Those sections thus describe adoption dynamics when each network good is unsponsored (competitively supplied), and also describe the demand side generally, including when each network good is strategically supplied by a single residual claimant or sponsor.

Turning to the supply side of network-effect markets, section 3.6 discusses how a sponsor might address coordination and externality problems; section 3.7 considers competition between sponsors of incompatible network products. In light of this analysis of incompatible competition, section 3.8 asks whether firms will choose to compete with compatible or incompatible products, and section 3.9 discusses public policy.

\subsection{Empirical Evidence}

\subsubsection{Case Studies}

Telecommunications Much early literature on network effects was inspired by telecommunications. Since telecommunications at the time was treated as a natural monopoly, the focus was mainly on how second-best pricing might take account of network effects/externalities, and on how to organize "universal service" cross-subsidies to marginal (or favored) users. ${ }^{97}$

Modern telecommunications policy stresses facilitating efficient competition. Compatibility in the form of interconnection, so that a call originated on one network can be completed on another, is fundamental to this. ${ }^{98} \mathrm{Un}$ like many compatibility decisions elsewhere, it is often paid for, and is widely regulated. Brock (1981) and Gabel (1991) describe how, in early unregulated US telephone networks, the dominant Bell system refused to interconnect with nascent independent local phone companies. Some users then subscribed to both carriers, somewhat blunting the network effects, as do similar "multi-homing" practices such as merchants accepting several kinds of payment cards.

Standards issues also arise in mobile telephony, although users on incompatible standards can call one another. Most countries standardized firstand second-generation air interfaces, predominantly on GSM, but the US did not set a compulsory standard for the second-generation air interface.

Radio and Television Besen and Johnson (1986) discuss standards obstacles to the adoption of AM stereo in the US after the government declined

\footnotetext{
${ }^{97}$ See for instance (in chronological order) Squire (1973), Rohlfs (1974), Kahn and Shew (1987), Einhorn (1993), Barnett and Kaserman (1998), Cremer (2000), Yannelis (2001), and Mason and Valletti (2001).

${ }^{98}$ Besen and Saloner $(1989,1994)$ studied standards and network effects in telecommunications; the International Telecommunications Union (ITU) has an entire "standardization sector."
} 
to mandate a standard; they argue that the competing standards were similar enough, and demand limited enough, for such a leadership vacuum to stall the technology. Greenstein and Rysman (2004) give a similar interpretation of the early history of 56k modem standards.

In television, governments have imposed standards, but they differ among countries; Crane (1979) interprets this as protectionist trade policy. Besen and Johnson describe how the US initially adopted a color TV standard that was not backward compatible with its black-and-white standard, so that color broadcasts could not be viewed at all on the installed base of sets; after brief experience with this, the FCC adopted a different standard that was backward-compatible. Farrell and Shapiro (1992) discuss domestic and international processes of picking high-definition television standards.

Microsoft Powerful network effects arise in computer platforms including operating systems, and Bresnahan (2001) argues that internal strategy documents confirm that Microsoft understands this very well. Because they have many users, Microsoft's operating system platforms attract a lot of applications programming. An indirect network effect arises because application software writers make it their first priority to work well with the dominant platform, although many applications are "ported" (a form of multi-homing), softening this effect. As we explore below, incompatible competition (and entry in particular) may well be weak unless applications programmers, consumers, and equipment manufacturers would rapidly coordinate and switch to any slightly better or cheaper operating system. ${ }^{99}$

The US antitrust case against Microsoft relied on this network effect or "applications barrier to entry", but did not claim that Windows is "the wrong" platform. Rather, Microsoft was convicted of illegal acts meant to preserve the network barrier against potential weakening through the Netscape browser and independent "middleware" such as Java. 100

Others complain that Microsoft vertically "leverages" control from the operating system to other areas, such as applications and servers. The European Commission's 2004 order against Microsoft addressed both leverage into media viewers and interface standards between PCs and servers.

In software more generally, Shurmer (1993) uses survey data and finds network effects in word processing and spreadsheet software; Liebowitz and Margolis (2001) however argue that product quality largely explains success.

\footnotetext{
${ }^{99} \mathrm{~A}$ barrier to incompatible entry matters most if there is also a barrier (here, intellectual property and secrecy) to compatible entry.

${ }^{100}$ Both the Department of Justice and Microsoft have made many documents available on their web sites, www.usdoj.gov/atr/ and www.microsoft.com/ respectively. A good introduction to the case is the 2001 decision of the DC Court of Appeals. A discussion by economists involved in the case is Evans et al. (2000); Fisher (2000) and Schmalensee (2000) give briefer discussions; see also the Journal of Economic Perspectives symposium (2001). See also Evans and Schmalensee (2001), and Rubinfeld (2003). Werden (2001) discusses the applications barrier to entry. Lemley and McGowan (1998b) discuss Java. (Farrell worked on this case for the Justice Department.)
} 
Gawer and Henderson (2005) discuss Intel's response to opportunities for leverage.

Computers Gabel (1991) contrasts case studies of standards in personal computers and in larger systems. In personal computers, initial fragmentation was followed by the rise of the IBM/Windows/Intel (or "Wintel") model, whose control passed from IBM to Intel and Microsoft. The standard, which lets many firms complement the microprocessor and operating system (and to a lesser extent lets others, such as AMD and Linux, compete with those), has thrived, in part due to the attraction of scale for applications software vendors and others, and relatedly due to the scope for specialization: see Gates, Myrhvold and Rinearson (1996), Grove (1999), and Langlois (e.g. 1990). Outside this standard only Apple has thrived.

Credit Cards From the cardholder side, a credit card system has indirect network effects if cardholders like having more merchants accept the card and don't mind having more other cardholders. The question is more subtle on the merchant side since (given the number of cardholders) each merchant loses when more other merchants accept a card. Since this negative "total effect" applies whether or not this merchant accepts the card, Katz (2001) and Rochet and Tirole (2002) show that the "marginal effect" (adoption encourages others to adopt) may apply but the total effect may fail even taking into account re-equilibration on the customer side, if card penetration is already high and total spending does not rise much with cardholding.

Network effects color inter-system competition, and dominant systems could remain dominant partly through self-fulfilling expectations, although both merchants and cardholders often "multi-home," accepting or carrying multiple cards, which weakens network effects (Rochet and Tirole 2003). The biggest card payment systems, Visa and Mastercard, have in the past been largely non-profit at the system level and feature intra-system competition: multiple banks "issue" cards to customers and "acquire" merchants to accept the cards. The systems' rules affect the balance between inter- and intra-system competition. Ramsey-style pricing to cardholders and merchants may require "interchange fees," typically paid by merchants' banks to cardholders' banks: see e.g. Katz (2001), Schmalensee (2002) and Rochet and Tirole (2002). But such fees (especially together with rules against surcharges on card purchases) may raise prices to non-card customers (Schwartz and Vincent 2006, Farrell 2006).

The QWERTY Keyboard David (1985) argued that the QWERTY typewriter keyboard became dominant through "historical small events." He suggested that QWERTY remains dominant despite being inferior (at least on a clean-slate basis) to other keyboard designs, notably the "Dvorak Simplified Keyboard" (DSK). Switching costs arise because it is costly to 
re-learn how to type. Network effects may arise "directly" because typists like to be able to type on others' keyboards, and "indirectly" for various reasons, e.g. because typing schools tend to teach the dominant design.

Liebowitz and Margolis $(1990,2001)$ deny that QWERTY has been shown to be substantially inferior, claiming that the technical evidence is mixed, weak, or suggests a relatively small inferiority-perhaps a few percent. If the penalty is small, switching (retraining) could be privately inefficient for already-trained QWERTY typists even without network effects. And evidently few users find it worth switching given all the considerations including any network effects.

But new users (who would not have to re-train from QWERTY) would find it worth adopting DSK or another alternative, if network effects did not outweigh their clean-slate stand-alone advantages. Combined with the technical evidence, this gives a lower bound on the strength of these network effects. If most typists type for a fifth of their working time and QWERTY has a stand-alone disadvantage of 5 percent, for instance, revealed preference of new QWERTY students suggests that the network effect is worth at least one percent of earnings. ${ }^{101}$ Yet many would doubt that network effects are terribly strong in keyboard design: most typists work mostly on their own keyboards or their employer's, and DSK training and keyboards are available (PC keyboards can be reprogrammed). We infer that even easily disparaged network effects can be powerful. ${ }^{102}$

But the efficiency of typing is mostly a parable; the deeper question is whether the market test is reliable. That question splits into two:

(a) Ex ante: did QWERTY pass a good market test when the market tipped to it? Can we infer that it was best when adopted, whether or not it remains ex post efficient now? A short-run form of this question is whether contemporary users liked QWERTY best among keyboards on offer; a long-run version is whether the market outcome appropriately took into account that not all keyboards had been tried and that taste and technology could (and later did) change.

On the short-run question, David suggests that "small" accidents of history had disproportionate effects; a prominent typing contest was won by an

\footnotetext{
${ }^{101}$ Since widespread dissemination of the PC, many typists type less than this; but for most of the keyboard's history, most typing probably was done by typists or secretaries who probably typed more than this.

${ }^{102}$ If one were very sure that network effects are weak, one might instead infer that the clean-slate stand-alone penalty of QWERTY must be small indeed, even negative. Even aside from the ergonomic evidence, however, that view is hard to sustain. For instance, the keyboard design problem differs among languages and has changed over time, yet QWERTY and minor variations thereof have been persistently pervasive. Thus if network effects were unimportant, the evidence from new typists' choices would imply that QWERTY was remarkably optimal in a wide range of contexts. And even if QWERTY is actually the best of all designs, the many people who believe otherwise would adopt DSK if they did not perceive network effects to be bigger.
} 
especially good typist who happened to use QWERTY. He suggests that the outcome was somewhat random and thus may well have failed even the shortrun test. Liebowitz and Margolis argue that because both typing-contest and market competition among keyboards was vigorous, one can presume that the outcome served short-run contemporary tastes.

A fortiori, David presumably doubts that the market's one-time choice of QWERTY properly took long-run factors into account. Liebowitz and Margolis do not directly address the long-run question, but suggest that it shouldn't be viewed as a market failure if QWERTY won because technically superior alternatives weren't yet on the market. ${ }^{103}$ In sections 3.5-3.7 below we discuss market forces toward contemporaneous efficiency.

(b) Ex post: As of now, would a switch be socially efficient? Many students of keyboard design believe DSK is better on a clean-slate basis. But the slate is not clean: there is a huge installed base of equipment and training. As things stand, no switch is taking place; should one? This question in turn can take two different forms.

In a gradual switch, new users would adopt DSK while trained QWERTY typists remained with QWERTY. This would sacrifice network benefits but not incur individual switching costs; it would presumably happen without intervention if switching costs were large but network effects were weak compared to DSK's stand-alone advantage. Private incentives for a gradual switch can be too weak ("excess inertia") because early switchers bear the brunt of the lost network benefits (see 3.5 below). But equally the private incentives can be too strong, because those who switch ignore lost network benefits to those who are stranded.

In a coordinated switch, everyone would adopt DSK at once (alreadytrained QWERTY typists would retrain). Thus society would incur switching costs but preserve full network effects. Because new users would unambiguously gain, already-trained QWERTY typists will be too reluctant to participate. Even if they were willing, coordination (to preserve full network benefits) could be a challenge; if they were opposed, compulsion or smooth side payments could be required for an efficient coordinated switch; of course, compulsion can easily lead to inefficient outcomes, and side payments seem unlikely to be smooth here.

Video Recordings: Betamax versus VHS; DVD and DIVX Gabel (1991) and Rohlfs (2001) argue that the VCR product overcame the chickenand-egg problem by offering substantial stand-alone value to consumers (for "time-shifting" or recording programs off the air) even with no pre-recorded programming for rent. By contrast, RCA and CBS introduced products to play pre-recorded programming (into which they were vertically integrated),

\footnotetext{
${ }^{103}$ Below, we discuss what institutions might have supported a long-run market test.
} 
but those failed partly because they did not offer time-shifting; laser disks suffered the same fate.

Later, the VCR market tipped, generally to VHS and away from Betamaxthough Gabel reports that (as of 1991) Betamax had won in Mexico. The video rental market created network effects (users value variety and convenience of programming availability, rental outlets offer more variety in a popular format, and studios are most apt to release videos in such a format). The rise of these network effects hurt Sony, whose Betamax standard was more expensive (VHS was more widely licensed) and, according to some, superior at equal network size, although Liebowitz and Margolis (1994) argue not. Gabel (1991) suggests that the strength of network effects may have surprised Sony.

Cusumano, Mylonadis and Rosenbloom (1992) describe the VHS-Betamax battle. Park, S. (2004) and Ohashi (2003) develop dynamic model of consumer choice and producer pricing for the VCR market and assess the extent to which network effects contributed to the tipping.

In the next generation of video, Dranove and Gandal (2003) and KaracaMandic (2003) found substantial indirect network effects in DVD adoption. Dranove and Gandal found that a preannouncement of a competing format, DIVX, delayed DVD adoption. Both papers find cross-effects such that the content sector as a whole could profitably have subsidized hardware sales, which could motivate vertical integration.

DVD players (until recently) did not record, like the laser disk product, but many households are willing to own both a VCR and a DVD player, allowing DVD's other quality advantages to drive success in a way that the laser disk could not. Again, such multi-homing blunts the network effects and can help with the chicken-and-egg problem.

Sound Recordings and Compact Disks Farrell and Shapiro (1992) argued that although prices of CDs and players fell during the period of rapid adoption, it would be hard to explain the adoption path without network effects; on the other hand, since CD players could be connected to existing amplifiers and loudspeakers, multi-homing was easy.

Gandal, Kende and Rob (2000) estimated a simultaneous-equations model of adoption in terms of price and software availability, stressing the crosseffects that would lead to indirect network effects.

Languages Human languages display classic network effects. Changes in patterns of who talks with whom presumably explain the evolution of language, both convergent (dialects merging into larger languages) and divergent (development of dialects). English is dominant, but there have been previous bandwagons such as French in diplomacy, or Latin as lingua franca.

Some Americans argue for "English only" laws based on a network externality; across the border, Canadians intervene to discourage de facto standardization on English (Church and King 1993). As we discuss in 3.3.5 
below, the net externality involved in choosing between two network goods (such as languages) is ambiguous. Of course, many people learn more than one language, but native English speakers are less apt to do so. Shy (1996) stresses that who learns a second language can be indeterminate and/or inefficient, as Farrell and Saloner (1992) noted for converters or adapters generally.

Law Klausner (1995) and Kahan and Klausner (1996, 1997) argue that contracts and corporate form are subject to network effects (especially under common law), as it is valuable to use legal forms that have already been clarified through litigation by others, although Ribstein and Kobayashi (2000) question this empirically. Radin (2002) discusses standardization versus customization in the law generally.

Securities Markets and Exchanges Securities markets and exchanges benefit from liquidity or thickness: see Economides and Siow (1988), Domowitz and Steil (1999), Andieh (2003). When there is more trade in a particular security its price is less volatile and more informative, and investors can buy and sell promptly without moving the market. This helps explain why only a few of the imaginable financial securities are traded, and why each tends to be traded on one exchange unless institutions allow smooth cross-exchange trading.

Not only do buyers wish for more sellers and vice versa, but this positive cross-effect outweighs the negative own-effect (sellers wish there were fewer other sellers); the difference is the value of liquidity, an efficiency gain from a large (thick) market. This fuels a network effect.

If products are differentiated, a larger network offers more efficient matches. This is the network effect behind eBay, and could be important in competition among B2B (business-to-business) exchanges (FTC 2000; Bonaccorsi and Rossi 2002). This also captures part of the value of liquidity, in that a larger market is more likely to have "coincidence of wants."

\subsubsection{Econometric Approaches}

Quantitative work on network effects has focused on two questions. First, it aims to estimate and quantify network effects. Second, some less formal work aims to test implications of the theory, notably the possibility of persistent inefficient outcomes.

The theory of network effects claims that widespread adoption causes high value. How can one test this? Clearly one cannot simply include demand for a good as an econometric predictor of demand for that good. At the level of individual adoptions, it may be hard to disentangle network effects from correlations in unobserved taste or quality variables (Manski 1993). Moreover, dynamic implications of network effects may be hard to distinguish econometrically from learning or herding. 
Meanwhile, the theory predicts path dependence, which implies both large "errors" and a small number of observations (a network industry may display a lot of autocorrelation). Likewise it predicts that modest variations in parameters will have unpredictable effects, and focuses largely on claims about efficiency, all of which makes testing a challenge. Nevertheless, some work aims to quantify these effects.

A popular hedonic approach compares demand for two products that differ in the network effects expected; the approach aims to isolate this effect from that of other quality variables. A natural proxy for expected network effects is previous sales: lagged sales or the installed base, relying on some inertia in network size. Thus Brynjolfsson and Kemerer (1996) estimated that the value of an installed base of spreadsheet users represented up to $30 \%$ of the price of the market leader in the late 1980s; similarly Gandal (1994, 1995) found a premium for Lotus-compatibility in PC spreadsheets. Hartman and Teece (1990) find network effects in minicomputers. This approach risks misinterpreting unobserved quality as network effects; but Goolsbee and Klenow (2002) find evidence of strictly local network effects in the adoption of PCs, using geographic variation to control for unobserved quality.

Another econometric approach rests on the fact that large adopters may better internalize network effects, and may care less than smaller adopters about compatibility with others. Saloner and Shepard (1995) found that banks with more branches tended to install cash machines (ATMs) sooner. Gowrisankaran and Stavins (2004) also use geographic variation to estimate network effects for automated transactions by banks. Gowrisankaran and Ackerberg (forthcoming) aim to separate consumer-level from bank-level network effects. ${ }^{104}$

It is easier to identify cross-effects between complementary groups, estimating how more adoption by one affects demand by the other (but recall that complementarities need not imply network effects). Rosse (1967) documented that newspaper advertisers pay more to advertise in papers with more readers, although news readers may not value having more advertisements; by contrast, readers do value having more advertisements in the Yellow Pages (Rysman 2004). Dranove and Gandal (2003) and Karaca (2003) also focus on the cross-effects.

Testing the central efficiency implications of the theory is hard, because (a) it is hard (and not standard economic methodology) to directly assess the efficiency of outcomes, and (b) the theory's prediction that outcomes depend sensitively on early events and are insensitive to later events, costs and tastes, is also hard to test. Liebowitz and Margolis (2001) argue that software products succeed when measured quality is higher, and that prices do not systematically rise after the market tips; they infer that network effects seem unimportant. ${ }^{05}$ Bresnahan (2004) argues that effective competition

\footnotetext{
${ }^{104}$ See also Guiborg (2001) and Kauffman and Wang (1999).

${ }^{105}$ Liebowitz and Margolis (1994) suggest that network effects may be essentially ex-
} 
for the market occurs only at rather rare "epochs" or windows of opportunity, so that high quality may be necessary but is not sufficient for success.

Fascinating though they are, these case studies and empirics do not satisfyingly resolve the theoretical questions raised below, which concern the efficiency of equilibria.

\subsection{Under-Adoption and Network Externalities}

In this sub-section we follow the early literature on network effects in focusing on the single-network case and on the total effect or (often) adoption externality.

\subsubsection{Formalities}

Each of $K$ players, or adopters, chooses an action: to adopt a product or not, or to adopt one product (network) or another. We often interpret these players not as individuals but as "groups" of adopters, where group $i$ is of size $n_{i}$ and $\sum n_{i}=N$. Often (but see 3.3.2), we treat each group as making an all-or-nothing choice, to adopt or not, or to adopt one product or its rival.

Player $i$ has payoff $u_{a}^{i}(x)$ from action $a$ if a total of $x$ adopters choose action $a$; for simplicity, assume there is only one alternative, $a^{\prime}{ }^{106}$ Recalling our definition in 3.1, we say that there are network effects in $a$ if, for each $i$, both the payoff $u_{a}^{i}(x)$ and the adoption incentive $u_{a}^{i}(x)-u_{a^{\prime}}^{i}(N-x)$ are increasing in $x .^{107}$ At this point we are considering adoption incentives, so these payoffs include prices.

For simplicity, the literature often takes $K=2$, though the problems might not be very interesting with literally only two adopters. Consider two groups choosing whether or not to adopt a single product. If a non-adopter's payoff is unaffected by how many others adopt, then we can normalize it as zero, and (dropping the subscript) write $u^{i}(x)$ for $i$ 's payoff from adoption, as in Figure 1:

$\begin{array}{ccc} & \text { Group 2 adopts } & \text { Group 2 does not adopt } \\ \text { Group 1 adopts } & u^{1}(N), u^{2}(N) & u^{1}\left(n_{1}\right), 0 \\ \text { Group 1 does not adopt } & 0, u^{2}\left(n_{2}\right) & 0,0\end{array}$

hausted at relevant scales, so that the $u$ function flattens out, as Asvanund et al. (2003) found in file sharing. However, Shapiro (1999) argues that network effects are less likely than classic scale economies to be exhausted.

${ }^{106}$ It is not immediately clear how best to extend the definition to more than two alternatives: for which alternative(s) $a^{\prime}$ must the "adoption incentive" described in the text increase with adoption of $a$, and which alternatives does that adoption displace? The literature has not focused on these questions and we do not address them here.

${ }^{107}$ In reality network benefits are not homogeneous (Beige 2001 discusses local network effects, or communities of interest). Also note that if $u_{a}^{i}(x)$ is linear in $x$ and independent of $i$, then the total value of the network is quadratic in $x$ : "Metcalfe's law." Swann (2002) and Rohlfs (2001) argue that this is very special and even extreme. 
Network effects arise for this single product if $u^{i}(N)>u^{i}\left(n_{i}\right)$ for $i=$ $1,2, \ldots K ;^{108}$ in 3.3 .3 , we show that this implies both parts of our definition. However, often the leading alternative to one network product is another, as in Figure 2:

$\begin{array}{ccc} & \text { Group 2 adopts A } & \text { Group 2 adopts B } \\ \text { Group 1 adopts A } & u_{A}^{1}(N), u_{A}^{2}(N) & u_{A}^{1}\left(n_{1}\right), u_{B}^{2}\left(n_{2}\right) \\ \text { Group 1 adopts B } & u_{B}^{1}\left(n_{1}\right), u_{A}^{2}\left(n_{2}\right) & u_{B}^{1}(N), u_{B}^{2}(N)\end{array}$

Network effects arise if $u_{a}^{i}(N)>u_{a}^{i}\left(n_{i}\right)$ for $i=1,2$ and $a=A, B$; again, this implies both parts of our definition.

Network effects are strong if they outweigh each adopter's preferences for $A$ versus $B$, so that each prefers to do whatever others do. Then "all adopt $A$ " and "all adopt $B$ " are both Nash equilibria of the simultaneous-move noncooperative game whose payoff matrix is Figure 2. Strong network effects thus create multiple equilibria if adoption is simultaneous (not literally, but in the game-theoretic sense that players cannot react to others' actual choices but must base their actions on expectations). For a single network product (Figure 1), network effects are strong if, for all $i, u^{i}(N)>0$ (each would adopt if others do, or more precisely if he expects others to adopt) and $u^{i}\left(n_{i}\right)<0$ (each will not if others do not). Thus "no adoption" can be an equilibrium even for valuable network goods: the chicken-and-egg problem (Leibenstein 1950), especially in the "fragmented" case where groups are small in the sense that each $u^{i}\left(n_{i}\right)$ is small relative to $u^{i}(N)$.

\subsubsection{What are the Groups?}

Calling each kind of adopter a group, even though it does not act as a single player, can help focus on the complementarity of adoption by different kinds of adopter. For instance, in camera formats, we might make photographers one group and film processors the other. Then each group's benefit from adoption increases when the other group adopts more strongly. Often this reformulation greatly reduces the number of groups: here, from millions of individuals to two groups.

This departs from our formal definition in two ways. First, each group does not coordinate internally and does not make an all-or-nothing adoption choice; rather, some but not all members of each group adopt. Second, there may be no intra-group network effects; there may even be intra-group congestion. Thus, given the number of photographers, a developer prefers fewer other developers for competitive reasons, just as with merchants accepting credit cards.

A different reformulation of the groups views only photographers as adopters, and diagnoses an "indirect network effect" among them, mediated through the equilibrium response of film processors. Doing so returns us to the strict

\footnotetext{
${ }^{108}$ We often assume for clarity that $u$ is strictly increasing when there are network effects.
} 
framework above, but pushes the processors into the background.

Another way in which identifying groups is a non-trivial modeling choice is that adoption choices often are made at several different vertical levels (see 3.8.3b). For instance, in the PC industry, memory technology is chosen by memory manufacturers, by producers of complements such as chipsets, by computer manufacturers (OEMs), and/or by end users or their employers. Even in a simple model, "adopters" may be vendors, or may be end users choosing between standards if vendors have chosen incompatible technologies.

\subsubsection{Total and Marginal Effects}

Our definition of network effects requires that (a) one agent's adoption of a good benefits other adopters, and that (b) his adoption increases others' incentive to adopt. We call these respectively the total effect and the marginal effect. We noted above that the marginal effect might apply to merchants' decisions to accept credit cards even if the total effect does not, if a merchant's adoption hurts his rivals who don't adopt more than it hurts those who do. On the other hand, the total effect can apply where the marginal effect does not: if one firm in a standard Cournot oligopoly chooses a lower output, it benefits other firms who have chosen a low output, but those other firms then typically have an incentive to increase their output. ${ }^{109}$

Although the two conditions are logically separate, definitions in the literature often mention only the total effect. The (seldom explicit) reason is that if the total effect holds for both alternatives $A$ and $B$ then the marginal effect follows. Group 2's incentive to adopt $A$ rather than $B$ is $u_{A}^{2}(N)-u_{B}^{2}\left(n_{2}\right)$ if group 1 has adopted $A$; it is $u_{A}^{2}\left(n_{2}\right)-u_{B}^{2}(N)$ if group 1 has adopted $B$. The marginal effect therefore holds if $u_{A}^{2}(N)-u_{B}^{2}\left(n_{2}\right)>u_{A}^{2}\left(n_{2}\right)-u_{B}^{2}(N)$, or $u_{A}^{2}(N)+u_{B}^{2}(N)>u_{A}^{2}\left(n_{2}\right)+u_{B}^{2}\left(n_{2}\right)$; but this follows from adding the two total-effect conditions $u_{y}^{i}(N)>u_{y}^{i}\left(n_{i}\right)$ for $i=2$ and $y=A, B$.

The early literature focused on a single network with a scale-independent outside good. Thus (as in Figure 1) each group's payoff from $B$ is independent of others' choices, so there are network effects in $A$ if and only if the total effect holds for $A$. Accordingly, although the early literature generally stressed the total effect, the marginal effect follows. By contrast, recent work stresses competing networks, with much more stress on the marginal effect, which is essentially Segal's (1999) "increasing externalities" or Topkis' (1978, 1998) "supermodularity" (see also Milgrom and Roberts 1990).

\subsubsection{Under-Adoption of a Single Network}

Two forms of under-adoption threaten a network good. First, the marginal effect causes a chicken-and-egg coordination problem. Second, if the network

\footnotetext{
${ }^{109}$ Other firms would have an incentive to reduce their outputs if firms' outputs are "strategic complements" (Bulow, Geanakoplos, and Klemperer 1985a,b), and the marginal effect then does apply.
} 
effect is an externality (see below), there is too little incentive to adopt at the margin, because the total effect means that adoption benefits other adopters. We discuss this marginal externality here and the chicken-and-egg problem in 3.4.2 below.

In Figure 1, if $u^{1}(N)>0>u^{2}(N)$ then player 1 would like the "all adopt" outcome but, even if he adopts, player 2 will not. If $u^{1}\left(n_{1}\right)<0$ then the unique equilibrium is no adoption; if instead $u^{1}\left(n_{1}\right)>0$ then equilibrium is adoption by group 1 alone. In either case, if $u^{1}(N)+u^{2}(N)>\max \left[u^{1}\left(n_{1}\right), 0\right]$ then adoption by all would increase total surplus. Since each player likes the other to adopt, each one's adoption incentive is too weak from the viewpoint of adopters jointly.

The efficient outcome can still be an equilibrium if this bias is not too strong, and this generic observation takes an interesting form here. Say that preferences are similar if the players agree on the best outcome, so $u^{i}(N)$ has the same sign for all $i$. Then the efficient outcome, which is either "all adopt" or "no adoption," is an equilibrium of the simultaneous-adoption game suggested by Figure 1, as Liebowitz and Margolis (1994) noted. Moreover, while this equilibrium need not be unique, it is each player's best feasible outcome, and many institutions (including side payments, sequential moves and commitment, and communication) preserve and reinforce it.

But normally the bias will cause wrong choices. In a static framework, it makes the network too small. ${ }^{110}$ If adoption is dynamic, for instance if costs fall over time, the same logic makes adoption too slow. ${ }^{111}$ It is efficient to subsidize a marginal adopter for whom the cost of service exceeds his private willingness to pay, but exceeds it by less than the increase in other adopters' value. Such subsidies can be hard to target, as we discuss next, but there is a deeper problem too, even with perfectly discriminatory prices. With complete information and adopter-specific pricing, Segal (1999) finds that without externalities on non-traders, efficiency results if the sponsor simultaneously and publicly makes an offer to each adopter, but because there are positive externalities on efficient traders, there is too little adoption when offers are "private," or essentially bilateral. Efficiency requires multilateral bargaining, in which trade between the sponsor and one trader depends on trade with others.

\footnotetext{
${ }^{110}$ Beige (2001) shows that equilibrium locally maximizes a "harmony" function that counts only half of the network effects in the sum of payoffs.

${ }^{111}$ Dynamic adoption paths with falling prices or other "drivers" of increasing adoption have been studied by (e.g.) Rohlfs (1974), Farrell and Shapiro (1992, 1993), Economides and Himmelberg (1995), Choi and Thum (1998), and Vettas (2000). Prices may fall over time because of Coasian dynamics: see 3.6. Adoption paths can also be driven by the strengthening of network effects: human languages with more trade and travel; computer programming languages with more modularity and re-use; VCRs with more movie rental.
} 


\subsubsection{Are Network effects Externalities?}

Network effects often involve externalities, in the sense that prices don't fully incorporate the benefits of one person's adoption for others. Indeed, early literature often simply called network effects "network externalities." But network effects are not always externalities, as Liebowitz and Margolis (1994) stressed.

Liebowitz and Margolis argue that many indirect network effects are pecuniary. If adoption by buyers just lowers price, it might be that Figure 1 describes payoffs to buyers, but sellers bear an equal negative effect. Then, while buyers jointly could be made better off by a well-targeted small subsidy from inframarginal to marginal buyers, no such subsidy can make everyone (sellers included) better off. However, the microfoundations of such pecuniary network effects seem unclear. Decreasing costs in a competitive industry often reflect a real economy of scale (perhaps upstream), so there is an efficiency (not just pecuniary) benefit of coordination. With no real economy of agglomeration, it is unclear how a sheer price shift can both favor buyers and also induce additional entry by sellers, as we noted in 3.1. Church, Gandal and Krause (2002) stress that there can be a real efficiency gain when a larger "hardware" network attracts more varied "software," not just lower prices.

More compellingly, any economic effect is an externality only if not internalized. A network effect might be internalized through side payments among adopters, although this will be hard if there are many players or private information. Alternatively (see 3.6-3.7) a seller who can capture the benefits of a larger network might internalize network effects and voluntarily subsidize marginal adopters, as in Segal's (1999) model of public offers. But unless a seller can accurately target those adopters, subsidy is costly, and while it may sometimes work well enough, it seems clear that it often won't. Indeed, first-best pricing would require the price to each adopter to be equal to incremental cost less his external contribution to others, and such pricing jeopardizes profits and budget balance. Suppose for instance that a good will be supplied if and only if all $K$ groups agree. For first-best adoption incentives, the price facing group $i$ should be equal to the cost $C$ of supplying the good to all, less the additional surplus accruing to groups other than $i$ as a result of group $i$ 's agreeing: $p_{i}=C-\sum_{j \neq i} u^{j}(N)$. Hence $\sum p_{i}-C=(N-1)\left[C-\sum u^{i}(N)\right]$, so costs are covered if and only if adoption is inefficient! (First-best incentives require that each adopter be a residual claimant, leaving the vendor a negative equity interest at the margin.) For these reasons, adoption prices will often not fully internalize network effects, and a profitably supplied single network good will be under-adopted.

Third, any externalities are smaller and ambiguous when networks compete. To illustrate, suppose that $K=3$, and that groups 1 and 2 have adopted $A$ and $B$ respectively; now group 3 is choosing. $A$-adopters (group 1 ) gain if group 3 adopts $A$, but $B$-adopters gain if it adopts $B$. When each 
choice means rejecting the other, the net effect on others is ambiguous. ${ }^{112}$

\subsection{The Coordination Problem}

When networks compete, we just noted that any conventional externality becomes weaker and ambiguous. The same logic, however, strengthens the marginal effect - the fact that adoption encourages others to adopt the same network. A user's adoption of $A$ instead of $B$ not only directly makes $A$ more attractive to others but also makes the alternative, $B$, less so. ${ }^{113}$ For instance, part of the positive feedback in the adoption of CDs was the declining availability of LP records as CDs became more popular.

Through the marginal effect, strong network effects create multiple adoption equilibria and hence coordination problems. Optimal coordination is hard, as everyday experience and laboratory experiments (Ochs 1995; Gneezy and Rottenstreich 2004) confirm. Coordination problems include actual breakdowns of coordination (3.4.1) and coordination on the wrong focal point (3.4.2). Coordination is especially difficult - and the institutions to aid it work less well - when (as in the Battle of the Sexes) the incentive for coordination coexists with conflict over what to coordinate on.

\subsubsection{Coordination Breakdowns: Mistakes, Splintering, and Wait- and-See}

Coordination "breaks down" when adopters choose incompatible options but would all prefer to coordinate. This can happen in at least two ways, which we call confusion and splintering. Economic theorists' equilibrium perspective pushes them toward (probably over-) optimistic views on the risks of such failures, but case studies and policy discussion often implicate coordination failures.

\footnotetext{
${ }^{112}$ To quantify, treat $K$ as large, and approximate the set of adopters with a continuum. A small shift of $\mathrm{d} x$ users from a network of size $x_{A}$ to one of size $x_{B}$ has a net effect on other adopters of $e=\left[x_{B} u_{B}^{\prime}\left(x_{B}\right)-x_{A} u_{A}^{\prime}\left(x_{A}\right)\right] \mathrm{d} x$ : this has ambiguous sign and is smaller in magnitude than at least one of the $x_{i} u_{i}^{\prime}\left(x_{i}\right) \mathrm{d} x$.

The incentive to "splinter" from what most others are doing is too strong at the margin (defection imposes a negative net externality, or conformity confers a positive externality) if $e<0$ whenever $x_{B}<x_{A}$. When the goods are homogeneous except for network size, that condition is that $x u^{\prime}(x)$ is increasing: see Farrell and Saloner (1992). In the convenient (if unrealistic) Metcalfe's Law case $u(n)=v n$, there is thus too much incentive to defect from a network to which most players will adhere. Then there is not just a benefit but a positive externality from conformity.

${ }^{113}$ With a continuum of adopters, the gain in $A$ 's relative attractiveness from a small increase in its adoption at $B$ 's expense is proportional not just to $u_{A}^{\prime}\left(x_{A}\right)$, as it would be if $A$ were the only network good, but to $u_{A}^{\prime}\left(x_{A}\right)+u_{B}^{\prime}\left(x_{B}\right)$. Note that this strengthening of the marginal effect depends on the total effect in both $A$ and $B$.
} 
Confusion Coordination can break down by mistake or confusion if adopters do not know what others are doing. ${ }^{114}$ Common knowledge of plans averts such confusion, and the simplest models assume it away by focusing on pure-strategy equilibrium, in which by definition players know one another's strategies and do not make mistakes. ${ }^{115}$ Other models use mixed-strategy equilibrium, ${ }^{116}$ which may be too pessimistic about coordination: each player's attempt to coordinate with others is maximally difficult in mixed-strategy equilibrium. ${ }^{117}$

Splintering Second, coordination can break down even in pure-strategy equilibrium with strategic certainty. This happens if product differentiation discourages unilateral moves (e.g. to slightly larger networks) but is weak enough that a coordinated move of everyone on networks $B, C$ and $D$ to network $A$ would benefit all.

When there are just two networks $A$ and $B$ splintering is impossible if the users of each network can optimally coordinate as a group, but can arise if, for example, a coordinated move of everyone on network $B$ to network $A$ would benefit all of them, but the users of $B$ cannot coordinate.

The incompatible outcome is thus (in game-theory language) an equilibrium but not coalition-proof: if multiple decision makers could coordinate a move they would all do better. We call this splintering: a dysfunctional equilibrium with multiple small and consequently unsuccessful networks instead of one large and successful one. Common knowledge of plans does not avert these problems; their solution requires a leadership-like ability to focus on "let's all do $X$ instead."

Evidence that splintering is important includes the demand for consensus compatibility standards, which provide just such leadership. ${ }^{118}$ Such standards (see 3.4.3) go beyond mere communication of plans, since common knowledge need not cure the problem. For instance, following Thompson (1954), Hemenway (1975) and Gabel (1991) argue that early twentiethcentury standardization of auto parts mainly reduced spurious variety. Even before the standardization meetings any manufacturer could have chosen to match another's (non-proprietary, non-secret) specifications; apparently

\footnotetext{
${ }^{114}$ In The Gift of the Magi, a famous short story by O. Henry, Jim sold his watch to buy his wife Della a comb; Della sold her hair to buy Jim a watch-chain. Their plans were secret because each was meant as a Christmas surprise for the other.

${ }^{115}$ Rationalizability, on the other hand, unhelpfully permits any outcome in a simultaneous-adoption game with strong network effects.

${ }^{116}$ See for instance Dixit and Shapiro (1986), Farrell (1987), Farrell and Saloner (1988), Bolton and Farrell (1990), Crawford (1995).

${ }^{117}$ But mixed-strategy equilibrium can be defended as a shorthand for a symmetric Bayesian-Nash equilibrium with incomplete information.

${ }^{118}$ An optimistic view would be that consensus standards promptly solve the problem wherever it arises, so splintering never persists. But finding consensus standards seems slow and painful, which casts doubt on such optimism. If the pain and slowness arises from difficulty in finding Pareto-improving coordinated shifts, however, then the theory sketched in the text is incomplete.
} 
such a unilateral move would not pay, but a coordinated voluntary move did. ${ }^{119}$ But consensus standards generally are non-binding and do not involve side payments, so they would not affect a failure to standardize that was a coalition-proof equilibrium reflection of (say) differences in tastes.

There is little theoretical work on splintering, although Kretschmer (2004) explores how it can retard innovation when there are multiple alternatives to a single established standard. ${ }^{120}$ But it features prominently in case studies. Postrel (1990) argued that quadraphonic sound in the 1970s failed because competing firms sponsored incompatible quad systems and because hardware producers did not adequately manage complements (recorded music). Rohlfs (2001) describes how competing incompatible fax systems (invented in 1843) stalled for over a century until consensus standardization in the late 1970s. ${ }^{121}$ Augereau, Greenstein and Rysman (forthcoming) claim that the adoption of $56 \mathrm{~K}$ modem technology in aggregate was stalled by the coexistence of two equally good incompatible standards until the ITU issued a third that became focal. Saloner (1990) discusses splintering among Unix implementations (widely blamed for slow adoption of Unix until Linux became relatively focal). Besen and Johnson (1986) argued that AM stereo was adopted slowly because there were competing, broadly comparable, standards and no player could start a strong bandwagon: adopters (radio stations) avoided explicit coordination because of antitrust fears, and the FCC did not take a lead. Microsoft was accused of "polluting" or intentionally splintering the Java standard when it perceived the latter as a threat to its own nonJava standard. Rysman (2003) notes that competition in yellow pages may involve splintering, thus reducing network benefits (although he finds that this does not outweigh losses from monopoly). He does not assess whether advertisers and users might instead all coordinate on the directory that offers them jointly the best deal - a sunnier non-splintering view of incompatible competition that theory has tended to find focal.

Do similar splintering concerns arise with traditional economies of scale? In terms of cooperative game theory (how much surplus is generated by various groups of participants) network effects and economies of scale are isomorphic, so concerns about splintering parallel classic concerns about inefficiently small-scale production in monopolistic competition. Modern models of the latter, since Spence (1977) and Dixit and Stiglitz (1977), mostly attribute splintering among monopolistically competitive firms to horizontal product differentiation, and because variety is valuable, these models find that although each firm is too small to minimize average cost, it need not be too small for overall efficiency. But the classical suspicion that equilibrium involves too much fragmentation re-surfaces in that a popular claimed

\footnotetext{
${ }^{119}$ The point is not that there are increasing returns in compatibility benefits, but that a critical mass may be necessary to overcome differences in tastes, beliefs, etc.

${ }^{120}$ Goerke and Holler (1995) and Woeckener (1999) also stress inefficiencies of splintering.

${ }^{121}$ Economides and Himmelberg (1995) estimated a demand system for the adoption of fax under a single standard.
} 
efficiency motive for horizontal mergers is achieving more efficient scale. ${ }^{122}$

Fear of Breakdowns Even mere fear of coordination breakdowns may delay adoption as people wait to see what others will do. ${ }^{123}$ This can inefficiently slow adoption through strategic uncertainty rather than because of the externality from adoption.

\subsubsection{Coordinating on the Wrong Equilibrium}

Because coordination is hard, clumsy cues such as tradition and authority are often used. Schelling (1960) suggested that two people wishing to meet in New York might well go, by tradition, to Grand Central Station at noon. Many species of animals meet at fixed times or places for mating. Human meetings, and work hours, are often arranged in advance, and thus do not respond sensitively to later-revealed information about what is convenient for participants. The persistence of such clumsy solutions testifies to the difficulty of flexible optimal coordination. It would therefore be surprising if multiple adopters of networks always coordinated on the choice that gives them the most surplus.

Other parts of economics have studied the possibility of (perhaps persistent) coordination on the wrong equilibrium. Rosenstein-Rodan (1943) and Murphy, Shleifer and Vishny (1989) suggested that industrialization requires a "Big Push" that coordinates many sectors of the economy and that may not happen under laissez-faire. That is, industrialization is a "good" equilibrium, but the economy may stay at the "bad" pre-industrial equilibrium without major intervention. Modern economic geography sees patterns of development as partly fortuitous (Saxenian 1994, Krugman 1991, Davis and Weinstein 2002). Macroeconomists have studied how otherwise irrelevant "sunspot" signals can guide economies to good or bad equilibria; ${ }^{124}$ game theory has studied how cheap talk can do so.

Starting from a bad equilibrium, there would (by definition) be joint rewards for getting to a better equilibrium, but no rewards to individually deviating. As Liebowitz and Margolis $(1994,1995)$ stressed, this can suggest a role for an entrepreneur: in 3.6-3.8 below, we note some entrepreneurial tactics.

i. Single Network With a single network (Figure 1), voluntary adoption is weakly Pareto-improving, so an equilibrium with more adoption Pareto-

\footnotetext{
${ }^{122}$ For a skeptical view see Farrell and Shapiro (2001). A merger removes all competition between firms, whereas a common standard replaces incompatible competition with compatible competition; see 3.9 .

${ }^{123}$ Kornish (forthcoming) describes a "decision-theoretic" model of adoption timing under strategic uncertainty, but takes as given the behavior of all agents but one.

${ }^{124}$ See e.g. Cooper (1999), Cooper and John (1988), Cooper and Haltiwanger (1988), Diamond (1982), and Bryant (1994).
} 
dominates one with less. Dybvig and Spatt (1983) show that there is a maximal equilibrium, in which all players who adopt in any equilibrium adopt. This maximal equilibrium is Pareto preferred to all other equilibria, which thus have too little adoption. ${ }^{125}$

As in any game with multiple equilibria, expectations are key. If players expect others to adopt, they too will adopt. Shifting from a simultaneousmove perspective to a more dynamic one (informally at this point), implications include positive feedback and critical mass: once enough adoption happens or is confidently foreseen, further self-reinforcing adoption follows. Similarly lack of adoption is self-reinforcing: a network product can enter a "death spiral" (a dynamic form of the chicken-and-egg problem) if low adoption persuades others not to adopt. ${ }^{126}$

While they both involve under-adoption, this chicken-and-egg problem is quite different from the marginal externality in 3.3.4-5 above. The marginal problem arises only when preferences are not similar, ${ }^{127}$ could typically be helped by small subsidies to marginal adopters, and cannot be solved by voluntary joint action without side payments; whereas the chicken-and-egg problem arises even with identical adopters, might be solvable by coordinating better without side payments, and often cannot be helped by small subsidies.

ii. Competing Networks Similar coordination problems can cause the adoption of the wrong network good. In Figure 2, if players expect others to adopt $A$, they will do so, but expectations in favor of $B$ are equally self-fulfilling. And if expectations clash, so too will choices. What, then, drives expectations? In general one must look to cues outside Figures 1 and 2 , as we discuss in the rest of this sub-section.

Clumsy coordination can also blunt competitive pressures among networks, since business does not reliably go to the best offer, as we discuss in 3.7 .

\subsubsection{Cheap Talk and Consensus Standards}

A natural response to a coordination problem is to talk. Credible talk can make plans common knowledge and thus avert confusion-based coordination failures, and may help adopters coordinate changes in plans and thus escape splintered equilibria or coordination on the wrong focal point. In fact,

\footnotetext{
${ }^{125}$ This is characteristic of games with supermodularity (Topkis 1978, 1998 or Milgrom and Roberts 1990) or "strategic complements" (Bulow, Geanakoplos, and Klemperer 1985a,b).

${ }^{126}$ Schelling (1978) describes such dynamics in a wide range of applications. Of course, the dynamics can also work in the other direction, with critical mass and take-off. Jeitschko and Taylor (2001) study the stability of "faith-based coordination."

${ }^{127}$ This assumes, as does most of the literature, that each adopter's choice is zero-one. When each adopter makes a continuous quantity choice a marginal problem arises even if preferences are identical.
} 
many voluntary "consensus standards" are reached through talk, sometimes mediated through standards organizations; David and Shurmer (1996) report that consensus standardization has grown dramatically. ${ }^{128}$ Large official organizations often have formal procedures; smaller consortia may be more flexible. ${ }^{129}$ The economics literature on consensus standards is less developed than that on de facto or bandwagon standards, perhaps because reaching consensus seems political rather than a narrowly economic process.

Game theory finds that cheap talk works less well the more conflict there is. At the vendor level, conflict can arise because not everyone wants to coordinate: see 3.8 below. Discussion of consensus standards has focused more on conflict that arises if all players want to coordinate but disagree over what to coordinate on, as in the Battle of the Sexes. For example, when a promising new technology arrives, conflict is likely between the "installed base" of those who are more locked in to an old technology and those who are less so. Gabel (1991) argues that conflict is likely between those who are and are not vertically integrated. Conflict may also arise because active participants in standards organizations tend to have vested interests (which indeed may motivate them to bear the costs of participating). ${ }^{130}$ Vested interest may be especially strong when potential standards incorporate intellectual property.

As a result, attempts to coordinate through talk may induce bargaining delays that dissipate much of the gains from coordination. The economics literature stresses this observation, echoing concerns of many standards participants. Economists have modeled the process as a war of attrition: participants who favor standard $A$ hope that those who favor $B$ will give up rather than delay further. Farrell and Saloner (1988) introduced such a model with complete information and two participants, and compared "committee" versus "bandwagon" standardization, and against a hybrid mechanism. ${ }^{131}$

\footnotetext{
${ }^{128}$ Some practitioners reserve the term "standard" for formal consensus coordination. Standards organizations include the International Telecommunications Union (ITU), and a wide variety of national standards bodies such as ANSI in the US; ANSI is an umbrella organization for specialized industry standards development. There are also many informal standards fora.

${ }^{129}$ On the institutions, see e.g. Hemenway (1975), Kahin and Abbate (1995). On the economics of consensus standards development see also Besen and Saloner (1988). Cargill (1989) describes the standards process in information technology.

Weiss and Sirbu (1990) econometrically study technology choices in voluntary consensus standards committees. Lehr (1995) describes consensus standardization in the internet; see also Simcoe (2004).

${ }^{130}$ Weiss and Sirbu (1990); Farrell (1996).

${ }^{131}$ In a hybrid mechanism, compatibility may result either by consensus or by one proponent driving a market bandwagon (but if both try simultaneously, the result is incompatibility). Thus the consensus standards process competes directly against the bandwagon process; Gabel (1991) stresses that network effects can be realized through consensus, bandwagons, or other means. Besen and Farrell (1991) note a different form of competition among processes: less-formal consensus processes may act faster than more formal ones such as the International Telecommunications Union (ITU); Lerner and Tirole (2004) study forum-shopping equilibria in consensus standards.
} 
Farrell (1996) and David and Monroe (1994) observe that when there is private information about the quality of proposed standards, the war of attrition may select for good proposals, although at a high cost (Simcoe 2004 shows how similar results can emerge from rational search by interested parties). They then assess efficiency consequences of rules in the consensus standards process. For instance, many standards organizations limit the exploitation of intellectual property embodied in standards (Lemley 2002), and this may reduce delays as well as limit patent-holders' ex post market power. Simcoe (2004) analyzes data from the Internet Engineering Task Force and finds evidence that more vested interest (measured as more patents, or more commercial participation) causes more delay. Another response is to seek rapid consensus before vested interest ripens.

With two players (as in those models), either can ensure immediate consensus by conceding. With more players, Bulow and Klemperer (1999) show that delays can be very long if conceding brings no reward until others also concede, as is the case if (as in many standards organizations) a standard requires near-unanimous consensus. ${ }^{132}$

\subsubsection{Coordination through Sequential Choice}

Game theory claims that with full information and strong network effects, fully sequential adoption ensures coordination on a Pareto-undominated standard. The argument (Farrell and Saloner 1985) is fairly convincing with two groups. For simplicity, consider the single-network case. Suppose that $u^{i}(N)>0>u^{i}\left(n_{i}\right)$ for all $i$, so that adoption is an efficient equilibrium and non-adoption is an inefficient equilibrium of the simultaneous-adoption game. If group 1 first adopts, then group 2 will also adopt: knowing this, group 1 can (and therefore will) get $u^{1}(N)$ by adopting. By moving first, group 1 can start an irresistible bandwagon: it need not fear that adoption will give it only $u^{1}\left(n_{1}\right)$; thus only the efficient equilibrium is subgame-perfect when adoption is sequential.

The argument extends in theory to any finite number of players, and to the choice between two (or more) networks. ${ }^{133}$ But it is much less compelling with many players: it assumes that each adopter sees all previous choices before making his own, and assumes strong common knowledge of preferences and of rationality to forge a chain of backward induction with (on the order of) $K$ steps, an unreliable form of reasoning (empirically) when $K$ is large. Thus the theoretical result is surely too strong: the first player shouldn't count on it if $u^{1}(n)$ is very negative for small $n$; and if players won't rely on the result, it becomes false. But it does express one possible route out

\footnotetext{
${ }^{132}$ By contrast, they show that if a player can cease to bear delay costs by unilaterally conceding (as in oligopolists competing to win a natural monopoly), a multi-player war will quickly collapse to a two-player one. Political scientists analogously have Duverger's Law, a claim that most elections will have two serious candidates.

${ }^{133}$ Farrell and Saloner (1985) also show (with two groups) that cheap talk need not help when information on preferences is incomplete; Lee (2003) extends this to $K$ groups.
} 
of inefficient coordination traps: an influential adopter could try to start a bandwagon. In this respect influence is related to size: when a big player moves, it shifts others' incentives by more than when a small player moves. Indeed, it may even become a dominant strategy for others to follow, surely a stronger bandwagon force than backward induction in the subgame among the remaining players. Thus size confers leadership ability, and markets with at least one highly concentrated layer are less apt (other things, notably conflict, equal) to be caught in pure coordination traps. Illustrating this idea, Holmes (1999) discusses the role of large players in the geographic shift of the US textile industry; Bresnahan (2001) discusses AOL's role (as a large and potentially pivotal user) in the Netscape-Microsoft battle for browser share.

This result is optimistic about the ability of adoption bandwagons to

avert Pareto-inferior outcomes. As we see next, however, bandwagons may be less good at balancing early and late adopters' preferences.

\subsection{Inertia in Adoption}

Individual switching costs can cause problems, as in section 2 above, but at least each user makes his own choice. Network effects, by binding together different users' choices, might generate a stronger and more worrying form of inertia, locking society in to an inefficient product (or behavior) because it is hard to coordinate a switch to something better but incompatible - especially where network effects coexist with individual switching costs. In a range of cases, including QWERTY, English spelling, VHS, and many computer software products, some suggest that a poor standard inefficiently persists because network effects create excessive inertia. Liebowitz and Margolis (1990, 1995) are skeptical (notably in QWERTY) and argue (2001) that success in computer software has followed trade reviewers' assessments of product quality; but Bresnahan (2003) argues that this has been true only in wide-open periods and that high quality is necessary but not sufficient for success. It is hard to test ex post excess inertia in case studies by directly assessing the efficiency of outcomes; we focus instead on the economic logic. Here we ask how much inertia there is in adoption dynamics at given prices. In 3.6-3.7, we ask how sponsors' price and other strategies affect it.

\subsubsection{Ex Post Inertia}

Inertia arises ex post if later adopters remain compatible with the installed base even though an alternative would be better if network effects were neutralized. Just as contestability theory observes that economies of scale alone do not create an advantage to incumbency, so too network effects alone need not generate inertia: in principle everyone could instantly shift to coordinate on the better alternative. But there are usually some sunk costs or switching costs; and if expectations centre on the status quo then inertia results even 
if there are no tangible intertemporal links.

Inertia surely is often substantial: Rohlfs (2001) argues from the history of fax that a network product without stand-alone value must be "truly wonderful and low-priced" to succeed; he and others attribute the VCR's success to its offering stand-alone value; Shapiro and Varian (1998) quote Intel CEO Andy Grove's rule of thumb that an incompatible improvement must be "ten times better."

Inertia can be efficient: incompatibility with the installed base is a real social cost if the status quo has network effects. But inertia is ex post "excess" if it would be more efficient for later adopters to switch, given earlier adopters' choice. (As that phrasing suggests, we follow the literature in assuming here that the installed base will not switch; if it would, then later adopters would sacrifice no network benefits and would collectively have excessive incentives to switch.) For example, it would be ex post excess inertia if society should switch to the DSK typewriter keyboard, counting the full social costs, but network effects and switching costs inefficiently prevent this. This requires that pivotal movers inefficiently fail to move, because they expect others not to move (the "horses" problem), or because they bear a larger share of the costs than of the benefits of moving (the "penguins" problem). ${ }^{134}$

In a simple two-group case where group 1 is committed and group 2 optimally coordinates internally, neither of these can happen, so inertia cannot be ex post excessive. In Figure 2, suppose that group 1 has irreversibly adopted (say) $A$. To be adopted by group $2, B$ must be substantially better: $u_{B}^{2}\left(n_{2}\right)>u_{A}^{2}(N)$, or equivalently $u_{B}^{2}\left(n_{2}\right)-u_{A}^{2}\left(n_{2}\right)>u_{A}^{2}(N)-u_{A}^{2}\left(n_{2}\right)$. That is, $B$ 's quality or price advantage (assessed by group 2 ) must outweigh the additional network benefit of compatibility with group 1 (assessed by group 2 when it adopts $A$ ). Of course, there is inertia: if group 2 values compatibility with group $1, B$ will fail unless it is much better than $A$. But to maximize total surplus ex post, group 2 should adopt $B$ only if $u_{B}^{2}\left(n_{2}\right)>u_{A}^{2}(N)+\left[u_{A}^{1}(N)-u_{A}^{1}\left(n_{1}\right)\right]$. Group 2 internalizes only part of the social benefit of inter-group compatibility, and is thus too ready to strand group 1. Far from excess inertia, this model displays ex post "excess momentum." 135

This result instructively contradicts the popular intuition that inertia is obviously ex post excessive. But with more than two groups, ex post excess

\footnotetext{
${ }^{134}$ Farrell and Saloner (1987) analogize the first problem to horses tied to one another who will not wander far or fast, because none can move independently and staying still is more focal than moving in a particular direction at a particular speed. They analogize the second problem to penguins, wishing to dive for fish but concerned that the first one in is most vulnerable to predators.

${ }^{135}$ Farrell and Saloner (1986b) phrased this result in terms of "unique equilibrium" because they did not assume that each group optimally coordinates. Ellison and Fudenberg (2000) use essentially this model with optimal coordination to argue that there may be excessive innovation. If early adopters (group 1 here) would switch ex post to retain compatibility with group 2 , group 2 is clearly again too willing to choose $B$. See also Shy (1996) and Witt (1997).
} 
inertia may well occur, because optimal coordination among ex post adopters may well fail due to coordination problems and/or free-riding. To see this, return to the sequential adoption model of Farrell and Saloner (1985). Adopters $1,2, \ldots, K$ arrive in sequence and, on arrival, irreversibly choose to adopt $A$ or $B$. Because of idiosyncratic preferences or relative technological progress over time, adopters have different preferences between $A$ and $B$. There are network effects: adopter $i$ gets payoff $u_{z}^{i}\left(x_{z}\right)$, where $x_{z}$ is the total number of adopters on his network $z=A, B$.

Arthur (1989) simplified this framework by assuming that an adopter gets network benefits only from previous adoptions, not future ones; thus adopters need not form expectations about the future. He showed that a technology favored by enough early adopters can become permanently locked in. If the relative network sizes ever become lopsided enough to outweigh the strongest idiosyncratic preferences, all subsequent adopters follow suit, because none wants to lead a new bandwagon, even if he knew that all future adopters would join it. There is a free-rider problem in overcoming an installed-base lead. Thus suppose that network effects make $x=2$ much more valuable than $x=1$, and that most adopters prefer $B$, but that by chance the first adopter prefers, and adopts, $A$. Adopter 2 , then, who prefers $B$, must compare $u_{B}^{2}(1)$ against $u_{A}^{2}(2)$. He may adopt $A$ only because $x=1$ is so undesirable, in which case he and all subsequent adopters would pick $A$; while if he chose $B$, then other $B$-lovers would be happy choosing $B$ thereafter. ${ }^{136}$ This is extreme, but getting a new network up to critical mass can generally be costly for the pioneer, harmful to the installed base, but valuable to those who arrive later.

Arthur's assumption that adopters do not care about future adoptions seems to fit learning-by-doing with spillovers rather than most network effects, but we can usefully re-formulate it. Adopters more generally get the present value of a flow of network benefits, where the flow is increasing in adoptions to date. Then if adopter 2 adopts $B$ and others follow, his sacrifice of network benefits is only temporary.

In this broader framework, Arthur's model assumes that adopters are infinitely impatient, thus both ignoring coordination problems and exaggerating the free-rider problem. On the other hand, Farrell and Saloner (1986a) considered ex ante identical adopters with a finite discount rate. Adopters adopt immediately on arrival, and good $B$ becomes available at date $T$. Specializing their model in the opposite direction from Arthur's, if identical adopters are infinitely patient and can optimally coordinate from any point on, the problem reduces to the two-group model outlined above in which $e x$ post excess inertia cannot arise.

But the coordination problem re-emerges as soon as we depart from

\footnotetext{
${ }^{136}$ This is similar to the "informational herding" literature: see e.g. Banerjee (1992), Scharfstein and Stein (1990), Ellison and Fudenberg (1993, 1995), Bikchandani, Hirshleifer and Welch (1992). Berndt, Pindyck and Azoulay (2003) argue that informational herding creates network effects in anti-ulcer drugs.
} 
Arthur's infinite impatience. In particular, if previous history is the leading cue for coordination, then a patient small adopter 2 will compare $u_{B}^{2}(1)$ against $u_{A}^{2}(K){ }^{137}$ so that an early lead would be even more powerful than Arthur's model suggests; it may be a self-fulfilling prophecy that a minority network will never grow. And if there are many contenders to displace the incumbent, adopters might expect splintering among those who abandon the incumbent (Kretschmer 2004). By the same logic, if everyone expects the new network to take over then it often will do so even if it is inefficient.

With identical adopters, the inductive logic of Farrell and Saloner (1985) suggests that the first adopter to arrive after $T$ is pivotal. If he prefers that everyone forever stick to $A$, he can adopt $A$ and thus make the next adopter feel all the more strongly the same way; similarly if he prefers that all from now on adopt $B .^{138}$ Because of the free-rider problem, the pivotal adopter may have too little incentive to adopt the new network, $B$; on the other hand, adopting $B$ strands the installed base. As in 3.3.5 above, the net externality can run in either direction, so ex post excess inertia and excess momentum are both possible, even in unique equilibrium. If we eschew the long chain of backward induction and instead assume that the date- $T$ adopter expects others' future choices to be unaffected by his own (he is small), then there are typically multiple equilibria and expectations determine the outcome, which can be biased in either direction. This would presumably also be the case if nobody knows which adopter is pivotal.

Farrell and Saloner (1986a) and Ostrovsky and Schwarz (2006) describe other models in which efficient coordination is hindered by delays before other adopters can follow an early mover's lead. Each is most easily described for two adopters. In Farrell and Saloner, each adopter has only occasional opportunities to adopt a new technology, so even if each adopts as soon as possible, adopting first entails a temporary loss of network benefits. If that is painful enough, no adopter is willing to lead; the private cost may be either greater or less than the social cost. In Ostrovsky and Schwarz, each adopter chooses a "target" time to adopt, and if there were no noise, immediate adoption by all would be a Pareto-dominant equilibrium. But when actual adoption time is affected by (continuous) noise, Pareto-dominance is not enough. Each adopter $i$ can contemplate slightly delaying its adoption, by $\mathrm{d} t$. If $p_{i}$ is the probability that it will be the first to adopt, slight delay is privately desirable with probability $p_{i}$ and then yields a gain of $\left[u_{A}^{i}(2)-u_{B}^{i}(1)\right] \mathrm{d} t$; it is privately undesirable with probability $1-p_{i}$ and then yields a loss of $\left[u_{B}^{i}(2)-u_{A}^{i}(1)\right] \mathrm{d} t$. Hence if $\left(1-p_{i}\right)\left[u_{B}^{i}(2)-u_{A}^{i}(1)\right]<p_{i}\left[u_{A}^{i}(2)-u_{B}^{i}(1)\right]$, or $p_{i}>r_{i} \equiv \frac{u_{B}^{i}(2)-u_{A}^{i}(1)}{u_{B}^{i}(2)-u_{A}^{i}(1)+u_{A}^{i}(2)-u_{B}^{i}(1)}$, it will prefer to delay slightly. Thus in any equilibrium with adoption by all, $p_{i} \leq r_{i}$ for all $i$. But $\sum p_{i}=1$, so if $\sum r_{i}<1$ then there is no equilibrium with adoption, even if all would gain

\footnotetext{
${ }^{137}$ This makes what may seem an unduly pessimistic assumption about later adopters' expectations if adopter 2 picks B. But that pessimistic assumption seems more natural if we are instead discussing adopter 3 after two A-adoptions.

${ }^{138}$ Thus his preference is evaluated assuming that all subsequent adopters follow his lead.
} 
$\left(u_{B}^{i}(2)>u_{A}^{i}(2)\right.$ for all $\left.i\right)$ and there is only a little noise. However much each player expects others (collectively) to delay, he wants to delay slightly more.

Entry Our discussion of inertia also informs us about competitive entry of a product that is incompatible with an established network. Inertia implies that even if an entrant offers a better deal, network effects aside, to new adopters, they may (and perhaps should) stick to the installed base, assuming that the base itself won't move (perhaps because of individual switching costs). Incompatible entry is difficult, and Fudenberg and Tirole (2000) show that limit pricing can be powerful with network effects.

If new adopters optimally coordinate, this inertia is presumably because, for them, compatibility with the installed base outweighs the new product's advantages. As noted above, inertia can be ex post efficient given incompatibility, ${ }^{139}$ although even ex post excess momentum (too-strong incentives for such entry) is possible. The point here is not whether incompatible entry is too hard ex post, given incompatibility and the installed base, but the fact that even efficient (indeed, even less-than-efficient) inertia can confer ex post market power on the established network.

Some incompatible innovation/entry succeeds in overcoming inertia. Of course, a product that is "ten times better" may simply outweigh inertia. But inertia can be lowered in other ways, as Bresnahan's (2003) discussion of competitive transitions in the computer industry stresses.

First, compatibility with the installed base eliminates the coordination and free-rider problems, and lowers individual switching costs; even partial compatibility through converters (see 3.8) can help. Similarly, multi-homing or double purchase (de Palma, Leruth and Regibeau 1999) mitigates pivotal adopters' losses of network benefits if they switch; Shapiro (1999) thus argues that exclusive dealing ${ }^{140}$ by incumbents in network markets is especially threatening. Complementors can also multi-home, as when applications software providers "port" their programs from one operating system to another.

Rapid market growth makes the installed base less important relative to new adopters, and can thus mitigate pivotal adopters' transient losses of network benefits if they lead a switch (Farrell and Saloner 1986a); large players may both suffer less from such losses and be especially effective leaders of a bandwagon. When expectations otherwise focus on the incumbent, mechanisms such as consensus standards to help adopters coordinate on the best deal can also lower entry barriers. Finally, just as splintering among

\footnotetext{
${ }^{139}$ Moreover, we saw that ex post excess inertia, blocking ex post efficient incompatible entry, is plausible when there are free-rider or coordination problems among adopters, and perhaps especially if expectations track history; Krugman (1991b) discusses the relationship between expectations and history. Since those problems may become more severe as the installed base grows, incompatible entrants may face "narrow windows" of opportunity (David, 1986).

${ }^{140}$ Broadly speaking this means agreements that make it hard for an entrant to thrive with small scale or limited scope.
} 
innovators tends to preserve the status quo (Kretschmer 2004), disarray and incompatibility in the installed base may open up opportunities for a "strong leader" that can offer coordination as well as (or instead of) a better product.

As this last point suggests, successful static compatibility or standardization might retard (incompatible) innovation. Although the logic requires care - it is natural that the better the status quo, the less likely a good system is to engage in costly change - this might be an argument (in the spirit of maintaining biodiversity) against static standardization, as Cabral and Kretschmer (forthcoming) explore. But while marketwide compatibility may retard incompatible replacement of the compatible outcome, mix-andmatch compatibility encourages component innovation (Langlois 1990).

\subsubsection{Early Power}

When there will be inertia-even ex post efficient inertia-early movers' choices determine later adoptions. Thus early movers might strategically or inadvertently commit to a standard that is bad for later adopters but won't be abandoned. We say there is excess early power if early movers adopt and are followed but this is ex ante inefficient: efficiency might demand instead that they defer to later adopters' preferences, or that they wait. That is, early adopters have excess power if their preferences weigh too heavily (relative to later adopters') in the collective choice of what is adopted.

Such an ex ante problem is sometimes called excess inertia, but we prefer to distinguish it more sharply from the ex post problem discussed above. They differ not only in timing, but in that ex post excess inertia concerns later adopters' choices, while ex ante excess early power concerns early adopters' choices. Excess early power does not imply ex post excess inertia: for instance, with two groups we saw that if group 2 optimally coordinates then there cannot be ex post excess inertia, but if inter-group network effects are strong and group 1 optimally coordinates, it has all the power. But the two concepts reflect the same force: the stronger ex post inertia will be, the more power early adopters have.

Arthur's model predicts excess early power; foresight complicates but does not fundamentally change the picture. Moving first gives commitment: early adopters are pivotal (early power), and the more they recognize that later adoptions will have to follow, the less sensitive early adopters will be to later preferences. Like inertia, early power can be efficient but can readily go too far: with strong network effects, long-run network technology choice can be determined by first-mover advantage and by historical small events. ${ }^{141}$ With positive (not necessarily small) probability, almost all adopters choose $A$ but total surplus would have been greater had almost all chosen $B{ }^{142}$

\footnotetext{
${ }^{141}$ Thus it can create a "butterfly effect:" a butterfly flapping its wings might cause a hurricane years later and thousands of miles away.

${ }^{142} \mathrm{In}$ principle this might also arise if good A is worth more than B when each network is
} 
Lock-in could go the other way, in which case foresight weakens early power: if group 2 finds adopting $B$ a dominant strategy, while group 1 wants to adopt whatever it expects group 2 to adopt, then group 2 is pivotal. ${ }^{143}$ But that requires network effects to be strong for group 1 but weak for group 2, so reverse lock-in seems likely to be rarer and weaker than forward lock-in. Thus Farrell and Saloner (1985) found that, given preferences, each player is better off moving earlier: this "New Hampshire Theorem" says that earlier adopters' preferences get more weight than later adopters' in the collective outcome, ${ }^{144}$ which strongly suggests excess early power. ${ }^{145}$

In summary, early adopters have the strategic advantage: there is a reasonable presumption of excess early power at the adopter level. As we see in 3.7.2 below, however, this need not imply that early advantages confer sustained success when sponsors of competing standards compete using penetration pricing.

\subsubsection{Positive Feedback and Tipping}

We have seen how early choices are powerful, able either to help coordination or to wield disproportionate influence. Thus any early lead in adoptions (whether strategic or accidental) will tend to expand rather than to dissipate. Network markets are "tippy": early instability and later lock-in.

To explore this, consider a continuum of identical adopters who only want to coordinate. There are three kinds of static pure-strategy Nash equilibria: all adopt $A$, all adopt $B$, and many splintered equilibria in which half adopt $A$ and half adopt $B$ (and all are indifferent). Now suppose market shares are randomly perturbed, and at each instant some adopters can change their move in response to current shares. Then as soon as the shares are unequal, those who can choose will adopt the majority product; this makes the half-and-half equilibrium unstable. The point carries over even with some horizontal product differentiation. ${ }^{146}$

Although sketchy, such dynamics suggest that re-equilibration by others

small but B is worth more than A when each network is large. As Liebowitz and Margolis (1994) observe, there is no obvious reason to expect that.

${ }^{143}$ Holmes (1999) shows how adopters who care less than others about network effects (relative to their preferences between products, or in his case locations) can lead a transition. He uses this in explaining the migration of the US cotton textile industry. Large groups that can successfully coordinate internally are thus prime candidates to be pivotal movers and get the best deals. Bresnahan (2001) explored this in the context of AOL's adoption of Internet Explorer during the Netscape-Microsoft browser war.

${ }^{144}$ Holding an early primary, as New Hampshire does, gives a state more influence when bandwagon effects are important in a national election.

${ }^{145}$ Excess late power (sometimes called ex ante excess momentum) is also possible, because the outcome depends only on ordinal preferences and not on their intensity.

${ }^{146}$ With a finite number of adopters rather than a continuum, the same force prevents equal shares being an equilibrium at all. See e.g. Katz and Shapiro (1985, 1994). Echenique and Edlin (2004) show that strategic complementarities make mixed-strategy equilibria unstable, unless adopters have perverse beliefs about how shares will evolve. 
(which is central to indirect network effects) strengthens instability.

Arthur $(1989,1990)$ and Arthur and Lane (1993) similarly find that if prices are fixed, and adoption decisions depend only on past adoptions (current shares of installed base), then one product or technology will come to dominate. ${ }^{147148}$

\subsubsection{Option Value of Waiting}

We have seen that early adoption can freeze a technology choice and foreclose what would otherwise be later adopters' preferred choices. Above, we asked whether early adopters instead ought to defer to the known preferences of later adopters. When those preferences (and/or later costs) are not known early on, waiting can thus be efficient. Lock-in-even lock-in to a choice that's optimal given available information at the time-sacrifices social option value.

Just as future preferences are often under-weighted by market forces, option value will be. And institutions may be less apt to repair this: it is probably easier to acquire residual rights in one potential network with a clear future than to internalize the gains from waiting for something unpredictable. Whether or not the Dvorak keyboard is better than QWERTY, there clearly was a chance in 1888 that something better would later appear. How might incentives at that date incorporate this option value - what would persuade early generations of typists to wait, or to adopt diverse keyboards, if that was socially desirable in the long run? In principle the option value might be internalized by a century-long monopoly on typing so that the monopoly could price the loss of option value into early adoptions, or by a futuristic patent on a range of alternative keyboards so that Dr Dvorak's grandparents could subsidize waiting or diversity. Even if there had been many individual long-lived patents on particular keyboards, their proprietors would have faced a public-good problem in encouraging waiting. These institutions seem far from reality. It might well not have been efficient for nineteenth-century typists to wait, or to use keyboards they didn't like, in order to preserve a more realistic option for a different design in 1940. But it is hard to think that the market gave a very good test of whether or not that would have been desirable.

Sometimes option value could be preserved by making later products compatible with early adoption. Section 3.8 below discusses incentives to do this, but clearly early adopters, or a sponsor of a product that they favor, may not want to ensure compatibility if they expect ex post inertia (excess or not) under incompatibility, as they gain from excess early power. Indeed, Choi

\footnotetext{
${ }^{147}$ In these models, the probability of winning a consumer is a function of prices and shares of installed base; this assumption is rationalized by horizontal differentiation.

${ }^{148}$ In Ellison and Fudenberg (2003) and Ellison, Fudenberg and Mobius (2004), there may be a plateau of non-tipped outcomes from which no player unilaterally wants to move, if buyers dislike (slightly) outnumbering sellers more than they like being in a bigger market.
} 
(1994) and Choi and Thum (1998) confirm that pre-emption competition for the New Hampshire first-mover advantage can make adoption inefficiently fast when moving quickly can drive a bandwagon. Recall however that adoption may be too slow because of the externality or because early adoption risks coordination failure.

\subsection{Sponsored Price and Strategy for a Single Network}

Having discussed the demand side of network markets — adopters' choices given the offers they face - we turn to the supply side. This section primarily discusses a network monopoly, but most of the insights apply equally to a firm trying to establish its standard against a rival standard, as section 3.7 further explores.

A sponsor seeking to establish its network has two generic strategies. First, it may focus selling effort on pivotal adopters, whose choices strongly affect others'. In particular, when a network involves different classes of adopters (for instance a credit card network that must be adopted by consumers and merchants) a sponsor can choose where to focus its marketing or price-cutting; and when there are different adoption dates a sponsor can choose (subject to commitment issues) when to do so. Second, a sponsor might seek to visibly commit to ensuring widespread adoption, or otherwise work on expectations.

\subsubsection{Pricing to Different Groups: Penetration Pricing}

First consider separate prices to two classes or groups of adopters with intergroup network effects. ${ }^{149}$ These groups might be peers at different dates (early and late adopters), or two sides of a market. As Rochet and Tirole (2002, 2004) and Armstrong (forthcoming) observe, such two-sided markets include credit cards, brokers, auctions, matchmakers, conferences, journals, computer platforms, and newspapers.

Suppose first that the sponsor simultaneously commits to both prices. Increased sales to one group raise the other group's demand: the inter-group marginal network effect. So in broadly Ramsey fashion the optimal price to group 1 will be lower, the more strongly group 2's demand responds to adoption by group 1 and the more profitable (endogenously) are sales to group 2, as well as the higher group 1's own demand elasticity (as usual). ${ }^{150}$ Thus a single seller's optimal prices to the two groups may well be asymmetric; indeed, one side often pays zero or below cost. ${ }^{151}$

\footnotetext{
${ }^{149}$ We consider only simple prices; Sundararajan (2003) discusses nonlinear pricing with network effects.

${ }^{150}$ As we noted in 3.3.2, there may be intra-group network effects (or congestion effects if the groups are different sides of a market). These affect the welfare economics, but for profit-maximizing pricing we can treat each group as a demand curve.

${ }^{151}$ See for instance Parker and Van Alstyne (2005), Schmalensee (2002), Rochet and Tirole (2004). As we saw in 3.3 .2 above, first-best prices would be below marginal cost
} 
At an abstract level this is simply pricing with complementarities, as in Gillette's early strategy of giving away razors and making money on blades (Adams 1978); but here the complementarities are between different customers' adoption choices. If there is no single sponsor, implementing an optimal markup structure may require payments between sectors such as the credit card interchange fees discussed in 3.2; if that's hard to do well, it can encourage vertical integration.

With early and late groups the analysis is the same if the seller commits to a price path. For Ramsey-style reasons, low-then-high penetration pricing is privately (and can be socially) efficient in the usual case where early adopters are pivotal.

Finally, with early and late groups but no commitment, low-high pricing is even further encouraged. The seller will predictably set a second-period price higher than would be optimal ex ante, since ex post it will not take into account the effect on first-period adoption. Thus first-period adopters will expect a high future price, lowering first-period demand; and incompatible competition among sponsors will lower first-period prices in anticipation of the ex post rents. All these forces push towards bargain-then-ripoff penetration pricing, the reverse of Coasean dynamics. ${ }^{152}$

That commitment problem puts a sponsored network at a disadvantage against an open (competitively supplied) network product in the relatively rare case of reverse lock-in where second-period adopters are pivotal. A proprietary sponsor might then seek even costly forms of commitment such as (delayed) free licensing of a technology (Farrell and Gallini 1988, Economides 1996b). But sellers of an open product cannot recoup investment in below-cost early prices, so a sponsored product has an advantage when (as is probably typical) overall adoption responds more sensitively to early prices than to sophisticated predictions of later prices (Katz and Shapiro 1986a).

\subsubsection{Single Monopoly Price}

Above, we separated the two roles of $p$ : each adopter viewed the price facing him in the ordinary way, and based his relevant expectations on the price facing the complementary group. With switching costs, the ex ante and ex post prices are similarly separable when locked-in customers buy a distinct

for both groups. Ramsey pricing looks qualitatively similar to profit-maximizing pricing because the problems are closely related.

${ }^{152}$ Cabral, Salant, and Woroch (1999) study monopoly penetration pricing of durable network goods when buyers have rational expectations. In certain classes of example, they find that Coase-conjecture price dynamics tend to predominate over penetration pricing: prices fall rather than rise over time, especially when there is complete information. Bensaid and Lesne (1996) find however that strong network effects remove the time-consistency Coase problem and cause optimal prices to increase over time. See also Mason (2000) and Choi (1994a). Radner and Sundararajan (2004) study a network monopolist's dynamic pricing problem when adopters expect each period's network size to be equal to last period's; they find extreme bargain-then-ripoff pricing (the monopolist prices at zero until the network reaches its desired size). 
good such as service; otherwise they may have to be equal, as we discussed in 2.4. Similarly here prices to two sides of a market are presumably separable, but with two groups of peer adopters they may not be. In that case it is natural to suppress the two groups and simply study overall demand at the given price.

The "fulfilled-expectations demand curve" then matches each price $p$ with those penetration levels $x$ such that, when adopters expect penetration $x$, just $x$ of them will adopt at price $p$ : see e.g. Leibenstein (1950), Rohlfs (1974), Katz and Shapiro (1985), Economides (1996a). Such a demand curve is more elastic than each of the fixed-expectations curves of which it is built (Leibenstein 1950). Gabel (1991) suggests that Sony, Betamax's sponsor in VCRs, may have optimized against a less elastic (perhaps short-run) perceived demand curve because it did not anticipate video-rental network effects. Monopoly deadweight loss may be more severe with network effects: monopoly not only deters marginal adoption, but also lowers surplus of inframarginal adopters. ${ }^{153}$

Multiple equilibria in adoption at price $p$ now show up as multiple intersections of the demand curve with a horizontal line at $p$. To pin down demand at $p$, one might rule out "unstable" equilibria (at which demand is upward-sloping); but if there is an unstable equilibrium, there are at least two stable equilibria. However one selects an adoption equilibrium for each $p$, there may well be discontinuous changes in behavior as a parameter such as cost varies continuously, as in catastrophe theory. ${ }^{154}$ Even if a network product only gradually becomes cheaper or better over time, it may suddenly acquire critical mass and take off. ${ }^{155}$

A strategic monopoly seller might persuade adopters to coordinate on the largest equilibrium $x$ given $p$. If so, we say that the seller can "affect expectations" and pick any $\left(x^{e}, p\right)$ such that $x^{e}$ is an adoption equilibrium at price $p$. The next sub-section discusses some tactics for affecting expectations in this sense.

\subsubsection{Commitment Strategies}

Since demand depends on expectations, a network sponsor can gain from commitment to size, to inspire confidence and optimism. Commitment can

\footnotetext{
${ }^{153}$ Farrell and Shapiro (1992) argue this in a linear example; but Lambertini and Orsini (2001), stressing network quality, reach different conclusions. One problem is that it is not clear what the demand curve "would be" without network effects. Rysman (2004) shows that, even if competition involves splintering, it is better than monopoly in his calibrated model of the market for Yellow Pages.

${ }^{154}$ Indeed, if the rational-expectations demand curve has an upward-sloping portion, there is typically no everywhere-continuous selection of adoption equilibrium, even if there is everywhere a locally continuous selection.

${ }^{155}$ Rohlfs (2001), Farrell and Shapiro (1992), Economides and Himmelberg (1995), and Gandal (2000) suggest examples of sudden success that might reflect such tipping. Liebowitz and Margolis (2001) question that interpretation and argue that price and share dynamics in computer software seem inconsistent with tipping.
} 
address both the marginal and multiple-equilibrium underadoption problems identified in 3.3 above.

One commitment is simply selling products early on. Sellers boast about (even exaggerate) sales. To be a useful commitment, sales must be visible and irreversible, so this strategy makes most sense for durables. Network effects typically arise from use, not from mere possession, so dumping (e.g., free) units on the market may be discounted. The most effective sales are to influential adopters whose adoption will boost others' by the most.

A blunt early-sales strategy is of course penetration pricing, as discussed above. As we will see in 3.7 below, competition can induce penetration pricing as the form of competition for the market. When a monopoly engages in penetration pricing, however, it would seem to be leaving money on the table relative to convincing early buyers in some other fashion that the longrun network size will be large. Thus we focus here on means to commit to that.

To encourage early adoption, a seller would like to commit to selling more later than it will then wish to sell, a point made by Katz and Shapiro (1986a) and put in a broader framework by Segal (1999). This kind of commitment strategy can operate even when there is a single equilibrium; commitment shifts the equilibrium. We have already noted some tactics such as second-sourcing that might help such a commitment. One might model commitment in a reduced-form way through assumptions about a sponsor's strategic variable. Rather than just setting a price, a sponsor might seek to commit to quantities sold or to the utility it will give each (type of) adopter.

Reputation and general market credibility can help communicate commitment or boost expectations. Another commitment strategy is to open a standard to guarantee competitive future behavior, increasing early adopters' expectations of long-run network size. And integration with complementors might visibly improve incentives for supply of complements, as well as facilitate Ramsey-style cross-pricing.

When there are multiple equilibria, some of the same commitment tactics can help ensure a more favorable equilibrium. Rohlfs (2001) develops a model of irreversible adoption by many small buyers that involves dynamics at two levels. First, at any time buyers adopt if they want to do so given prices and given the current installed base, but they lack foresight and the adoption-equilibrium selection is thus pessimistic: there may be other equilibria with more adoption. In the second kind of dynamics, sponsors try to push the market past critical mass and generate positive feedback. For instance, a sponsor may dump enough units on the market to enter the basin of attraction of a preferred equilibrium.

In addition to the use of equilibrium-path price discrimination (penetration pricing), out-of-equilibrium (discriminatory) offers can eliminate an equilibrium that the seller dislikes, as we discuss next and as Segal and Whinston (2000) explored in the context of exclusive dealing. As that case illustrates, these equilibrium-selection tactics can work against buyers when 
networks compete, whereas in the case of a single network both seller and buyers prefer an equilibrium with more adoption. ${ }^{156}$

\subsubsection{Contingent Contracts}

Commitment through contracts could in principle overcome the coordination problem, as Dybvig and Spatt (1983) noted. Suppose a seller offers buyers a contract: "The price is $p<u(N)$ if all other buyers also adopt (which I expect); if not, the price is $p^{\prime}<u\left(n_{i}\right)$." Each buyer should accept this contract whatever he expects other buyers to do. Of course, $p^{\prime}$ may have to be (perhaps far) below cost, so the seller will make a loss if some buyers reject the offer. But in principle success depends only on buyers' individual rationality, not on their coordinating.

Likewise, the theory suggests, a contingent contract can profitably attract buyers away from coordination on the wrong network if a better alternative has a residual claimant (sponsor). Thus, suppose that buyers expect one another to adopt $A$, and that $u_{B}\left(n_{i}\right)-c_{B}<u_{A}(N)-p_{A}<u_{B}(N)-c_{B} .{ }^{157}$ Seller $B$ offers the contract: "If $x$ of you buy $B$, the price will be $u_{B}(x)-$ $u_{A}(N)+p_{A}-k$." For $k>0$, it is a dominant strategy for each buyer to accept, and the contract is profitable if all buyers do so and $k$ is small enough. Indeed, as we noted in the previous sub-section, such a contract may inefficiently succeed: Segal (1999) and Jullien (2001) show that, because adoption of $B$ imposes a negative externality on those who continue to buy $A$, there will be excessive adoption of $B$ even if initial expectations favor $A$, when $B$ (but not $A$ ) can offer public flexible pricing under complete information. But Park, I.-U. (2004) applies mechanism-design methods and finds that such contingent inducement schemes (and a range of other schemes) will induce less than efficient adoption when the seller has incomplete information about adopters' tastes.

It is not surprising that some flexible contracting can in theory solve coordination problems. ${ }^{158}$ At the level of cooperative game theory, network effects are like ordinary economies of scale: in each case a coalition consisting of a seller and $x$ buyers achieves more surplus per buyer as $x$ increases. Indeed, Sutton's (1998, chapters 14.2 and 15.2) models of network effects and learning effects are formally identical. Since simple contracts often enable efficient competition with economies of scale (even dynamically if contestability holds), some contracts would in principle do so with network effects. ${ }^{159}$

\footnotetext{
${ }^{156}$ The reason is that one player's adoption of network A hurts - relative to the alternative - those who adopt B; thus in Segal's (1999) terms there is a negative externality on non-traders, leading to conflict at equilibrium when offers are public (full commitment by the seller).

${ }^{157}$ Recall here that $c_{A}$ is the production cost of good $A$, etc.

${ }^{158}$ Thum (1994) also considers how contract form affects efficiency.

${ }^{159}$ One could also reach the same optimistic view via the Coase Theorem.
} 
Contingent contracts might be differently implemented depending on whether adopters make a one-time purchase or continue to buy in order to use the network. When adopters will continue to trade with the seller over time, penetration pricing can become contingent pricing; ${ }^{160}$ one version is usage-based pricing. ${ }^{161}$ With one-time purchases, a seller might either charge low prices and later collect top-up fees if the network succeeds, or charge prices consonant with a successful network, promising refunds if the network falls short. Refund promises might not be believed, either because a nascent $B$-supplier would lack funds for such a large, non-diversifiable risk, or because buyers would suspect fine print in the contract.

Despite the advantages of contingent contracts, they do not seem the norm in network markets. ${ }^{162}$ Very low, especially negative, prices may be problematic, as we discussed in section 2, and the nuisance adopter issue is arguably worse here because network benefits normally hinge on use, not just possession, of the good. Especially if $A$ is well established, this can make users' opportunity costs of adopting $B$ large and hard to observe. Thus contingent contracts might work better against the single-network chickenand-egg problem than to help an entrant displace an established network rival.

While cost-side economies of scale often do not raise the coordination issues that we argue are central in network effects, this is not a fact of technology and preferences: it hinges on the contracts used. Thus contract theory should play more role in the study of network effects than it has hitherto, and in particular understanding the use, or lack of use, of contingent contracts would be an important advance.

\subsection{Sponsored Pricing of Competing Networks}

In incompatible competition firms vie to control expectations. Competition will focus on pivotal customers; these are often early adopters - as with switching costs, where competition is largely for early purchases. Central questions are whether more efficient firms reliably win and whether profits reflect only their efficiency advantage.

\footnotetext{
${ }^{160}$ Another view of penetration pricing with one-time purchases is that it is an attempt at contingent pricing but sacrifices part of the surplus from early adopters: they "ought to" see that the network will succeed and hence be willing to pay a lot, but they don't.

${ }^{161}$ Oren and Smith (1981) and Rohlfs (2001). That is, if each adopter's use of a telecommunications product, say, is proportional to the value he derives from it, then trafficsensitive pricing may solve the chicken-and-egg problem even at the cost of inefficiently deterring usage given network size. See also Carter and Wright (1999).

${ }^{162}$ Arguably this suggests either that there is no problem to be solved, or that (as we suspect) the contracts are problematic. See also Innes and Sexton (1994) and Haruvy and Prasad (2001).
} 


\subsubsection{Competition with Cost/Quality Differences}

Consider incompatible competition with purely vertical differentiation: either a cost difference or a quality difference valued equally by all consumers. First we treat efficiency advantages as fixed over time; in 3.7 .2 we allow them to vary. Expectations may respond in various ways to quality and price differences: for instance they may track surplus, track quality, track past success, or stubbornly favor one firm. ${ }^{163}$

We say expectations track surplus if each buyer expects all others to buy the product that, network effects held constant, offers the most surplus. For instance, suppose firms set prices just once and then there is a sequence of adoption choices by small cohorts. If adopters have similar preferences (agree on which product offers them more surplus if all adopt it), one might expect adoption of that product. ${ }^{164}$ Price competition then works just as it would if the products were compatible. The efficient product wins, and (with nondrastic efficiency differences) consumers get the same surplus as they would if the second-best product were offered at average cost and adopted by all. Consumers capture the network effect and any economies of scale. Quality competition also is therefore just as under compatibility. ${ }^{165}$

But this changes dramatically if instead expectations track quality. Although this is a static model, this assumption can be motivated because, as Katz and Shapiro (1992) showed, this is the equilibrium if sponsors can adjust prices in response to adoption dynamics: suppose for instance that $A$ has higher quality (or lower costs), and that this outweighs the network gain from adoption by a single additional cohort. Then, $A$ will not fail through a bandwagon effect that starts because a few buyers adopt $B$ instead. Rather, such a loss will lead $A$ 's sponsor to cut its price to subsequent adopters: it can profitably do what it takes to win, even coming from a bit behind in installed base. ${ }^{166}$ So each adopter will recognize that even if he and his cohort adopt product $B$, product $A$ will still win the rest of the market. Since no buyer is pivotal, the price to any buyer (or cohort) should not affect expectations. So rational expectations will track quality - focus on the network with higher quality (or lower costs) - and ignore any period's prices.

In this case, if $A$ has higher quality it wins current sales if: ${ }^{167} u_{A}(N)-$ $p_{A} \geq u_{B}(1)-c_{B}$, or $p_{A}-c_{A} \leq\left[u_{A}(N)-u_{B}(N)\right]+\left[u_{B}(N)-u_{B}(1)\right]-\left[c_{A}-c_{B}\right]$. Its profit is equal to its actual (cost and/or quality) advantage plus the

\footnotetext{
${ }^{163}$ These terms are from Farrell and Katz (1998).

${ }^{164} \mathrm{As}$ we saw in 3.4.4, this is the unique subgame-perfect equilibrium. As we argued there, this may not be conclusive; but it is one plausible expection.

${ }^{165}$ Baake and Boom (2001), and Bental and Spiegel (1995) discuss static competition with network effects and quality differentiation when consumers' willingness to pay for quality varies.

${ }^{166}$ Therefore $B$ will not attempt penetration pricing: there is no follow-on gain to winning a cohort or two. See Fudenberg et al. (1983) on races without leapfrogging.

${ }^{167}$ We assume that each adopter is of size 1 and that a losing seller is willing to price down to cost.
} 
network effect. If $A$ visibly could make consumers a significantly better offer than can $B$, it need not actually match $B$ 's offer! Consumers would get more surplus if they all adopted the losing network $B$ priced at cost. ${ }^{168}$

Of course, when such lucrative expectations track quality, firms will compete intensely on quality. Consumers gain from additional quality created by the second highest-quality firm. ${ }^{169}$ The network effect accrues to the winner, and/or is dissipated in quality competition, which can therefore be socially excessive.

Worse, other factors might make consumers expect a product to win the market even after (out of equilibrium) losing a round or two - making expectations stubbornly unresponsive to price or performance. For instance, this logic would focus expectations on a firm that plainly could dramatically improve its product if necessary - even if it never actually does so. Other forces might include deep pockets, history or reputation, a convincing roadmap for future products, control of a key complement, control of formal standards efforts, or marketing activity. As we saw, a seller thus favored by expectations can extract profits commensurate with the network effects, and may thus profitably control the market even with an inferior product or offering - provided, crucially, that its inferiority does not loosen its control of expectations. Such dysfunctional patterns of expectations may be most likely where adopters have dissimilar preferences, hindering attempts (e.g. through talk) to coordinate better.

When expectations thus stubbornly favor one firm, it has monopoly-like incentives for quality improvement. Its rivals cannot gain from ordinary innovation. But if $B$ 's quality improves so much that each user will adopt $B$ no matter what he expects others to do, then adopters should now give $B$ the benefit of expectations. Thus $A$ 's rivals have strong incentives for dramatic innovation (Grove's "ten times better").

Thus these models suggest that quality competition can produce stronger incentives for innovation than monopoly (even inefficiently strong incentives), while expectations-dominant firms have incentives for incremental innovation and other firms have little incentive for other than breakthrough innovation.

If expectations track past market success, they reinforce installed base in giving past winners an advantage in future competition. This increases collective switching costs and accentuates the bargain-then-ripoff pattern of dynamic competition.

\footnotetext{
${ }^{168}$ This is an instance of the principle that pivotal adopters get the surplus: when there are no such buyers, firms can keep the surplus. (Raskovich (2003) argues, on the other hand, that pivotal buyers find themselves saddled with the responsibility of ensuring that a good is actually provided.) In predatory pricing policy, Edlin (2002) discusses how a firm's ability to make a better offer can forestall the need to do so (to consumers' detriment).

${ }^{169}$ As always when competition gives no gross return to investment by a subsequent "loser", there can be equilibria in which only one firm invests. Thus details of the quality competition game may be important.
} 


\subsubsection{Competition with Cost/Quality Differences that Vary over Time}

Now suppose that competing networks' efficiency advantages may shift over time. We revisit the inertia questions of 3.5 but now when competing networks are strategically priced. In doing so we address the scope for competitive entry (perhaps via penetration pricing) by a sponsored network product that must come from behind in network size and hence (often) in static efficiency, but that might become more efficient than an incumbent if widely adopted.

As we saw in 3.5, if early efficiency advantages determine offers to the pivotal early adopters, then a technology with an early lead will beat a technology that will (or may) be better later. This is the New Hampshire Theorem: early power for any given prices. In particular, if each network is competitively supplied, there is excess early power: a bias toward the one that early adopters prefer.

Now suppose instead that network sponsors compete for early adopters through penetration pricing. We describe how competitive penetration pricing can yield efficient adoption choices in favorable circumstances. More realistically, biases can arise in either direction, but we argue that excess early power remains more likely than its opposite.

Suppose that $A$ has costs $a_{t}$ in period $t$, while $B$ has costs $b_{t}$, and that network effects are strong: second-period adopters would follow first-period adopters if both products were priced at cost, and will pay $r$ for a product compatible with first-period adoption. Finally, suppose that if a firm fails to win first-period sales, it exits (it knows it will lose in the second period). Then $A$ would price as low as $a_{1}-\left(r-a_{2}\right)$ to win first-period sales, while $B$ would go down to $b_{1}-\left(r-b_{2}\right)$. Consequently, second-period efficiencies feed through efficiently into first-period penetration pricing, and the firm that can more efficiently provide the good in both periods wins sales in both periods, if each cohort optimally coordinates internally and first-period buyers correctly foresee second-period behavior. In this model, collective technology choice is efficient, and the pivotal (first-period) adopters get the benefit of competition. ${ }^{170}$

How robust is this optimistic result? Second-period efficiency can feed through more strongly than is efficient into first-period penetration pricing. In Katz and Shapiro (1986a), a first-period loser does not exit but continues to constrain pricing. Thus the second-period prize for which $A$ is willing to price below its cost in the first period is $b_{2}-a_{2}+\beta$, where $\beta$ represents a network-size advantage ${ }^{171}$ similarly $B$ expects a second-period prize of

\footnotetext{
${ }^{170}$ Welfare may still be lower than under compatibility if different products would then be adopted in different periods, although firms have an incentive to achieve compatibility in that case (Katz and Shapiro 1986b; see 3.8 below).

${ }^{171}$ Specifically, $\beta$ is the difference in value between a network of all consumers and one consisting only of second-generation consumers. With strong network effects, $\beta$ exceeds second-period cost differences.
} 
$a_{2}-b_{2}+\beta$ for winning the first period. So firm $\mathrm{A}$ wins first-period (and hence all) sales if and only if $a_{1}-\left[b_{2}-a_{2}+\beta\right] \leq b_{1}-\left[a_{2}-b_{2}+\beta\right]$. Secondperiod efficiency is double-counted relative to first-period efficiency, leading to excess late power ${ }^{172}$ despite the excess early power for any given prices: strategic pricing here reverses the adoption-level bias.

Or feed-through can be weaker than is efficient. There is no feed-through when both standards are unsponsored (firms cannot later capture gains from establishing a product). Uncertainty and capital market imperfections can weaken feed-through. ${ }^{173}$ Feed-through is also inefficient if first-period competition is not entirely through better offers but consists of rent-seeking through unproductive marketing. Feed-through can work efficiently even if consumers do not know why they are getting good first-period offers, or do not know the extent of gouging, provided the latter is symmetric. But, as we saw in Section 2, bargain-then-ripoff competition can cause inefficiencies.

As Katz and Shapiro (1986a) also noted, when one product is sponsored but its rival is not, feed-through is asymmetric, biasing the outcome toward the sponsored product. And, as Farrell and Katz (2005) note, feed-through is also asymmetric if $A$ would stay in the market for the second period after losing the first, but $B$ would exit if it lost the first round. ${ }^{174}$

To summarize, at given prices, network effects cause pivotal adopters' preferences to be over-weighted; since early adopters are often pivotal, products that appeal to them fare better than products that appeal comparably to later adopters. That is, there is typically excess early power for any given prices. But relative efficiencies in serving non-pivotal adopters may feed through into prices to pivotal adopters, and thus into the outcome. This feed-through can be zero (as with unsponsored products), weak, correct (as in the model above where first-round losers exit), or excessive (as in Katz and Shapiro 1986a and Jullien 2001). Nevertheless, in general we think feedthrough seems likely to be too weak, even if buyers optimally coordinate: the arguments for optimal or excessive feed-through put a lot of weight on firms' ability to predict future quasi-rents and incorporate them into today's pricing. Perhaps more importantly, however, feed-through can be asymmetric for reasons unrelated to the qualities of the competing products, and the

\footnotetext{
${ }^{172}$ This is why Katz and Shapiro (1986a) find excess late power (or "new-firm bias") with sponsored products when network effects are strong. When network effects are weaker, they found a new-firm bias for a different reason. The ("new") firm with the secondperiod advantage certainly would win second-period sales if it won first-period sales; but the other firm with the second-period disadvantage might not. The "old" firm would like to commit to doing so, in order to offer first-period customers a full network, but cannot.

${ }^{173}$ Feed-through will be weakened (as in switching-cost markets) if firms cannot lower first-period prices enough to pass through all prospective ex post profits to the pivotal early adopters (e.g. because of borrowing constraints, or because negative prices attract worthless demand).

${ }^{174}$ Then, $A$ 's second-period prize for winning the first period is $r-a_{2}$, but $B$ 's is only $\min \left[r-b_{2}, a_{2}-b_{2}+\beta\right]$. Thus if $r>a_{2}+\beta$, feedthrough is asymmetric and $A$ wins both periods if and only if $a_{1}-\left[r-a_{2}\right] \leq b_{1}-\left[a_{2}-b_{2}+\beta\right]$, or $a_{1}+a_{2} \leq b_{1}+b_{2}+\left[r-a_{2}-\beta\right]$. The last term in brackets is a bias toward the firm with a reputation for persistence.
} 
asymmetry probably tends to favor established or sponsored products over nascent or unsponsored ones.

Thus entry by an incompatible product is often hard, and may well be too hard even given the incumbent's installed base and given incompatibility. Switching costs and network effects can work in tandem to discourage incompatible entry: switching costs discourage large-scale entry (which would require the installed base to switch) while network effects discourage gradual, small-scale entry (offering a small network at first).

A Switching-Cost Analogy The models above have close switching-cost analogies, although the switching-cost literature has not stressed efficiency differences between firms. With costs as described above and no network effects or quality differences but a switching cost $s$, suppose first that each buyer expects to face a second-period price $p_{2}$ that is independent of which seller he is locked into. Then of course he will buy the lower-priced product in the first period. If he is correct about second-period pricing (for instance, if his reservation price $r$ is low enough that switching can never pay, so $p_{2}=r$ ), then seller $A$ is willing to price down to $a_{1}-\left[p_{2}-a_{2}\right]$ in the first period, and similarly for $B$. Hence, the firm with lower life-cycle costs makes the sale, as efficiency requires. This is the switching-cost analogy to the model with exit above. ${ }^{175}$

But if second-period prices are instead constrained by the buyer's option to switch, then $A$ will price at $b_{2}+s$ in the second period if it wins the first, while $B$ will price at $a_{2}+s$ if it does. If myopic buyers do not foresee this difference then second-period costs are double-counted relative to firstperiod costs: this is an asymmetric version of the model in 2.2.1 above, and is the switching-cost analogy to Katz and Shapiro (1986a). Finally, if secondperiod prices are constrained by the option to switch and buyers have rational expectations and know firms' second-period costs, then the buyer chooses $A$ only if its first-period price is at least $b_{2}-a_{2}$ lower than $B$ 's, and again the firm with lower lifecycle costs wins.

\subsubsection{Static Competition when Consumers' Preferences Differ}

Without network effects, or with compatibility, horizontal differentiation has several effects. First, tipping is unlikely: a variety of products make sales. Second, prices reflect each firm's marginal cost and its market power due to the horizontal differentiation (in a Hotelling model, for instance, the level of transport costs). Third, if a seller modestly improves its product, it gets modestly higher share and profits.

With strong network effects and incompatibility, all these lessons change. Buyers want to coordinate and all adopt a single network, though they dis-

agree on which one. If they will succeed in doing so, and if their collective choice is responsive to changes in quality or price, then firms are competing

${ }^{175}$ See also section 3.2 of Klemperer (1995). 
for the market, which blunts horizontal differentiation. Thus, strong proprietary network effects can sharpen price competition when expectations are up for grabs and will track surplus; ${ }^{176}$ Donanoglu and Grzybowski (2004) contrast this with competition-softening switching costs. Product improvement by the leader does not change market shares; nor does marginal product improvement by other firms. If price reflects cost, it will reflect the loser's average cost, because the loser is willing to price down that far in competition for the whole market.

When differentiation is stronger, or network effects weaker, niche minority products such as Apple can survive. Multiple products can also survive if network effects are primarily localized within subgroups of adopters, segmenting the market. But the strategy of selling only to closely-matching buyers is less appealing than under compatibility (or than without network effects), and if network effects strengthen or become less localized, or the dominant network grows, niches may become unsustainable, as speakers of "small" human languages are finding and as Gabel (1987) argues was the case for Betamax.

\subsubsection{Dynamic Competition when Consumers' Preferences Differ}

Just as excess early power at fixed prices need not imply excess early power when firms compete in penetration pricing, tipping at given prices might not imply tipping when sponsors price to build or exploit market share. If one network gets ahead, will its sponsor raise price to exploit that lead and thus dissipate it, as (recall 2.7.1) happens with switching costs, repeated sales of a single good, and no price discrimination; or will it keep price low and come to dominate the market? The literature suggests the answer is ambiguous. Arthur and Rusczcynski (1992) studied this question when firms set prices in a many-period dynamic game; Hanson (1983) considered a similar model. In stochastic duopoly they find that if firms have high discount rates, a large firm tends to lose share by pricing high for near-term profit. But if firms have lower discount rates, a large firm sets low prices to reinforce its dominant position. ${ }^{177}$

In summary, strong network effects tend to cause tipping or unstable (positive feedback) dynamics at given prices (including the case of unsponsored standards and constant costs); sometimes, they also do so where sponsors strategically set prices.

\footnotetext{
${ }^{176}$ Large buyers in oligopoly markets often negotiate discounts in return for exclusivity. One possible explanation is that a "large buyer" is really a joint purchasing agent for many differentiated purchases; exclusivity commits the buyer to ignore product differentiation and thus sharpens price competition.

${ }^{177}$ Dosi, Ermoliev and Kaniowski (1994) find that market sharing can occur if firms adjust prices in response to market shares according to an exogenous non-optimal rule.
} 


\subsection{Endogenous Network Effects: Choosing How to Compete}

Incompatibility of competing products can be inevitable, but is often chosen. Why would a firm prefer one form of competition over another?

When firms do not compete, or when competition is equally fierce either way, efficiency effects should normally govern: firms internalize efficiency advantages of compatibility choices. But competitive effects modify this, and can readily reverse it. Finally, when firms disagree on how to compete, who gets to choose?

\subsubsection{Efficiency Effects}

Incompatibility has some obvious inefficiencies. Network benefits are lost if some adopters are unwilling to follow the crowd (network effects are weak) or the market splinters because adopters choose simultaneously or in ignorance. If, on the other hand, the market cleanly tips, it worsens matching of products to consumers when tastes differ or if the market tips the wrong way. When networks' future relative advantages are uncertain, compatibility makes switching easier (whether or not inertia is efficient given incompatibility) and thus preserves option value and reduces adopters' incentives either to wait and see which network wins or to adopt hastily and pre-empt.

Compatibility can also enable mix-and-match of complements. When the best hardware and the best software may not come from the same family, compatibility yields a direct mix-and-match efficiency gain.

But compatibility need not be efficient. Compatibility may require costly adapters or impose design constraints that may be severe if a standard requires a slow-moving consensus process. Proprietary control of a standard can encourage investment in development or in penetration pricing. It thus makes sense to supplement thinking directly about the pluses and minuses of compatibility with thinking about firms' competitive incentives.

\subsubsection{Competitive Effects}

The first competitive effect is leveling: compatibility neutralizes the competitive advantage of one firm having a larger installed base or being better at attracting expectations. When firm 1 is larger than firm 2 , so $x_{1}>x_{2}$, compatibility boosts the value of firm 1's product from $u\left(x_{1}\right)$ to $u\left(x_{1}+x_{2}\right)$, and firm 2's product from $u\left(x_{2}\right)$ to $u\left(x_{1}+x_{2}\right)$. Since a firm's profit is increasing in the value of its own product and decreasing in that of its rival, compatibility helps the large firm less and hurts it more than it helps or hurts the small firm if we can take the (expected) sizes $x_{1}$ and $x_{2}$ as broadly given. So a firm with a big locked-in installed base, or a firm that is exogenously expected to be big, is apt to resist compatibility with a smaller but fierce rival. ${ }^{178}$

\footnotetext{
${ }^{178}$ See for instance Katz and Shapiro (1985), de Palma and Leruth (1996), Cremer, Rey and Tirole (2000), and Malueg and Schwartz (forthcoming). Belleflamme (1998) explores
} 
Thus the dominant Bell system declined to interconnect with upstart independents in the early post-patent years of telephone competition in the US, and Faulhaber $(2002,2003)$ describes AOL's failure to interlink with rivals' instant messaging systems. Borenstein (2003) similarly argues that interline agreements between airlines, which let customers buy discount tickets with outbound and return on different airlines, help smaller airlines much more than larger ones; interlining has declined over time. Bresnahan (2003) describes how Word Perfect sought compatibility with the previously dominant WordStar, but then fought compatibility with its challengers.

Second is the un-differentiating effect. As in 3.7.3, when tipping is likely and size is (or expectations are) completely up for grabs, incompatibility can neutralize ordinary horizontal differentiation that would soften price competition in compatible competition. Even when it is less efficient, incompatible competition can then be sharper. But when tipping is unlikely, incompatibility can create horizontal differentiation (segment the market), as in switching-cost markets. ${ }^{179}$ Thus firms' incentives will depend on the likelihood of tipping and on whether expectations are largely exogenous or are symmetrically competed for. Real-world frictions, including switching costs, limit short-run shifts of customers (or expectations), and simple network models that understate such frictions will thus overestimate the strength of incompatible competition.

Third, if each side has proprietary complements that remain fixed independent of scale, and compatibility enables mix and match, duopoly models suggest that firms' private gains from compatibility exceed the social gains, but this is less clear with more than two firms (see section 2.8.4). We digress briefly here to discuss the relationship between these mix-and-match models and indirect network effects.

Indirect Network Effects and Mix-and-Match Both indirect network effects and the mix-and-match literature discussed in 2.8.4 above study modularity (mix-and-match) versus proprietary complements in a systems market, but the two literatures are surprisingly hard to relate; we note some key differences, but future research should develop a more unified understanding.

When more customers buy "hardware" of type $A$, the demand for $A$ compatible "software" increases, so there is more profit to be made from providing such software if entry does not dissipate that profit. The mixand-match literature, like the bundling literature (e.g. Nalebuff 2000), allows

how the leveling effect varies with the number of firms and with the form (e.g. Cournot vs Bertrand) of competition. It may be particularly unfortunate if large players resist compatibility, since they tend to be best at leading bandwagons.

${ }^{179}$ Augereau, Greenstein and Rysman (forthcoming) find that when ISPs chose between incompatible $56 \mathrm{kbps}$ modems, there was less compatibility than random choice would imply in each local market. They attribute this to ISPs' desire for horizontal differentiation, though it may have been more a switching-cost effect (consumers invested in modems) than a network effect. 
for this profit increase to be captured by the $A$-hardware provider through vertical integration. It then studies pricing and profits when this fact does not induce additional entry into A-compatible software.

In contrast, as we discussed in 3.1, the indirect network effect literature assumes that when more $A$-hardware is sold, the boost in $A$-software demand does induce additional (re-equilibrating) software entry, making $A$ 's hardware more attractive to customers and thus indirectly increasing hardware profits. But a boost in software profits is not part of this calculation, both because entry dissipates software profits and because most models assume there is no integration.

We also note that with indirect network effects, tipping at the hardware level increases software variety while reducing hardware variety. ${ }^{180}$

\subsubsection{Institutions and rules: Who chooses?}

If participants disagree on compatibility, who chooses? This question arises at several levels. We pose it primarily as a tussle among competing vendors with different preferences over how to compete. Another version of the question pits one vertical layer against another: often customers against vendors. A third version concerns the various means to achieve network benefits. Finally, there may be (as in television) compatibility domestically but not internationally.

i. Horizontal competitors Sometimes side payments can be made smoothly enough that the outcome is the one that maximizes joint profits. If side payments are fixed or one-shot, efficiency effects and the ferocity/softness of competition will drive the joint decision. And if firms can charge one another running royalties for compatibility, that may itself soften compatible competition. In telecommunications, interconnection (compatibility) is largely compulsory but charges for interconnection are common; Ennis (2002) shows that the curvature of the network-benefit function can determine equilibrium payments, while Hermalin and Katz (2005) show how efficient carrier-to-carrier pricing depends on demand elasticities. Brennan (1997) and Laffont, Rey and Tirole (1998a) ask whether competing firms can use such charges to support monopoly outcomes as noncooperative equilibria. Similar concerns may arise if firms agree to include one another's intellectual property in a consensus standard or a patent pool, as Gilbert (2002) stresses. ${ }^{181}$ But these strategems might be hard to distinguish in practice from side payments to encourage efficient compatibility.

\footnotetext{
${ }^{180}$ When indirect network effects are proprietary (mixing and matching is impossible), tipping at the hardware level tends to improve the match between customers' software tastes and the software varieties endogenously provided, by increasing the size of the winning hardware platform's market (though tipping worsens hardware matches).

${ }^{181}$ Firms might also sustain price collusion by threatening to withdraw cooperation on compatibility.
} 
In other cases firms choose how to compete noncooperatively without smooth side payments. As above, any firm wants to offer its customers bigger network benefits, and wants its rival's customers to get smaller network benefits. Thus each firm would like to offer a one-way converter that gives its customers the network benefits of compatibility with its rivals' customers; but would like to block converters in the other direction. ${ }^{182}$ In a noncooperative framework, then, if any firm can block such a one-way converter (e.g. through intellectual property or by secretly or frequently changing an interface), incompatibility results. But if any firm can unilaterally offer a one-way converter, compatibility results.

One can then study incentives for two-way compatibility by thinking of converters in the two directions as inseparably bundled. If both sides want compatibility, or if neither does, the question of who chooses is less prominent. If the firms disagree, incompatibility results if the firm who dislikes compatibility (typically the larger or expectations-dominant player) can prevent it, perhaps through intellectual property or through secrecy or frequent changes of interface. ${ }^{183}$ MacKie-Mason and Netz (2006) explore micro-analytics and institutions of such strategies. On the other hand, compatibility results if it is easier to imitate than to exclude, as Gabel (1991) argues it was for auto parts.

With more than two firms, compatible coalitions may compete against incompatible rivals. ${ }^{184}$ Extending Katz and Shapiro (1985), Cremer, Rey, and Tirole (2000) describe a dominant firm's incentive for targeted (at one smaller rival) degradation of interconnection even if it has no incentive for uniform degradation. But Malueg and Schwartz (forthcoming) observe that a commitment to compatible competition may attract users and deter degradation; Stahl (1982), Dudey (1990), and Schulz and Stahl (1996) similarly discuss incentives to locate near competitors. Cusumano et al. (1992) suggest that this was important in VHS's victory over Betamax.

ii. Vertical locus of compatibility choice Network benefits can result from choices at various vertical layers (see section 3.3.2). The efficiency effects may broadly be the same, but competitive effects may differ according to the vertical layer at which compatibility happens. Many consensus standards organizations bring together participants from multiple layers, though few true end users attend. The literature's focus on competing interests is a simplification of the web of interests that results. In particular, end users

\footnotetext{
${ }^{182}$ See Manenti and Somma (2002). Adams (1978) recounts how Gillette and others fought this battle of one-way converters in the razor/blade market.

183 Besen and Farrell (1994) analyze compatibility choice in these terms. Farrell and Saloner (1992) analyzed effects of two-way converters, and also found that converters can reduce static efficiency; Choi (1996b, 1997b) finds that converters can block the transition to a new technology. See also David and Bunn (1987), Kristiansen (1998), and Baake and Boom (2001).

${ }^{184}$ Axelrod et al. (1995), Economides and Flyer (1998), and Farrell and Shapiro (1993) also study coalitions in network markets with more than two players.
} 
often compete with one another less than do the vendors who sell to them, making it easier for end users than for vendors to agree on standards; but there are typically many end users, making it hard.

A value-chain layer with a single dominant provider may also be a relatively likely locus for standards. Thus for instance Intel has championed, even imposed, compatibility in some layers complementary to its dominant position. In favorable cases, a dominant firm has salutary incentives to influence complementary layers.

iii. Means to network benefits One way to achieve network benefits is that all the players at one vertical layer of a value chain-perhaps vendors, perhaps end users - decide to adopt the same design. That in turn can happen through various mechanisms of coordination, including consensus agreements and sequential bandwagons, but also including tradition, authority, or the use of sunspot-like focal points. Another path to network benefits is the use of converters or adapters, ${ }^{185}$ or the related multi-homing strategies such as learning a second language. ${ }^{186}$

iv. International Trade Just as firms might choose incompatibility for strategic advantage, so too may nations pursuing domestic (especially producers') benefits at the expense of foreigners'. As in strategic trade with economies of scale, one strategy conscripts domestic consumers as a protected base to strengthen domestic firms in international competition: incompatibility may be a tool to do so, and Crane (1979) argues that this was why governments imposed incompatible standards in color television. ${ }^{187}$ As with competing firms, Jensen and Thursby (1996) note that a country may prefer compatibility when its standard is behind, but will shift to preferring incompatibility if it wins. Gandal and Shy (2001) argue that countries will not choose standards autarky but may inefficiently form standardization unions that exclude some countries (as indeed happened in color TV). ${ }^{188}$

\footnotetext{
${ }^{185}$ See David and Bunn (1990), Farrell and Saloner (1992), and Choi (1994, 1997). Because converters affect competition between otherwise incompatible networks, they may be subsidized or provided by sponsors of networks or may be independently supplied. Because network transitions are not first-best, strange effects can occur: for instance Choi shows that they can retard a transition.

${ }^{186}$ See de Palma et al. Multi-homing is also discussed in the context of two-sided markets by Rochet and Tirole (2004).

${ }^{187}$ Farrell and Shapiro (1992), and Rohlfs (2001) discuss this in terms of network effects. Note also that US high-definition standards however contain many "options," which might threaten compatibility.

${ }^{188}$ Walz and Woeckener (2003) also find forces for inefficient incompatibility in trade policy. Kubota (1999) notes that transfer payments can make this less likely. Adams (1996), Choi, Lim and Yu (1999), Gandal (2002), Matutes and Regibeau (1996), and Klimenko (2003) also study trade policy with network effects.
} 


\subsection{Network Effects and Policy}

Economists disagree on the strength and efficiency of incompatible competition. In our judgment, this largely reflects different views on how well adopters coordinate in the presence of network effects. ${ }^{189}$

Optimists expect that adopters can find ways to coordinate on shifting to any better offer that might be available: bandwagon leadership, communication (including through standards organizations), and penetration pricing all help. In a static framework, such good coordination makes the market behave as if there were a single adopter. Relative to compatible competition, incompatible competition then sacrifices variety but neutralizes horizontal differentiation, sharpening competition (possibly even making it fiercer than compatible competition). In a dynamic framework adopters often invest in the standard they adopt, creating individual switching costs. These can interact with network effects to create large collective switching costs, but (as we saw in the simplest models of section 2) a switching-cost market may perform tolerably well, giving adopters up-front the quasi-rents that will later be gouged out of them. ${ }^{190}$ Thus in the optimists' view, competition for the market works well, both in a static framework and dynamically. ${ }^{191}$

Pessimists see coordination as more likely to fail, or to succeed only by tracking cues other than adopter surplus, notably history. That implies several layers of pessimism about markets with proprietary network effects. First, both splintering and coordination on the "wrong" standard are possible, so that adopters collectively may fail to take the best deal offered. Second, because offering better deals is thus unreliable as a way to win the market, sponsors focus more on attracting expectations in other ways and on arranging to extract more rent if they do win - so sponsors offer less good deals. Third, if expectations track history rather than surplus, collective switching costs come to include the value of network effects, cementing us into what can be badly outdated (or just bad) standards.

Fourth, the strong competitive advantage conferred on a firm that attracts adopters' expectations opens up new avenues for mischief. Exclusive dealing may be especially problematic (see Shapiro 1999), and product preannouncements by incumbents can block efficient entrants' "narrow windows"

\footnotetext{
${ }^{189}$ Pessimists include David (1985) and Arthur (e.g., 1989) who contend long-run technology choice is inefficiently driven by accidental short-run small events. Liebowitz and Margolis (e.g., 1994, 1998a,b) are famously optimistic. Between these extremes, Bresnahan (2003) suggests that in the computer industry long periods of lock-in are punctuated by occasional "epochs" of competition for the market when barriers due to network effects and switching costs are much lower than usual because of a shift of the incumbent's standard or a strong independent complement.

${ }^{190}$ With individual switching costs, this broadly applies to each adopter. With network effects and collective switching costs, the up-front bargains are targeted on pivotal (typically early) adopters; other adopters may only experience the later rip-offs.

${ }^{191}$ Demsetz (1968) is often cited on competition for the market, although the idea goes back to Chadwick (1859). Contestability (Baumol, Panzar and Willig (1988)) is closely related.
} 
of opportunity. There is more than usual scope for predation if, as seems likely, expectations tend to center on the products of a powerful incumbent firm, because achieving the status of dominant incumbent will be especially profitable (making recoupment more likely, for instance) even after a more efficient rival attempts (re-)entry. And (whether or not incompatible entry would be efficient) the difficulty of entry, especially gradual or small-scale entry, sharpens other competitive concerns. For instance, a merger among incumbents who would jointly control an established standard may do more harm than a similar merger if entrants could be compatible. ${ }^{192}$

If proprietary network effects coupled with imperfect coordination creates competitive problems, might those problems be addressed directly? Of course, but doing so effectively is very hard because the dynamics of markets with proprietary network effects are complex. For example, recognizing that product preannouncements can be anticompetitive in such a market does not point to any reliably helpful policy interventions; banning or controlling product preannouncement is obviously problematic. ${ }^{193}$ Likewise, conventional anti-predation policy starts from a suspicion of below-cost pricing; but in network industries below-cost pricing early on or to pivotal adopters is a big part of incompatible competition, just as with individual switching costs. Thus, addressing the problems directly is probably not enough.

Still taking as given that there will be incompatible competition, a more promising approach probably is to help adopters coordinate better. Information policy (helping adopters know what they're choosing), or contract policy (enforcing sponsors' promises) may help; because of the externalities among adopters, private incentives to research alternatives or to extract and enforce promises may well be too low. ${ }^{194}$ Sensibly, policy generally seems recently to be moving to protect standard-setting organizations' ability to help focus adopters' expectations. In particular, these organizations have been lamentably spooked by fear of antitrust complaints (notably for taking account of the pricing of patent licenses), and we applaud policies to assuage that fear and to help them protect themselves against patent "trolls" whose patents have inadvertently been written into consensus standards. ${ }^{195}$

\footnotetext{
${ }^{192}$ Robinson (1998) describes concerns that the MCI-Worldcom combination would have so large a share in the internet backbone market that it might profitably deny efficient interconnection. Cremer et al (2000), Dewatripont and Legros (2000), Ennis (2002), and Malueg and Schwartz (forthcoming) discuss the economics of this concern.

${ }^{193}$ Farrell and Saloner (1986) and Haan (2003) explore the anticompetitive potential of preannouncements or vaporware; Dranove and Gandal (2003) found preannouncement had a significant effect in DVDs. Fisher (1991) and others have stressed the difficulty of crafting good policies to address this concern.

${ }^{194}$ Large, forward-looking buyers can also take into account the effects of their purchases on future market power. For example, government procurement might sensibly eschew offers by sponsors of proprietary networks (e.g. Microsoft) that are more attractive in the short run (e.g., cheaper, or come with free training) than competing open networks (e.g. based on Linux) if the latter would benefit future competition.

${ }^{195}$ Since much of the harm from hold-up is borne downstream, standards organizations have insufficiently strong incentives to avoid these problems (e.g. by requiring disclosure in
} 
But we think that even with such policies adopters will often not coordinate well enough to make incompatible competition work efficiently. So the best policy may be to encourage compatibility and compatible competition. This conclusion is reinforced by the fact that - in large part because of the problems above - the incentives of firms, especially dominant firms, are often biased towards incompatibility. ${ }^{196}$ Denial of compatibility is profitable if this allows a firm to retain adopters' expectations and remove them from rivals.

Sometimes government should mandate a standard to ensure compatibility, just as other organisations often impose internal compatibility (indeed firms enforce internal compatibility by fiat more often than governments), and so avoid splintering or confusion or inefficient variety. Most nations do this in broadcasting, all insist that everyone drive on the same side of the road, ${ }^{197}$ and many mandate mobile phone standards. But government should not always seek rapid standardization when the merits of competing standards are unclear. Considerations akin to biodiversity can suggest prolonging rather than cutting short market experimentation; the case for mandated standardization is strongest when technological progress is unlikely (as with weights and measures standards, which side of the road to drive on, or currency). ${ }^{198}$ Moreover, government may be inexpert, and standards may need to evolve, and (partly as a result) compliance may not be clear. So governments wisely, we think, seldom intervene to displace an established standard because it was thought inefficient. (And when they do change a standard it is typically to replace a previously mandated standard - as with weights and measures, driving-sides, and currencies - rather than to secondguess a previous market choice.)

advance and "reasonable and non-discriminatory" (RAND) licensing). For similar reasons there can be an incentive for firms to agree to charge one another running royalties for compatibility, perhaps by agreeing to incorporate one another's intellectual property in a standard: see Gilbert (2002) and Laffont, Rey and Tirole (1998a,b).

${ }^{196}$ When network effects are indirect, compatibility is part of the broader question of vertical openness: if A wants to complement B, can B say no, or set terms such as exclusivity? The "one monopoly rent theorem" that suggests B will choose an efficient policy (because having better complements makes its product more appealing) can fail for a range of reasons (such as price discrimination, see e.g., Farrell and Weiser 2003), even absent network effects. But with indirect network effects, vertical integration creates particular concerns if independent complementors can be important potential entrants, as Bresnahan and Greenstein (1999) argue in the computer industry (the trial court in the US Microsoft case echoed this logic with its proposed remedy of breaking up Microsoft into an operating system company and one that would initially sell applications, though the appeals court overturned this).

${ }^{197}$ Failure to say which side of the road people should drive would induce confusion (see 3.4 above), and saying "drive on the right" without enforcement leads to inefficient variety (those drivers that buck the norm may take account of their own sacrifice of compatibility benefits, but they also spoil those benefits for others).

Besen and Johnson (1986) argue that government failure to set a standard in AM stereo led to splintering.

${ }^{198}$ Cabral and Kretschmer (2006) find that in Arthur's (1989) model it is ambiguous whether policy should retard or accelerate lock-in. 
We are therefore most enthusiastic about facilitating, rather than directly requiring, compatibility. Standards organisations help when all want to coordinate, but when powerful players resist compatibility we are sympathetic to policies that give more power to complementors and competitors who want compatibility, in the analysis of 3.8. Thus telecommunications policy gives competitors the right of interconnection on regulated terms, and the EU and increasingly the US have done this for computer software. ${ }^{199}$ Firms often enforce incompatibility through intellectual property that may have little or no inherent innovative value; in such cases, we favor a right to achieve compatibility despite the intellectual property.

How do these lessons and views relate to those we suggested for switchingcost markets in 2.9 above? In antitrust terms, incompatible competition with network effects tends to increase the risks of exclusion, whereas incompatible competition with switching costs is more apt to soften competition. But in both cases we emerge with a cautious preference for compatible competition, which often has direct efficiency benefits and is apt to be more competitive. Firms' own incentives somewhat align with direct efficiency effects but (especially for dominant firms) often include competitive effects with the "wrong sign." Thus one might especially suspect that firms have picked incompatibility inefficiently if compatibility would be low-cost or would even save costs directly, or if a firm imposes incompatibility while its rivals seek compatibility.

\section{Conclusion}

Switching costs and network effects create fascinating market dynamics and strategic opportunities. They link trades that are not readily controlled by the same contract: future trades in the case of switching costs, and trades between the seller and other buyers in the case of network effects. We have stressed that the result can be efficient competition for larger units of business - "competition for the market". Thus neither switching costs nor network effects are inherently and necessarily problematic. But they very often make competition, perhaps especially entry, less effective. So we favor cautiously pro-compatibility public policy. And policymakers should look particularly carefully at markets where incompatibility is strategically chosen rather than inevitable.

\footnotetext{
${ }^{199}$ See Lemley and McGowan (1998a), Menell (2002), and Samuelson and Scotchmer (2002). But Llobet and Manove (2006) argue that because incumbents may build smaller networks if entrants can share them, R\&D subsidies are better policy than compatibility rights. Kristiansen and Thum (1997) stress that network size is a public good in compatible competition.
} 


\section{References}

Abreu, D. (1988), "On the theory of infinitely repeated games with discounting", Econometrica, 56:383-396.

Acquisti, A. and H. Varian (2005), "Conditioning prices on purchase history", Marketing Science 24:367-381.

Adams, M. (1996) "Norms, standards, rights", European Journal of Political Economy, 12:363-375.

Adams, R.B. (1978), C.K. Gillette: The Man and his Wonderful Shaving Device, (Little, Brown \& Co., Boston).

Aghion, P. and P. Bolton (1987), "Contracts as a barrier to entry", American Economic Review 77:388-401.

Agliardi, E. (1991a), "Competing technologies and lock-in by random events", University of Cambridge Economic Theory Discussion Paper, 160.

Agliardi, E. (1991b), "Technology adoption and the optimal rate of obsolescence", Cambridge - Risk, Information and Quantity Signals, \# 162.

Agliardi, E. (1998), Positive Feedback Economies (St. Martin's Press, New York).

Agliardi, E. and M. Bebbington (1994), "Self-reinforcing mechanisms and interactive behavior", Economics Letters 46:281-287.

Agliardi, E. and M. Bebbington (1997), "Self-reinforcing mechanisms and market information", European Journal of Operational Research 96:444-454.

Ahdieh, R.B. (2003), "Making markets: network effects and the role of law in the creation and restructuring of securities markets", Southern California Law Review 76:277-350.

Ahtiala, P. (1998), "The optimal pricing of computer software and other products with high switching costs", Working Paper, University of Tampere.

Anderson, E.T., N. Kumar and S. Rajiv (2004), "A comment on: revisiting dynamic duopoly with consumer switching costs", Journal of Economic Theory 116:177-186.

Anderson, S.P. and L. Leruth (1993), "Why firms may prefer not to price discriminate via mixed bundling", International Journal of Industrial Organization 11:49-61. 
Anton, J.J. and D.A. Yao (1995), "Standard-setting consortia, antitrust and hightechnology industries", Antitrust Law Journal 64:247-265.

Aoki, R. and J. Small (2000), "The economics of number portability: switching costs and two part tariffs", in: Marching into the New Millenium: Economic Globalization Conference Proceedings, June 3-4, Tamkank University.

Arbatskaya, M. (2000), "Behaviour-based price discrimination and consumer switching", in: M.R. Baye, ed., Industrial Organization, vol. 9 of Advances in Applied Microeconomics (JAI Press, New York) 149-171.

Armstrong, M. (forthcoming), "Competition in two-sided markets", Rand Journal of Economics

Arthur, W.B. (1988), "Competing technologies", in: G. Dosi, C. Freeman and G. Silverberg, eds., Technical Change and Economic Theory (Pinter London) 590-607.

Arthur, W.B. (1989), "Competing technologies, increasing returns, and lock-in by historical events", Economic Journal 99:116-131.

Arthur, W.B. (1990), "Positive feedbacks in the economy", Scientific American February:92-99.

Arthur, W.B. and D.A. Lane (1993), "Information contagion", Economic and Dynamics and Structural Change 4:81-104.

Arthur, W.B. and A. Rusczcynski. (1992), "Dynamic equilibria in markets with a conformity effect", Archives of Control Sciences 37:7-31.

Asvanund, A., K. Clay, R. Krishnan and M. Smith (2004), "An empirical analysis of network externalities in peer-to-peer music sharing networks", Information Systems Research 15:155-174.

Augereau, A., S. Greenstein, and M. Rysman (forthcoming), "Coordination vs. Differentiation in a Standards War: 56K Modems" RAND Journal of Economics.

Ausubel, L. (1991), "The failure of competition in the credit card market", American Economic Review 81:50-81.

Baake, P. and A. Boom. (2001), "Vertical product differentiation, network externalities, and compatibility decisions", International Journal of Industrial Organization 19:267-284. 
Bagwell, K. (forthcoming) "CHAPTER TITLE", in: M. Armstrong and R. Porter, eds., Handbook of Industrial Organization, vol. 3. xx-xx

Bagwell, K. and G. Ramey. (1994), "Coordination economies, advertising and search behavior in retail markets", American Economic Review 84:498-517.

Banerjee, A. (1992), "A simple model of herd behavior", Quarterly Journal of Economics 107:797-817.

Banerjee, A. and L.H. Summers (1987), "On frequent-flyer programs and other loyalty-inducing economic arrangements", Harvard University Working Paper.

Barnett, A.H. and D.L. Kaserman (1998), "The simple welfare economics of network externalities and the uneasy case for subscribership subsidies", Journal of Regulatory Economics 13:245-254.

Basu, K. (1993), "Switching Costs and Rural Credit", in: Lectures in Industrial Organization Theory (Blackwells, Oxford) 202-204.

Basu, K. and C. Bell. (1991) "Fragmented duopoly: theory and applications to backward agriculture", Journal of Development Economics 36:145-165.

Baye, M.R., D. Kovenock and C.G. de Vries (1992), "It takes two to tango: equilibria in a model of sales", Games and Economic Behavior 4:493-510.

Beggs, A. (1989), "A note on switching costs and technology choice", Journal of Industrial Economics 37:437-440.

Beggs, A. and P.D. Klemperer (1989), "Multiperiod competition with switching costs", Discussion Paper 45, Nuffield College, Oxford University.

Beggs, A. and P.D. Klemperer (1992), "Multiperiod competition with switching costs", Econometrica 60:651-666.

Beige, O. (2001), "The Structure of Coordination: Three Essays on Network Externalities, Expert Influence and Party-line Voting", Ph.D. Dissertation, Haas School of Business, University of California, Berkeley.

Belleflamme, P. (1998), "Adoption of network technologies in oligopolies", International Journal of Industrial Organization 16:415-444.

Bensaid, B. and J.P. Lesne (1996), "Dynamic monopoly pricing with network externalities", International Journal of Industrial Organization 14:837-855. 
Bental, B. and M. Spiegel (1995), "Network competition, product quality, and market coverage in the presence of network externalities", Journal of Industrial Economics 43:197-208.

Berg, J.L. and H. Schumny (1990), An Analysis of the Information Technology Standardization Process: Proceedings (Elsevier Science, Amsterdam).

Berndt, E., R. Pindyck and P. Azoulay (2003) "Consumption externalities and diffusion in pharmaceutical markets: antiulcer drugs", Journal of Industrial Economics 51:243-270.

Bernheim, D. and M. Whinston (1987), "Coalition-proof Nash equilibria," Journal of Economic Theory 42:1-12.

Besen, S.M. and J. Farrell (1991), "The role of the ITU in standardization: preeminence, impotence or rubber stamp?", Telecommunications Policy 15:311321.

Besen, S.M. and J. Farrell. (1994), "Choosing How to Compete: Strategies and Tactics in Standardization", Journal of Economic Perspectives 8:117-131.

Besen, S. and L. Johnson. (1986), "Compatibility standards, competition, and innovation in the broadcasting industry", Rand Report, \#R-3453-NSF, November.

Besen, S. and G. Saloner (1989), "The economics of telecommunications standards," in R.W. Crandall and K. Flamm, eds., Changing the Rules: Technological Change, International Competition, and Regulations in Communications (Brookings Institution, Washington DC) 177-220.

Besen, S. and G. Saloner (1994), "Compatibility standards and the market for telecommunications services", in A. Thomas and M. Morton, eds., Research Studies. Information Technology and the Corporation of the 1930s (Oxford University Press, Oxford) 149-183.

Biglaiser, G., J. Crémer and G. Dobos (2003), "You won’t get rich on switching costs alone", Working Paper, Universities of North Carolina and Toulouse, November.

Bikchandani, S., D. Hirshleifer and I. Welch. (1992), "A theory of fads, fashion, custom, and cultural change in informational cascades", Journal of Political Economy 100:992-1026. 
Bolton, P. and J. Farrell (1990), "Decentralization, duplication, and delay", Journal of Political Economy 98:803-826.

Bonaccorsi, A. and C. Rossi (2002), "The adoption of business to business ecommerce: heterogeneity and network externality effects", LEM Working Paper, May.

Borenstein, S. (2003), "Inter-lining and competition in the US airline industry", Working Paper, University of California, Berkeley.

Borenstein, S., J.K. MacKie-Mason and J.S. Netz (1995), "Antitrust policy in aftermarkets", Antitrust Law Journal 63:455-482.

Borenstein, S., J.K. Mackie-Mason and J.S. Netz (2000), "Exercising market power in proprietary aftermarkets", Journal of Economics and Management Strategy 9:157-188.

Bouckaert, J. and H. Degryse (2004), "Softening competition by inducing switching in credit markets", Journal of Industrial Economics 52:27-52.

Brehm, J.W. (1956), "Post-decision changes in the desirability of alternatives", Journal of Abnormal and Social Psychology 52:384-389.

Brennan, T. (1997), "Industry parallel interconnection agreements", Information Economics and Policy 9:133-149.

Bresnahan, T. (2001a), "The economics of the Microsoft case", Working Paper, Stanford University, Department of Economics.

Bresnahan, T. (2001b), "Network effects and Microsoft", Working Paper, Stanford University, Department of Economics.

Breuhan, A. (1997), "Innovation and the persistence of technical lock-in", PhD Dissertation, Stanford University.

Brock, G.W. (1981), The Telecommunications Industry: The Dynamics of Market Structure (Harvard University Press, Cambridge).

Bryant, J. (1994), "Coordination Theory, the Stag Hunt, and Macroeconomics", in: J.W. Friedman, ed., Problems of Coordination in Economic Activity (Kluwer Academic Publishers, Boston).

Brynjolfsson, E. and C. Kemerer (1996), "Network externalities in microcomputer software: an econometric analysis of the spreadsheet market", Management Science 42:1627-1647. 
Budd, C., C. Harris and J. Vickers (1993), "A model of the evolution of duopoly: does the asymmetry between firms tend to increase or decrease?", Review of Economic Studies 60:543-753.

Bulow, J., J. Geanakoplos and P.D. Klemperer (1985a), "Multimarket oligopoly: strategic substitutes and complements", Journal of Political Economy 93:488511.

Bulow, J., J. Geanakoplos and P.D. Klemperer (1985b), "Holding idle capacity to deter entry", Economic Journal 95:178-182.

Bulow, J. and P.D. Klemperer (1998), "The tobacco deal", Brookings Papers on Economic Activity: Microeconomics 323-394.

Bulow, J. and P.D. Klemperer (1999), "The generalized war of attrition", American Economic Review 89:175-189.

Cabral, L. and T. Kretschmer (forthcoming), "Standards battles and public policy", forthcoming in S.Greenstein and V. Stango, eds., Standards and Public Policy, Cambridge University Press

Cabral, L. and S. Greenstein (1990), "Switching costs and bidding parity in government procurement of computer systems", Journal of Law, Economics, and Organization 6:463-469.

Cabral, L.M.B. and M.H. Riordan (1997), "The learning curve, predation, antitrust, and welfare", Journal of Industrial Economics 45:155-69.

Cabral, L.M.B., D.J. Salant and G.A. Woroch (1999), "Monopoly pricing with network externalities", International Journal of Industrial Organization, 17:199214.

Calem, P. and L. Mester (1995), "Consumer behavior and the stickiness of creditcard interest ates", American Economic Review 85:1327-1336.

Caminal, R. and C. Matutes (1990), "Endogenous switching costs in a duopoly model", International Journal of Industrial Organization 8:353-374.

Campello, M., (2003), "Capital structure and product markets interactions: evidence from business cycles", Journal of Financial Economics 68:353-378.

Campello, M. and Z. Fluck (2004), "Product market: performance, switching costs, and liquidation values: the real effects of financial leverage", Working Paper University of Illinois and Michigan State University. 
Cargill, C.F. (1989), Information Technology Standardization, (Digital Press, Bedford, MA).

Carlsson, F. and A. Löfgren (2004), "Airline choice, switching costs and frequent flyer programs", Working Paper, Gothenburg University, January.

Carlton, D.W., W.M. Landes and R.A. Posner (1980), "Benefits and costs of airline mergers: a case study", Bell Journal of Economics 80:65-83.

Carter, M. and J. Wright (1999) "Interconnection in network industries", Review of Industrial Organization 14:1-25.

Cason, T.N. and D. Friedman (2002), "A laboratory study of customer markets", Advances in Economic Analysis and Policy 2:Article 1 http://www.bepress.com/bejeap/advances/vol2/iss1/art1.

Cason, T.N., D. Friedman and G.H. Milam (2003), "Bargaining versus posted price competition in customer markets", International Journal of Industrial Organization 21:223-251.

Chadwick, E. (1859), "Results of different principles of legislation and administration in Europe; of competition for the field, as compared with competition within the field, of service", Journal of the Statistical Society of London 22:381-420.

Chen, P.-Y. (2005), "Information technology and switching costs", Preliminary Draft for Chapter in: Handbook on Economics and Information Systems (Elsevier, Amsterdam).

Chen, Y. (1997), "Paying customers to switch", Journal of Economics and Management Strategy 6:877-897.

Chen, Y. and R.W. Rosenthal (1996), "Dynamic duopoly with slowly changing customer loyalties", International Journal of Industrial Organisation 14:269296.

Chen, P-Y. and L. Hitt (2002), "Measuring switching costs and their determinants in internet enabled businesses: a study of the on-line brokerage industry", Information Systems Research 13:255-274.

Chevalier, J. and D. Scharfstein (1996), "Capital-market imperfections and countercyclical markups: theory and evidence", American Economic Review 86:703725 . 
Choi, J.P. (1994a), "Network externality, compatibility choice, and planned obsolescence", Journal of Industrial Economics 42:167-182.

Choi, J.P. (1994b), "Irreversible choice of uncertain technologies with network externalities", RAND Journal of Economics 25:382-401.

Choi, J.P. (1996a), "Pre-emptive R\&D, rent dissipation, and the leverage theory", Quarterly Journal of Economics 111:1153-1181.

Choi, J.P. (1996b), "Do converters facilitate the transition to a new incompatible technology - a dynamic analysis of converters", International Journal of Industrial Organization 14:825-835.

Choi, J.P. (1997a), "Herd behavior, the penguin effect, and the suppression of informal diffusion: an analysis of informational externalities and payoff interdependency", RAND Journal of Economics 28:407-425.

Choi, J.P. (1997b), "The provision of (two-way) converters in the transition process to a new incompatible technology", Journal of Industrial Economics 45:167-182.

Choi, J.P. and M. Thum (1998), "Market structure and the timing of technology adoption with network externalities", European Economic Review 42:225244.

Choi, S.C., K.S. Lim and P.I. Yu (1999), "Strategic joint ventures with developing country in battles for technical standards", Japan and the World Economy 11:135-149.

Chou, C.F. and O. Shy (1990), "Network effects without network externalities" International Journal of Industrial Organization 8:259-270.

Chow, G.C. (1995), "Multiperiod competition with switching costs: solution by Lagrange multipliers", Journal of Economic Dynamics and Control 19:51-57.

Church, J. and N. Gandal (1992), "Network effects, software provision, and standardization" Journal of Industrial Economics 40:85-103.

Church, J. and N. Gandal (1993), "Complementary network externalities and technological adoption", International Journal of Industrial Organization 11:239-260.

Church, J., N. Gandal and D. Krause (2002), "Indirect network effects and adoption externalities", Foerder Institute for Economic Research Working Paper 02-30. 
Church, J., and I. King (1993), "Bilingualism and network externalities", Canadian Journal of Economics 26:337-345.

Clements, M. (2004), "Direct and indirect network effects are they equivalent?", International Journal of Industrial Organisation 22:633-645.

Clements, M.T. and H. Ohashi (2005), "Indirect network effects and the product cycle, video games in the U.S., 1994-2002", Journal of Industrial Economics $53: 515-542$.

Cohen, A. (2005), "Asymmetric Information and Learning: Evidence from the Automobile Insurance Market", Review of Economics and Statistics 87:197207.

Cooper, R.W. (1999), Coordination Games: Complementarities and Macroeconomics (Cambridge University Press, Cambridge, MA).

Cooper, R. and A. John (1988), "Coordinating coordination failures in Keynesian models" Quarterly Journal of Economics 103:441-463.

Crane, R.J. (1979). The Politics of International Standards: France and the Color T.V. War (Norwood, New Jersey).

Crawford, V.P. (1995), "Adaptive Dynamics in Coordination Games", Econometrica 63:103-143.

Crawford, V.P. and J. Sobel (1982), "Strategic information transmission", Econometrica 50:1431-1451.

Crémer, J. (2000), "Network Externalities and Universal Service Obligation in the Internet", European Economic Review 44:1021-1031.

Crémer, J., P. Rey, and J. Tirole (2000), "Connectivity in the Commercial Internet", Journal of Industrial Economics 48:433-472.

Cusumano, M.A., Y. Mylonadis and R.S. Rosenbloom (1992), "Strategic Maneuvering and Mass Market Dynamics: The Triumph of VHS over Beta", Business History Review 66:51-94.

David, P. (1985), "Clio and the Economics of QWERTY", American Economic Review 75:332-337.

David, P. (1986), "Narrow Windows, Blind Giants and Angry Orphans: The Dynamics of Systems Rivalries and Dilemmas of Technology Policy", CEPR 
Paper \#10, Stanford University, March.

David, P. and J.A. Bunn (1987), "The economics of gateway technologies and network evolution: lessons from electricity supply history", Information Economics and Policy 3:165-202.

David, P. and H. Monroe (1994), "Standards development strategies under incomplete information", Mimeo.

David, P. and M. Shurmer (1996), "Formal standards-setting for global telecommunications and information services towards an institutional regime transformation?", Telecommunications Policy 20:789-815.

Davis, D.R., and D.E. Weinstein (2002), "Bones, bombs and breakpoints: the geography of economic activity", American Economic Review 92:1269-1289.

Demsetz, H. (1968), "Why regulate utilities?", Journal of Law and Economics 12:229-239.

Deneckere, R., D. Kovenock and R. Lee (1992), "Model of price leadership based on consumer loyalty", Journal of Industrial Economics 41:147-156.

DeNicolo, V. (2000), "Compatibility and bundling with generalist and specialist firms", Journal of Industrial Economics 48:177-188.

de Palma, A. and L. Leruth (1996), "Variable willingness to pay for network externalities with strategic standardization decisions", European Journal of Political Economy 12:235-251.

Dewatripont, M. and P. Legros (2000), "Mergers in emerging markets with network externalities: the case of telecoms", Wissenschaftszentrum Berlin: CIC Working Paper, \#FS IV 00-23.

Diamond, P.A. (1982), "Aggregate demand management in search equilibrium", Journal of Political Economy 90:881-894.

Diamond, P. and E. Maskin (1979), "An equilibrium analysis of search and breach of contract I: steady states", Bell Journal of Economics 10:282-316.

Dixit, A.K. and C. Shapiro (1986), "Entry dynamics with mixed strategies," in: L.G. Thomas, ed., The Economics of Strategic Planning: Essays in Honor of Joel Dean, (Heath, Lexington Books, Lexington, Massachussetts and Toronto) 63-79.

Dixit, A.K. and J. Stiglitz (1977), "Monopolistic competition and optimum prod- 
uct diversity", American Economic Review 67:297-308.

Domowitz, I. and B. Steil. (1999), "Automation, trading costs, and the structure of the securities trading industry", Brookings-Wharton Papers on Financial Services 2:33-92.

Doganoglu, T. (2004), "Switching costs, experience goods and dynamic price competition", Working Paper, University of Munich, April.

Doganoglu, T. and L. Grzybowski (2004), "Dynamic duopoly competition with switching costs and network externalities", Working Paper, University of $\mathrm{Mu}$ nich, January.

Dosi, G., Y. Ermoliev and Y. Kaniovski (1994), "Generalized urn schemes and technological dynamics", Journal of Mathematical Economics 23:1-19.

Dranove, D. and N. Gandal (2003), "The DVD vs. DIVX standard war: network effects and empirical evidence of preannouncement effects", Journal of Economics and Management Strategy 12:363-386.

Dranove, D. and W.D. White (1996), "Specialization, option demand, and the pricing of medical specialists", Journal of Economics and Management Strategy 5:277-306.

Dudey, M. (1990), "Competition by choice: the effect of consumer search on firm location decisions", American Economic Review 80:1092-1104.

Dybvig, P.H. and C.S. Spatt (1983), "Adoption externalities as public goods", Journal of Public Economics 20:231-247.

Eber, N. (1999), "Switching costs and implicit contracts", Journal of Economics (Zeitschrift-fur-Nationalokonomie) 69:159-171.

Echenique, F. and E. Edlin (2004), "Mixed equilibria in games of strategic complements are unstable", Journal of Economic Theory 118:61-79.

Economides, N. (1989), "Desirability of compatibility in the absence of network externalities", American Economic Review 79:1165-1181.

Economides, N. (1996a), "The economics of networks", International Journal of Industrial Organization 14:673-699.

Economides, N. (1996b), "Network externalities, complementarities, and invitations to enter", European Journal of Political Economy 12:211-233. 
Economides, N. and F. Flyer (1995), "Technical standards coalition for network goods", New York University Salomon Brothers Working Papers.

Economides, N. and F. Flyer (1998), "Equilibrium coalition structures in markets for network goods", Annales d'Economie et de Statistique 49/50:361-380.

Economides, N. and C. Himmelberg (1995), "Critical mass and network evolution in telecommunications", in: G.W. Brock, ed., Toward a Competitive Telecommunications Industry: Selected Papers from the 1994 Telecommunications Policy Research Conference, (Lawrence Erlbaum Associates Manwah, NJ).

Economides, N. and A. Siow (1988), "The division of markets is limited by the extent of liquidity (spatial competition with externalities)", American Economic Review 78:108-121.

Economides, N. and L.J. White (1994), "Networks and compatibility: implications for antitrust", European Economic Review 38:651-662.

Edlin, A. (2002), "Stopping above-cost predatory pricing", Yale Law Journal 111:941-991.

Einhorn, M.A. (1992), "Mix and match compatibility with vertical product dimensions", RAND Journal of Economics 23:535-547.

Einhorn, M.A. (1993), "Biases in optimal pricing with network externalities", Review of Industrial Organization 8:741-746.

Ellison, G. (2005), "A model of add-on pricing", Quarterly Journal of Economics 120:585-637.

Ellison, G. and D. Fudenberg (1993), "Rules of thumb and social learning", Journal of Political Economy 101:612-643.

Ellison, G. and D. Fudenberg (1995), "Word-of-mouth communication and social learning", Quarterly Journal of Economics 110:93-125.

Ellison, G. and D. Fudenberg (2000) "The Neo-Luddite's lament: excessive upgrades in the software industry", RAND Journal of Economics 31:253-272.

Ellison, G. and D. Fudenberg (2003), "Knife-edge or plateau: when do market models tip?", Quarterly Journal of Economics 118:1249-1278.

Ellison, G., D. Fudenberg and M. Möbius (2004) "Competing auctions", Journal of the European Economic Association 2:30-66. 
Elzinga, G. and D. Mills. (1998), "Switching costs in the wholesale distribution of cigarettes", Southern Economic Journal 65:282-293.

Elzinga, G. and D. Mills (1999), "Price wars triggered by entry", International Journal of Industrial Organisation 17:179-198.

Ennis, S. (2002), "Network connection and disconnection", U.S. Department of Justice Working Paper, \#02-5.

Evans, D., F.M. Fisher, D.L. Rubinfeld and R.L. Schmalensee (2000) "Did Microsoft harm consumers? - two opposing views", AEI-Brookings Joint Center for Regulatory Studies.

Evans, D. and R. Schmalensee (2001), "Some economic aspects of antitrust analysis in dynamically competitive industries", NBER Working Paper, \#W8268.

Farrell, J. (1986a), "A note on inertia in market share", Economics Letters 21:7375 .

Farrell, J. (1986b), "Moral hazard as an entry barrier", RAND Journal of Economics 17:440-449.

Farrell, J. (1987), "Cheap talk, coordination and entry", RAND Journal of Economics 18:34-39.

Farrell, J. (1989), "Communication, coordination and Nash equilibrium", Economics Letters 27:209-214.

Farrell, J. (1993), "Choosing the rules for formal standardization", Working Paper, University of California, Berkeley, Department of Economics.

Farrell, J. (1995), "Talk is cheap", American Economic Review 85:186-190.

Farrell, J. (1997), "Prospects for deregulation in telecommunications", Industrial and Corporate Change 6:719-740.

Farrell, J. (1998), "Cheap talk and coordination", in: P. Newman, ed., The New Palgrave Dictionary of Economics and the Law (McMillan, London) 224-227.

Farrell, J. (2006) "Efficiency and competition between payment instruments," Review of Network Economics 5:19-44.

Farrell, J. and N.T. Gallini (1988), "Second-sourcing as a commitment: monopoly incentives to attract competition", Quarterly Journal of Economics 103:673- 
694.

Farrell, J. and M.L. Katz (1998), "The effects of antitrust and intellectual property law on compatibility and innovation", Antitrust Bulletin 43:609-650.

Farrell, J. and M.L. Katz (2000), "Innovation, rent extraction, and integration in systems markets", Journal of Industrial Economics 48:413-432

Farrell, J. and M.L. Katz (2005), "Competition or predation? Consumer coordination, strategic pricing, and price floors in network markets," Journal of Industrial Economics 53:203-232.

Farrell, J., H.K. Monroe and G. Saloner (1998), "The vertical organization of industry: system competition versus component competition", Journal of Economics and Management Strategy 7:143-182.

Farrell, J. and M. Rabin (1996), "Cheap talk", Journal of Economic Perspectives 10:103-118.

Farrell, J. and G. Saloner (1985), "Standardization, compatibility and innovation" RAND Journal of Economics 16:70-83.

Farrell, J. and G. Saloner (1986a), "Installed base and compatibility: innovation, product preannouncements, and predation", American Economic Review 76:940-955.

Farrell, J. and G. Saloner (1986b), "Standardization and variety", Economics Letters 20:71-74.

Farrell, J. and G. Saloner (1988), "Coordination through committees and markets", RAND Journal of Economics 19:235-252.

Farrell, J. and G. Saloner (1992), "Converters, compatibility, and the control of interfaces", Journal of Industrial Economics 40:9-35.

Farrell, J. and C. Shapiro (1988), "Dynamic competition with switching costs", RAND Journal of Economics 19:123-137.

Farrell, J. and C. Shapiro (1989), "Optimal contracts with lock-in", American Economic Review 79:51-68.

Farrell, J. and C. Shapiro (1992), "Standard setting in high-definition television", Brookings Papers on Economic Activity, Microeconomics 0:1-77.

Farrell, J. and C. Shapiro (1993), "The dynamics of bandwagons", in: J.W. Fried- 
man, ed., Problems of Coordination in Economic Activity (Kluwer Academic Publishers, Boston) 149-184.

Farrell, J. and P. Weiser (2003), "Modularity, vertical integration, and open access policies: towards a convergence of antitrust and regulation in the internet age", Harvard Journal of Law and Technology 17:85-135.

Farrell, J. and G.A. Woroch (1995), "Brief amicus curiae", U.S. Supreme Court in Lotus v. Borland.

Faulhaber, G. (2002), "Network effects and merger analysis: instant messaging and the AOL-Time Warner case", Telecommunications Policy 26:311-333.

Federal Trade Commission (2000), "Entering the 21st century: competition policy in the world of B2B electronic marketplaces: a report", Washington, DC: The Commission.

Ferguson, C. and C. Morris (1993), "Computer wars: how the west can win in a post-IBM world", (Times Books, New York).

Fernandes, P. (2001) "Essays on customer loyalty and on the competitive effects of frequent-flyer programmes", European University Institute, Ph.D. Thesis.

Fisher, F.M. (1991), "Organizing industrial organization: reflections on the handbook of industrial organization", Brookings Papers on Economic Activity, Microeconomics 0:201-225.

Fisher, F.M. (2000), "The IBM and Microsoft cases: what's the difference?", American Economic Review 90:180-183.

Fisher, E.O'N. and C.A. Wilson (1995), "Price competition between two international firms facing tariffs", International Journal of Industrial Organisation $13: 67-87$.

Fishman, A. and R. Rob (1995), "The durability of information, market efficiency and the size of firms", International Economic Review 36:19-36.

Fitoussi, J-P. and E. Phelps (1988), The slump in Europe: reconstructing open economy theory (Blackwells, Oxford).

Froot, K.A. and P.D. Klemperer (1989), "Exchange rate pass-through when market share matters", American Economic Review 79:637-654.

Fudenberg, D., R. Gilbert, J. Stiglitz and J. Tirole (1983), "Preemption, leapfrogging and competition in patent races", European Economic Review 22:3-31. 
Fudenberg, D. and J. Tirole (1984), "The fat-cat effect, the puppy-dog ploy and the lean and hungry look", American Economic Review 74:361-366.

Fudenberg, D. and J. Tirole (2000), "Customer poaching and brand switching", RAND Journal of Economics 31:634-657.

Gabaix, X. and D. Laibson (2006), "Shrouded attributes, consumer myopia and information suppression in competitive markets", Quarterly Journal of Economics 121:505-540.

Gabel, H.L. (1987), Product Standardization and Competitive Strategy (NorthHolland)

Gabel, H.L. (1991), Competitive Strategies for Product Standards (McGraw-Hill, London).

Gabrielson, T.S. and S. Vagstad (2003), "Consumer heterogeneity, incomplete information and pricing in a duopoly with switching costs", Information Economics and Policy 15:384-401.

Gabrielsen, T. S. and S. Vagstad (2004) "On how size and composition of customer bases affect equilibrium in a duopoly with switching costs", Review of Economic Design 9:59-71.

Gabszewicz, J., L. Pepall and J. Thisse (1992), "Sequential entry, with brand loyalty caused by consumer learning-by-doing-using", Journal of Industrial Economics 40:397-416.

Galbi, D.A. (2001), "Regulating prices for shifting between service providers", Information Economics and Policy 13:191-98.

Gallini, N. and L. Karp (1989), "Sales and consumer lock-in", Economica 56:279294.

Gandal, N. (1994), "Hedonic price indexes for spreadsheets and an empirical test for network externalities", RAND Journal of Economics 25:160-170.

Gandal, N. (1995a), "A selective survey of the indirect network externalities: a discussion", Research in Law and Economics 17:23-31.

Gandal, N. (1995b), "Competing compatibility standards and network externalities in the PC software market", Review of Economics and Statistics 77:599603. 
Gandal, N. (2001), "The dynamics of competition in the internet search engine market", International Journal of Industrial Organization 19:1103-1117.

Gandal, N. (2002), "Compatibility, standardization, and network effects: some policy implications", Oxford Review of Economic Policy 18:80-91.

Gandal, N., M. Kende and R. Rob (2000), "The dynamics of technological adoption in hardware/software systems: the case of compact disc players", RAND Journal of Economics 31:43-61.

Gandal, N. and O. Shy (2001), "Standardization policy and international trade", Journal of International Economics 53:363-83.

Gandal, N., D. Salant and L. Waverman (2003), "Standards in wireless telephone networks", Telecommunications Policy 27:325-332.

Gans, J.S. and S.P. King (2001), "Regulating endogenous customer switching costs", Contributions to Theoretical Economics 1(1): http://www.bepress.com/bejte/contributions/vol1/iss1/art1

Gans, J., S. King and G. Woodbridge (2001), "Numbers to the people: regulation, ownership, and local number portability", Information Economics and Policy 13:167-180.

Gans, J., S. King and J. Wright (2004), "Wireless Communications" in: S. Majumdar, et al., eds., Handbook of Telecommunications Economics, vol. 2 (North-Holland, Amsterdam) xx-xx.

Garcia Marinoso, B. (2001), "Technological incompatibility, endogenous switching costs and lock-in", Journal of Industrial Economics 49:281-98.

Garcia Marinoso, B. (2003), "Endogenous switching costs and exclusive systems: a reply", Review of Network Economics 1:36-40.

Gawer, A. and R. Henderson (2005), "Platform owner entry and innovation in complementary markets: evidence from Intel", NBER working paper 11852.

Gehrig, T. and R. Stenbacka (2002), "Introductory offers in a model of strategic competition", Working Paper, University of Freiburg and Swedish School of Economics, Helsinki.

Gehrig, T. and R. Stenbacka (2004a), "Differentiation-induced switching costs and poaching", Journal of Economics and Management Strategy 13:635-655.

Gehrig, T. and R. Stenbacka (2004b), "Information sharing and lending market 
competition with elationship benefits and poaching", Working Paper, University of Freiburg and Swedish School of Economics, Helsinki.

Gehrig, T. and R. Stenbacka (2005), "Two at the top: quality differentiation in markets with switching costs," CEPR Discussion Paper \#4996, Universität Freiburg and Swedish School of Economics.

Gerlach, H. A. (2004) "Announcement, entry, and preemption when consumers have switching costs", RAND Journal of Economics 35:184-202.

Gilbert, R. J. (2004), "Antitrust for patent pools: a century of policy evolution", Stanford Technology Law Review.

Gilbert, R.J. and M.L. Katz (2001), "An economist's guide to U.S. v. Microsoft", Journal of Economic Perspectives 15:25-44.

Gilbert, R.J. and P.D. Klemperer (2000), "An equilibrium theory of rationing", RAND Journal of Economics 31:1-21.

Goerke, L. and M.J. Holler (1995), "Voting on standardisation", Public Choice 83:337-351.

Good, J. B. (2006), "The Incentive for a Dominant Firm to Innovate", M.Phil. thesis, Oxford University.

Goolsbee, A. and P.J. Klenow (2002), "Evidence on learning and network externalities in the diffusion of home computers", Journal of Law and Economics 45:317-344.

Gottfries, N. (2002) "Market shares, financial constraints, and pricing behavior in the export market", Economica 276:583-607.

Gowrisankaran, G. and D. Ackerberg (forthcoming), "Quantifying equilibrium network externalities in the ACH banking industry", RAND Journal of Economics.

Gowrisankaran, G. and J. Stavins (2004), "Network externalities and technology adoption: lessons from electronic payments", RAND Journal of Economics $35: 260-276$.

Green, E.J. and R.H. Porter (1984), "Noncooperative collusion under imperfect price information", Econometrica 52:87-100.

Green, J. and S.A. Scotchmer (1986), "Switching costs as an explanation for price dispersion", Working Paper, Graduate School of Public Policy, University of 
California, Berkeley.

Greenstein, S.M. (1993), "Did installed base give an incumbent any (measurable) advantage in federal computer procurement", RAND Journal of Economics 24:19-39.

Greenstein, S.M. and M. Rysman (2004), "Testing for agglomeration and dispersion", Economics Letters 86:405-411.

Grindley, P. (1995), Standards Strategy and Policy: Cases and Stories (Oxford University Press, Oxford).

Gruber, H. and F. Verboven (2001), "The evolution of markets under entry and standards regulation - the case of global mobile telecommunications", International Journal of Industrial Organization 19:1189-1212.

Guadagni, P. and J. Little (1983), "A logit model of brand choice calibrated on scanner data", Marketing Science 1:203-238.

Guibourg, G. (2001), "Interoperability and network externalities in electronic payments", Sveriges Riksbank Working Paper Series, September, \#126.

Haan, M. (2003), "Vaporware as a means of entry deterrence", Journal of Industrial Economics 51:345-358.

Hakenes, H. and M. Peitz (forthcoming), "Selling reputation when going out of business", International Economic Review.

Hanson, W.A. (1983), "Bandwagons and orphans: dynamic pricing of competing technological systems subject to decreasing costs", Working Paper, Stanford University.

Hartigan, J.C. (1995), "Perverse consequences of the GATT: export subsidies and switching costs", Economica 63:153-161.

Hartman, R. and D. Teece (1990), "Product emulation strategies in the presence of reputation effects and network externalities: some evidence from the minicomputer industry", Economics of Innovation and New Technology $1: 157-182$.

Haruvy, E. and A. Prasad (2001), "Optimal freeware quality in the presence of network externalities: an evolutionary game theoretical approach", Journal of Evolutionary Economics 11:231-248.

Haucap, J. (2003), "Endogenous switching costs and exclusive systems applica- 
tions", Review of Network Economics 1:29-35.

Heal, G. (1999), "Price and market share dynamics in network industries" in: G. Chichilnisky, ed., Markets, Information and Uncertainty: Essays in Honor of Kenneth J. Arrow, (Cambridge University Press, Cambridge) 191-215.

Hemenway, D. (1975), Industrywide Voluntary Product Standards, (Ballinger Publishing Co. Cambridge).

Hermalin, B. and M. Katz (205). "Customer or complementor? Intercarrier compensation with 2-sided benefits", Working Paper, University of California, Berkeley.

Holmes, T.J. (1990), "Consumer investment in product specific capital: the monopoly case", Quarterly Journal of Economics 105:789-801.

Holmes, T.J. (1999), "How industries migrate when agglomeration economies are important", Journal of Urban Economics 45:240-263.

Inceoglu, F. and W. Park (2003), "Diffusion of a new product under network effects: the case of the US DVD player market," mimeo Boston University.

Innes, R. and R. Sexton (1994), "Strategic buyers and exclusionary contracts", American Economic Review 84:566-584.

Israel, M.A. (2005), "Tenure dependence in consumer-firm relationships: an empirical analysis of consumer departures from automobile insurance firms", RAND Journal of Economics 36:165-192

Jacoby, J. and R.W. Chestnut (1978), Brand Loyalty: Measurement and Management (John Wiley and Sons, New York).

Jeitschko, T.D. and C.R. Taylor (2001), "Local discouragement and global collapse: a theory of coordination avalanches", American Economic Review 9:208-244.

Jensen, R. and M. Thursby (1996), "Patent races, product standards, and international competition", International Economic Review 37:21-49.

Jullien, B. (2001), "Competing in network industries: divide and conquer", Working Paper, IDEI and GREMAQ, University of Toulouse.

Kahan, M. and M. Klausner (1996), "Path dependence in corporate contracting: increasing returns, herd behavior, and cognitive biases", Washington University Law Quarterly 74:347. 
Kahan, M. and M. Klausner (1997), "Standardization and innovation in corporate contracting (or "the economics of boilerplate"), Virginia Law Review 83:713.

Kahin, B. and J. Abbate (1995), Standards Policy for Information Infrastructure (MIT Press, Cambridge).

Kahn, A.E. and W.B. Shew (1987), "Current issues in telecommunications regulation: pricing", Yale Journal on Regulation 4:191-256.

Kandori, M., G.J. Mailath and R. Rob (1993), "Learning, mutation, and long run equilibria in games", Econometrica 61:29-56.

Karaca-Mandis, P. (2004), "Estimation and evaluation of externalities and complementarities", Ph.D. Dissertation, University of California, Berkeley.

Katz, M.L. and C. Shapiro (1985), "Network externalities, competition and compatibility", American Economic Review 75:424-440.

Katz, M.L. and C. Shapiro (1986a), "Product compatibility choice in a market with technological progress", Oxford Economic Papers 38:146-165.

Katz, M.L. and C. Shapiro (1986b), "Technology adoption in the presence of network externalities", Journal of Political Economy 94:822-841.

Katz, M.L. and C. Shapiro (1992), "Product introduction with network externalities", Journal of Industrial Economics 40:55-83.

Katz, M.L. and C. Shapiro (1994), "System competition and network effects", Journal of Economic Perpectives 8:93-115.

Katz, M.L. and C. Shapiro (1999), "Antitrust in software markets", in: J. Eisenach and T.M. Lenard, eds., Competition, Innovation and the Microsoft Monopoly: Antitrust in the digital marketplace (Kluwer Academic Press, Boston) 29-81.

Kauffman, R. and Y.M. Wang (1999) "Network externalities and the determinants of network survival", MIS Research Center Working Paper 99-03.

Keilbach, M. and M. Posch. (1998), "Network externalities and the dynamics of markets", IIASA Report IR-98-089.

Kim, B.-D., M. Shi and K. Srinivasan (2001), "Reward programs and tacit collusion", Marketing Science 20:99-120. 
Kim, J.-Y. and D.-H. Koh (2002), "Attracting the rival's customers in a model with switching costs", Japanese Economic Review 53:134-139.

Kim, M., D. Kliger and B. Vale (2003) "Estimating switching costs: the case of banking", The Journal of Financial Intermediation 12:25-56.

Klausner, M. (1995), "Corporations, corporate law, and networks of contracts", Virginia Law Review 81:757-852.

Klein, B., R.G. Crawford and A.A. Alchian. (1978), "Vertical integration, appropriable rents, and the competitive contracting process", Journal of Law and Economics 21:297-326.

Klemperer, P.D. (1983), "Consumer switching costs and price wars", Working Paper, Stanford Graduate School of Business.

Klemperer, P.D. (1987a), "Markets with consumer switching costs", Quarterly Journal of Economics 102:375-394.

Klemperer, P.D. (1987b), "The competitiveness of markets with switching costs", RAND Journal of Economics 18:138-150.

Klemperer, P.D. (1987c), "Entry deterrence in markets with consumer switching costs", Economic Journal (Supplement) 97:99-117.

Klemperer, P.D. (1988), "Welfare effects of entry into markets with switching costs", Journal of Industrial Economics 37:159-165.

Klemperer, P.D. (1989), "Price wars caused by switching costs", Review of Economic Studies 56:405-420.

Klemperer, P.D. (1992), "Equilibrium product lines: competing head-to- head may be less competitive", American Economic Review 82:740-755.

Klemperer, P.D. (1995), "Competition when consumers have switching costs", Review of Economic Studies 62:515-539.

Klemperer, P.D. and A.J. Padilla (1997), "Do firms' product lines include too many varieties?", RAND Journal of Economics 28:472-488.

Klemperer, P.D. and I. Png (1986), "Frequent-flyer plans: marketing device with insidious effects", Los Angeles Times, Section IV, June 8: 3.

Klimenko, M. (2002), "Strategic interoperability standards and trade policy in 
industries with network externalities", IRPS Working Paper.

Knittel, C.R. (1997), "Interstate long distance rate: search costs, switching costs and market power", Review of Industrial Organization, 12:519-536.

Knittel, C.R. and V. Stango (2004a), "Compatibility and pricing with indirect network effects: evidence from ATMs", NBER Working paper 10774.

Knittel, C.R. and V. Stango (2004b), "Incompatibility, product attributes and consumer welfare: evidence from ATMs", NBER Working Paper \#10962.

Koh, D.-H. (1993), "Competition by endogenous switching time", UCLA Graduate School of Management Working Paper.

Kornish, L. (2006), "Technology choice and timing with positive network effects", European Journal of Operational Research, 173:268-282

Kretschmer, T. (2001), "Competition, inertia and network effects", INSEAD Working Paper.

Kristiansen, E.G. (1998), "R\&D in the presence of network externalities: timing and compatibility", RAND Journal of Economics 29:531-547.

Kristiansen, E.G. and M. Thum (1997), "R\&D incentives in compatible networks", Journal of Economics 65:55-78.

Krugman, P. (1991a) Geography and Trade (Leuven University Press and MIT Press, Cambridge).

Krugman, P. (1991b) "History versus expectations", Quarterly Journal of Economics 106:651-667.

Kubota, K. (1999) "Trade negotiations in the presence of network externalities", Mimeo, World Bank - Country Economics Department.

Kudrle, R.T. (1975), Agricultural Tractors: A World Industry Study (Ballinger Publishing Co., Cambridge).

Laffont, J.J., P. Rey and J. Tirole (1998a), "Network competition: I. Overview and nondiscriminatory pricing", RAND Journal of Economics 29:1-37.

Laffont, J.J., P. Rey and J. Tirole (1998b), "Network competition: II. Price discrimination", RAND Journal of Economics 29:38-56. 
Lal, R. and C. Matutes (1994), "Retail pricing and advertising strategies", Journal of Business 67:345-370.

Lambertini, L. and R. Orsini (2001), "Network externalities and the overprovision of quality by a monopolist", Southern Economic Journal 67:969-982.

Langlois, R.N. (1992), "External economies and economic progress: the case of the microcomputer industry", Business History Review 66:1-50.

Larkin, I. (2004) "Switching costs and competition in enterprise software: theory and evidence", Working Paper UC Berkeley

Lee, B. (1997), "Markets with consumer switching benefits", Working Paper, Management Research Lab, Korea Telecom.

Lee, R. (2003), "The adoption of standards with incomplete information", Harvard undergraduate thesis (economics).

Lee, S-Y. T. and I.P.L. Png (2004), "Buyer shopping costs and retail pricing: an indirect empirical test", Review of Marketing Science 2, http://www.bepress.com/romsjournal/vol2/iss1/art6

Lehr, W. (1995), "Compatability Standards and Interoperability: Lessons from the Internet", in B. Kahin and J. Abbate, eds., Standards Policy for Information Infrastructure, (MIT Press, Cambridge) 121-147.

Leibenstein, H. (1950), "Bandwagon, snob and Veblen effects in the theory of consumers' demand", Quarterly Journal of Economics 64:183-207.

Lemley, M.A. (2002), "Intellectual property rights and standard setting organizations", California Law Review 90:1889-1980.

Lemley, M.A. and D. McGowan (1998a), "Legal implications of network economic effects", California Law Review 86:479-612.

Lemley, M.A. and D. McGowan (1998b), "Could Java change everything? The competitive propriety of a propriety standard", Antitrust Bulletin 43:715773 .

Lewis, T.R. and Yildirim, H. (forthcoming), "Managing switching costs in multiperiod procurements with strategic buyers", International Economic Review.

Liebowitz, S.J. and S.E. Margolis (1990), "The fable of the keys", Journal of Law and Economics 33:1-25. 
Liebowitz, S.J. and S.E. Margolis (1994), "Network externality: an uncommon tragedy", Journal of Economic Perspectives 8:133-150.

Liebowitz, S.J. and S.E. Margolis (1995), "Path dependence, lock-in and history", Journal of Law Economics and Organization 11:205-226.

Liebowitz, S.J. and S.E. Margolis (1996), "Should technology choice be a concern of antitrust policy?", Harvard Journal of Law and Technology 9:284-317.

Liebowitz, S.J. and S.E. Margolis (1998a), Network Effects and Externalities Vol. II, pp. 671-674, in The New Palgrave Dictionary of Economics and the Law (MacMillan, Basingstoke).

Liebowitz, S.J. and S.E. Margolis (1998b), Path Dependence - Vol III, pp. 1723, in The New Palgrave Dictionary of Economics and the Law (MacMillan, Basingstoke).

Liebowitz, S.J. and S.E. Margolis (second edition: 2001), Winners, Losers and Microsoft: Competition and Antitrust in High Technology, The Independent Institute.

Llobet, G. and M. Manove (2006), "Network size and network capture", Working Paper, CEMFI and Boston University.

Lofaro, A. and D. Ridyard (2003), "Switching costs and merger assessment don't move the goalposts", European Competition Law Review 6:268-271.

MacKie-Mason, J.K. and J. Metzler (1999), "Links between vertically related markets: ITS vs. Kodak", in: J. Kwoka and L. White, eds., The Antitrust Revolution (Oxford University Press, Oxford).

MacKie-Mason, J. and J. Netz (2006), "Manipulating interface standards as an anti-competitive strategy," forthcoming in S.Greenstein and V. Stango, eds., Standards and Public Policy, Cambridge University Press .

Malueg, D. and M. Schwartz (forthcoming), "Compatability incentives of a large network facing multiple rivals", Journal of Industrial Economics.

Manenti, F.M. and E. Somma (2002), "One-way compatibility, two-way compatibility and entry in network industries", Working Paper, Southern European Research in Economic Studies, Series \#4.

Mankiw, N.G. and M.D. Whinston (1986), "Free entry and social inefficiency", RAND Journal of Economics 17:48-58. 
Manski, C. (1993), "Identification of endogenous social effects: the reflection problem", Review of Economic Studies 60:531-542.

Mason, R. (2000), "Network externalities and the Coase conjecture," European Economic Review 44:1981-1992.

Matsumura, T. and M. Ueda (1996) "Endogenous timing in the switching of technology with Marshallian externalities", Journal of Economics 63:41-56.

Matutes, C. and P. Regibeau (1988), "Mix and match: product compatibility without network externalities", RAND Journal of Economics 19:221-234.

Matutes, C. and P. Regibeau (1992), "Compatibility and bundling of complementary goods in a duopoly", Journal of Industrial Economics 40:37-54.

Matutes, C. and P. Regibeau (1996), "A selective review of the economics of standardization: entry deterrence, technological progress and international competition", European Journal of Political Economy 12:183-209.

Menell, P. (2002), "Envisioning Copyright Law's Digital Future," New York Law Review, 62(3).

Merrill, T., and H. Smith (2000) "Optimal Standardization in the Law of Property: The Numerus Clausus Principle ," Yale Law Journal 110:1-70.

Milgrom, P. and J. Roberts (1990), "Rationalizability, learning, and equilibrium in games with strategic complementarities", Econometrica 58:1255-1277.

Miles, D. (2004), "The UK Mortgage Market: Taking a Longer-Term View", Report for the UK Treasury (The Stationery Office, UK).

Moshkin, N. and R. Shachar (2000), "Switching cost or search cost?", Working Paper \#3-2000, Foerder Institute for Economic Research.

Murphy, K., A. Shleifer and R. Vishny (1989) "Industrialization and the big push", Journal of Political Economy 97:1003-1026.

Nair, H., P. Chintagunta and J. Dube (2004) "Empirical analysis of indirect network effects in the market for personal digital assistants", Quantitative Marketing and Economics 2:23-58.

Nalebuff, B. (2000), "Competing against bundles", in: P.J. Hammond and G.D. Myles, eds., Incentives, Organization, and Public Economics (Oxford University Press, Oxford) 323-335. 
Nalebuff, B. (forthcoming), "Bundling as an entry deterrent", Quarterly Journal of Economics.

Nelson, P. (1970), "Information and consumer behavior", Journal of Political Economy 78:311-329.

Nilssen, T. (1992), "Two kinds of consumer switching costs", RAND Journal of Economics 23:579-589.

Nilssen, T. (2000), "Consumer lock-in with asymmetric information", International Journal of Industrial Organization 18:641-666.

Ochs, J. (1995), "Coordination problems", in: J. Kagel and A. Roth, eds., The Handbook of Experimental Economics (Princeton University Press, Princeton) $195-251$.

OECD (1991) Information Technology Standards: the Economic Dimension (Paris).

Office of Fair Trading (2003), "Switching costs: annex C", Economic Discussion Paper \#5, London, UK.

Ohashi, H. (2003) "The role of network externalities in the U.S. VCR market, 1978-86", Journal of Economics and Management Strategy 12:447-494.

Oren, S.S. and S.A. Smith (1981), "Critical mass and tariff structure in electronic communications markets", The Bell Journal of Economics 12:467-487.

Ostrovsky, M. and M. Schwarz (2006), "Synchronization under uncertainty", International Journal of Economic Theory 2:1-16.

Padilla, A.J. (1992), "Mixed pricing in oligopoly with consumer switching costs", International Journal of Industrial Organization 10:393-412.

Padilla, A.J. (1995), "Revisiting dynamic duopoly with consumer switching costs", Journal of Economic Theory 67:520-530.

Palfrey, T. (1983), "Bundling decisions by a multiproduct monopolist with incomplete information", Econometrica 51:463-483.

Panzar, J. and S.S. Wildman (1995), "Network competition and the provision of universal service", Industrial and Corporate Change 4:711-719.

Panzar, J.C. and R.C. Willig (1981), "Economies of scope", American Economic Review 71:268-272. 
Park, I.-U. (2004) "A Simple inducement scheme to overcome adoption externalities", Contributions to Theoretical Economics 4:Article 3, http://www.bepress.com/bejte/contributions/vol4/iss1/art3

Park, S. (2004), "Quantitative analysis of network externalities in competing technologies: the VCR case", Review of Economics and Statistics 86:937-945.

Parker, G. and M. Van Alstyne (2005), "Two-Sided Network Effects: A Theory of Information Product Design", Management Science 51:1494-1504.

Pereira, P. (2000), "Price dynamics with consumer search and cost volatility", Working Paper, University of Madrid.

Phelps, E. and S. Winter (1970), "Optimal price policy under atomistic competition", in: E. Phelps, ed., Microeconomic Foundations of Employment and Inflation Theory, (Norton, New York). 309-337

Porter, M.E. (1980), Competitive Strategy, (Macmillan Publishing Co., Inc. New York).

Porter, M.E. (1985), Competitive Advantage, (Macmillan Publishing Co., Inc. New York).

Postrel, S.R. (1990), "Competing networks and proprietary standards: the case of quadraphonic sound", Journal of Industrial Economics 39:169-185.

Puffert, D.J. (2002), "Path dependence in spacial networks: the standardization of railway track gauge", Explorations in Economic History 39:284-314.

Radin, M.J. (2002), "Online standardization and the integration of text and machine", Fordham Law Review 70:1125.

Radner, R. (2003), "Viscous demand", Journal of Economic Theory 112:189-231.

Raskovich, A. (2003), "Pivotal buyers and bargaining position", Journal of Industrial Economics 51:405-426.

Rasmusen, E., J.M. Ramseyer and J. Wiley (1991), "Naked exclusion", American Economic Review 81:1137-1145.

Ribstein, L. and B. Kobayashi (2001), "Choice of form and network externalities", William \& Mary Law Review 43:79-140.

Robinson, C. (1999), "Network effects in telecommunications mergers: MCI WorldCom merger: protecting the future of the internet", before the Prac- 
ticing Law institute, San Francisco, CA, August, http://www.usdoj.gov/atr/public/speeches/3889.htm.

Rochet, J.C. and L.A. Stole (2003), "The economics of multidimensional screening", in: Advances in Economics and Econometrics: Theory and Applications, 8th World Congress.

Rochet, J.C. and J. Tirole (2002), "Cooperation among competitiors: the economics of credit card associations", RAND Journal of Economics 33:1-22.

Rochet, J.C. and J. Tirole (2003), "Platform competition in two-sided markets", Journal of the European Economic Association 1:990-1029.

Rogerson, W.P. (1982), "The social cost of monopoly and regulation: a game theoretic analysis", The Bell Journal of Economics 13:391-401.

Rohlfs, J. (1974), "A theory of interdependent demand for a communications service", Bell Journal of Economics 5:16-37.

Rohlfs, J. (2001), Bandwagon Effects in High Technology Industries (MIT Press, Cambridge).

Rosenstein-Rodan, P. (1943) "Problems of industrialization of eastern and southeastern Europe", The Economic Journal 53:202-211.

Rosenthal, R. (1980), "A model in which an increase in the number of sellers leads to a higher price", Econometrica 48:1575-1580.

Rosse, J.N. (1967), "Daily newspapers, monopolistic competition, and economies of scale", American Economic Review, Papers and Proceedings 57:522-533.

Rubinfeld, D. (2003), "Maintenance of Monopoly: US v. Microsoft (2001)", in: J.E. Kwoka and L.J. White, eds., The Antitrust Revolution (Oxford University Press, Oxford).

Rysman, M. (2004), "Competition between networks: a study of the market for yellow pages", The Review of Economic Studies 71:483-512.

Saloner, G. (1990), "Economic issues in computer interface standardization", Economics of Innovation and New Technology 1:135-156.

Saloner, G. and A. Shepard (1995), "Adoption of technologies with network effects: an empirical examination of the adoption of automated teller machines", RAND Journal of Economics 20:479-501. 
Samuelson, P. and S. Scotchmer (2002), "The law and economics of reverse engineering", Yale Law Journal 111:1575-1664.

Sapir, A. and K. Sekkat (1995), "Exchange rate regimes and trade prices: does the EMS mattter?", Journal of International Economics 38:75-94.

Saxenian, A. (1994) Regional Advantage (Harvard University Press, Cambridge).

Scharfstein, D. and J. Stein. (1990), "Herd behavior and investment", American Economic Review 80:465-479

Schelling, T.C. (1960), The Strategy of Conflict (Harvard University Press, Cambridge).

Schelling, T.C. (1978), Micromotives and Macrobehavior (Norton, New York).

Schiff, A (2003), "Open and closed systems of two-sided networks", Information Economics and Policy 15:425-442

Schlesinger, H. and J.M.G. von der Schulenburg (1993), "Consumer information and decisions to switch insurers", The Journal of Risk and Insurance 60:591615 .

Schmalensee, R. (1982), "Product differentiation advantages of pioneering brands", American Economic Review 72:349-365.

Schmalensee, R. (2000), "Antitrust issues in Schumpeterian industries", American Economic Review 90:192-196.

Schmalensee, R. (2002), "Payment systems and interchange fees", Journal of Industrial Economics 50:103-122.

Schwartz, M. and D. Vincent (2006) "The no-surcharge rule and card user rebates: vertical control by a payment network," Review of Network Economics 5:72-102.

Seetharaman, P.B., A. Ainslie and P.K. Chintagunta (1999), "Investigating household state dependence effects across categories", Journal of Marketing Research 36:488-500.

Seetharaman, P.B. and H. Che. (forthcoming), "Price competition in markets with consumer variety seeking," Marketing Science.

Segal, I. (1999), "Contracting with externalities", Quarterly Journal of Economics 114:337-388. 
Segal, I. (2003), "Coordination and discrimination in contracting with externalities: divide and conquer?", Journal of Economic Theory 113:147-181.

Segal, I.R. and M.D. Whinston (2000), "Naked exclusion: comment", American Economic Review 90:296-311.

Selten, R. (1965), "Spieltheoretische behandlung eines Oligopolmodells mit nachfrägetragheit", Zeitschrift für die Gesamte Staatswissenschaft 121:301-324 and 667-689.

Shaffer, G. and Z.J. Zhang (2000), "Pay to switch or pay to stay: preference-based price discrimination in markets with switching costs", Journal of Economics and Management Strategy 9:397-424.

Shankar, V. and Bayus, B.L. (2003), "Network effects and competition: an empirical analysis of the video game industry", Strategic Management Journal 24:375-394.

Shapiro, C. (1995) "Aftermarkets and consumer welfare: making sense of Kodak", Antitrust Law Journal 63:483-512.

Shapiro, C. (1999), "Exclusivity in network industries", George Mason Law Review, Spring.

Shapiro, C. and D.J. Teece (1994), "Systems competition and aftermarkets: an economic analysis of Kodak", The Antitrust Bulletin 39:135.

Shapiro, C. and H.R. Varian (1998), Information Rules-A Strategic Guide to the Network Economy (Harvard Business School Press, Boston).

Sharpe, S.A. (1990), "Asymmetric information, bank lending and implicit contracts: a stylized model of customer relationships", Journal of Finance 45:10691087.

Sharpe, S.A. (1997), "The effect of consumer switching costs on prices: a theory and its application to the bank deposit market", Review of Industrial Organization 12:79-94.

Shilony, Y. (1977), "Mixed pricing in oligopoly", Journal of Economic Theory, 14:373-388.

Shum, M. (2004) "Does advertising overcome brand loyalty? Evidence from the breakfast-cereals market", Journal of Economics \& Management Strategy $13: 241-272$. 
Shurmer, M. (1993) "An investigation into sources of network externalities in the packaged PC software market", Information Economics and Policy 5:231-251.

Shy, O. (1996), "Technology revolutions in the presence of network externalities", International Journal of Industrial Organization 14:785-800.

Shy, O. (2001), The Economics of Network Industries (Cambridge University Press, Cambridge).

Shy, O. (2002), "A quick-and-easy method for estimating switching costs", International Journal of Industrial Organization 20:71-87.

Simcoe, T. (2003), "Committees and the creation of technical standards", Working Paper, University of California, Berkeley, Haas School of Business.

Skott, P. and G.T. Jepsen (2000), "Paradoxical effects of drug policy in a model with imperfect competition and switching costs", Journal of Economic Behaviour and Organization 48:335-354.

Spence, A.M. (1976), "Product selection, fixed costs, and monopolistic competition", Review of Economic Studies 43:217-235.

Squire, L. (1973), "Some aspects of optimal pricing for telecommunications", Bell Journal of Economics 4:515-525.

Stahl, K. (1982), "Differentiated products, consumer search, and locational oligopoly", Journal of Industrial Economics 37:97-113.

Stango, V, (2002), "Pricing with consumer switching costs: evidence from the credit card market", Journal of Industrial Economics 50:475-492.

Stigler, G. (1951), "The division of labor is limited by the extent of the market", Journal of Political Economy 59:185-193.

Stigler, G. (1964), "A theory of oligopoly", The Journal of Political Economy $72: 44-61$.

Stiglitz, J.E. (1989), "Imperfect information in the product market", in: R. Schmalensee and R.D. Willig, eds., Handbook of Industrial Organization, vol. 1 (North-Holland, Amsterdam) 769-847.

Sundararajan, A. (2003), "Network effects, nonlinear pricing and entry deterrence", Working Paper, Stern School of Business, New York University.

Stole, L.A. (forthcoming), "Price discrimination in competitive environments", 
in: M. Armstrong and R. Porter, eds., Handbook of Industrial Organization, vol. 3. $\mathrm{xx}-\mathrm{xx}$

Sutton, J. (1980), "A model of stochastic equilibrium in a quasi-competitive industry", Review of Economic Studies 47:705-22.

Sutton, J. (1998), Technology and Market Structure: Theory and History (MIT Press, Cambridge).

Swann, G.M.P. (2002), "The functional form of network effects", Information Economics and Policy 14:417-429.

Taylor, C. (2003), "Supplier surfing: competition and consumer behavior in subscription markets", RAND Journal of Economics 34:223-246.

Thompson, G.V. (1954) "Intercompany technical standardization in the early american automobile industry", The Journal of Economic History 14:1-20.

Thum, M. (1994), "Network externalities, technological progress, and the competition of market contracts", International Journal of Industrial Organization 12:269-289.

Tivig, T. (1996), "Exchange rate pass-through in two-period duopoly", International Journal of Industrial Organization 14:631-45.

To, T. (1994), "Export subsidies and oligopoly with switching costs", Journal of International Economics 37:97-110.

To, T. (1995) "Multiperiod competition with switching costs: an overlapping generations formulation", Journal of Industrial Economics 44:81-87.

Topkis, D.M. (1978), "Minimizing a submodular function on a lattice", Operations Research 26:305-321.

Topkis, D.M. (1998), Supermodularity and Complementarity, in D.M. Kreps, T.J. Sargent and P. Klemperer, eds., Frontiers of Economic Research Series, (Princeton University Press, Princeton).

Valletti, T.M. (2000), "Switching costs in vertically related markets", Review of Industrial Organisation 17:395-409.

Varian, H. (1980), “A model of sales”, American Economic Review 70:651-659.

Varian, H.R. (1989), "Price discrimination", in: R. Schmalensee and R.D. Willig, eds., Handbook of Industrial Organization, vol. 1 (North-Holland, Amster- 
dam) 597-654.

Vettas, N. (2000), "Investment dynamics in markets with endogenous demand", Journal of Industrial Economics 48:189-203.

Viard, B.V. (forthcoming), "Do switching costs make markets more or less competitive?: The case of 800-number portability", RAND Journal of Economics.

Vickers, J.S. (2003), "Economics for consumer policy", British Academy Keynes Lecture.

Villas-Boas, M. (1999), "Dynamic competition with customer recognition", RAND Journal of Economics 30:604-631.

Villas-Boas, J.M. (2006), "Dynamic competition with experience goods", Journal of Economics and Management Strategy 15:37-66.

von Weizsäcker, C.C. (1984), "The cost of substitution", Econometrica 52:10851116.

Walz, U. and B. Woeckener (2003), "Compatibility standards and strategic trade policy" CEPR Discussion Paper \#3815, Universities of Frankfurt and Stuttgart.

Wang, R. and Q. Wen (1998), "Strategic invasion in markets with switching costs", Journal of Economics and Management Strategy 7:521-549.

Waterson, M. (2003), "The role of consumers in competition and competition policy", International Journal of Industrial Organization 21:129-150.

Weiss, M. and M. Sirbu (1990), "Technological choice in voluntary standards committees: an empirical analysis", Economics of Innovation and New Technology 1:111-133.

Werden, G.J. (2001), "Network effects and conditions of entry: lessons from the Microsoft case", Antitrust Law Journal 69:87-111.

Wernerfelt, B. (1991), "Brand loyalty and market equilibrium", Marketing Science 10:229-245.

Whinston, M.D. (1990), "Tying, foreclosure and exclusion", American Economic Review 80:837-859.

Whinston, M.D. (2001), "Exclusivity and tying in US v. Microsoft: what we know, and don't know", Journal of Economic Perspectives 15:63-80. 
Williamson, O.E. (1975), Markets and Hierarchies: Analysis and Anti-trust Implications (Free Press, New York).

Witt, U. (1997), "Lock-in vs. critical masses: industrial change under network externalities", International Journal of Industrial Organization 15:753-773.

Woeckener, B. (1999), "Network effects, compatibility decisions, and monopolization", Zeitschrift fur Wirtschafts und Sozialwissenschaften 119:23-44.

Yannelis, D. (2001), "On the simple welfare economics of network externalities", International Journal of Social Economics 28:344-348.

Zephirin, M.G. (1994), "Switching costs in the bank deposit market", Economic Journal 104:455-461. 